\title{
Language, Gender and Generation The Social Economy Approach to Health and the Case of Estrie's English-speaking Communities
}

\author{
By Joanne Pocock, B.A., M.A.
}

\author{
A thesis submitted to \\ The Faculty of Graduate Studies and Research \\ in partial fulfillment of \\ the requirements for the degree of \\ Doctor of Philosophy \\ Department of Sociology and Anthropology \\ Carleton University \\ Ottawa, Ontario \\ (CJoanne Pocock, 2009
}


Library and

Archives Canada

Published Heritage

Branch

395 Wellington Street

Ottawa ON K1A 0N4

Canada
Bibliothèque et

Archives Canada

Direction du

Patrimoine de l'édition

395 , rue Wellington

Ottawa ON K1A 0N4

Canada

Your file Votre référence

ISBN: 978-0-494-52073-4

Our file Notre référence

ISBN: 978-0-494-52073-4

NOTICE:

The author has granted a nonexclusive license allowing Library and Archives Canada to reproduce, publish, archive, preserve, conserve, communicate to the public by telecommunication or on the Internet, loan, distribute and sell theses worldwide, for commercial or noncommercial purposes, in microform, paper, electronic and/or any other formats.

The author retains copyright ownership and moral rights in this thesis. Neither the thesis nor substantial extracts from it may be printed or otherwise reproduced without the author's permission.
AVIS:

L'auteur a accordé une licence non exclusive permettant à la Bibliothèque et Archives Canada de reproduire, publier, archiver, sauvegarder, conserver, transmettre au public par télécommunication ou par l'Internet, prêter, distribuer et vendre des thèses partout dans le monde, à des fins commerciales ou autres, sur support microforme, papier, électronique et/ou autres formats.

L'auteur conserve la propriété du droit d'auteur et des droits moraux qui protège cette thèse. $\mathrm{Ni}$ la thèse ni des extraits substantiels de celle-ci ne doivent être imprimés ou autrement reproduits sans son autorisation.
In compliance with the Canadian

Privacy A'ct some supporting forms may have been removed from this thesis.

While these forms may be included in the document page count, their removal does not represent any loss of content from the thesis.
Conformément à la loi canadienne sur la protection de la vie privée, quelques formulaires secondaires ont été enlevés de cette thèse.

Bien que ces formulaires aient inclus dans la pagination, il n'y aura aucun contenu manquant.

\section{Canadä}




\section{Abstract}

This study uses the case of Quebec's aging minority language communities living in the rural Estrie region as an occasion to think through the social economy approach to health widely implemented in recent years. Evidence gathered using qualitative and quantitative methods reveals the intersection of language, gender and generation to be a critical, yet largely neglected, indicator of the state of community-based care and associated health outcomes.

The study claims that even as Estrie's minority language communities hold community as a cherished value and demonstrate a long-standing history of exemplary community capacity, they have experienced the decline of their position with respect to key determinants of health during Quebec's era of thirdsector development. While high levels of voluntarism and civic engagement, a history of reliance on community-based organizations and a tradition of unpaid family care for vulnerable groups suggests an ideal cultural fit, social policy promoting "community development" as a strategy towards improved health in fact undermines community in this instance and in so doing is itself a health risk.

This claim is supported by the observation of excessively high levels of high intensity unpaid care by the women of middle and low-income minority language households; narrowing social support networks; intergenerational decline in the volunteer labor force of community-based organizations; the decreased capacity of households to pay for the increasingly mandatory solution 
of private care services; and the increased fragmentation of this group as participants in the new "partnership" arrangement between public health institutions and local communities. The extent to which the benefits of the social economy model rely upon the presence of the middle-generation, middle-income professional group notably reduced among this "left behind" minority population is underlined as contributing to the decline of their health status. 


\section{Acknowledgements}

I am very grateful to all those who gave so generously of their time and their hearts in sharing their story with me in the course of my doctoral project. Families kindly welcomed me into their homes and lives of care; volunteers shared their heritage of civic-mindedness and community spirit; health workers and community activists accompanied me through the busy worlds of community-based organizations and health policy shops.

In-depth case studies such as mine can mean a fair amount of time spent working in the dark. My deepest respect for, and trust in, three people enabled me to sustain the focus needed to discover the valuable insights lying buried within what is always an unpredictable endeavour. Special thanks to Dr. Wallace Clement for his intellectual clarity and ever-available support at every stage of this work. My appreciation to Dr. Andrea Doucet for her warm encouragement and critical methodological insights. Many thanks to Dr. Hugh Armstrong whose advice in the conceptualization of my research project was particularly valuable.

I am grateful to my colleagues at CHSSN, namely, James Carter, Jennifer Johnson and Jan Warnke, who have supported my research and are an inspiration in their commitment to the health and well-being of the minority language communities with whom they are engaged. The work of Jan Warnke and Laura Lee Bolger in the preparation of a map of the Estrie region and their permission to include it in this dissertation is gratefully acknowledged. I would like to acknowledge my colleagues Roger Farley, Roger Guillemette and the 
research team at the Official Language Community Development Bureau at Health Canada.

My heartfelt thanks go to my family who has patiently and lovingly supported me in my research over the years. Special mention goes to my husband and dearest companion, William Floch, who has been both an inspiring collaborator and comforting shoulder throughout this project. My children remind me daily of the precious joy and wonder of family caring. Thanks to James, Paul, Anna and D'Arcy for understanding. Terry, thanks for your help. You are family, too, Nellie.

Finally, I want to thank two very dear people from the very bottom of my heart - my parents, Lindsay and Phyllis - whose lives have influenced and inspired my work in more ways than I can possibly name. My dissertation is dedicated to you. 


\section{Table of Contents}

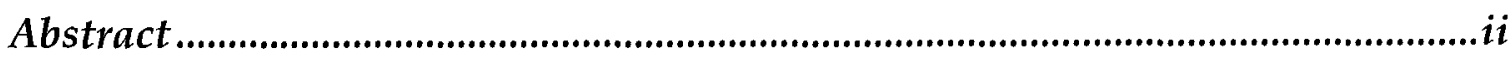

Acknowledgements ..............................................................................................................iv

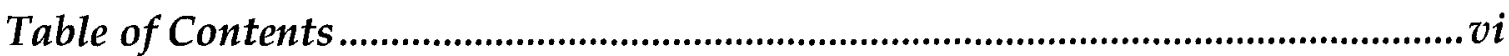

List of Tables ............................................................................................................ viii

List of Figures.............................................................................................. vii

List of Appendices............................................................................................................ viii

Chapter 1 - Social Economy, Health, and the Case of Quebec's Rural Minority

Language Communities...................................................................................... 1

The Problem …………………………………………….....................................

Summary of Major Thesis Claims …………………………………………………….... 8

Overview of Research Methods...................................................................................... 10

Demographic Profiling...........................................................................................................13

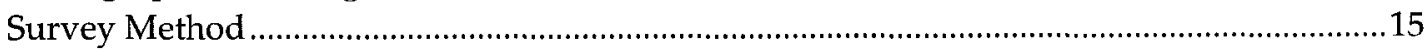

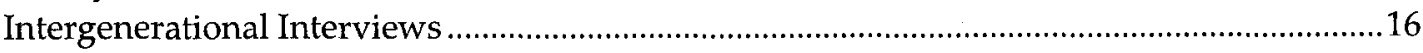

Expert Interviews ....................................................................................................................19

Definitions of Key Terms.............................................................................................. 21

Conclusion: The Puzzle of Estrie ............................................................................................ 31

Chapter 2 - The Missing Middle: Considering the Relevance of Third Sector

Health Strategies for Quebec's Rural English-speaking Communities..... 32

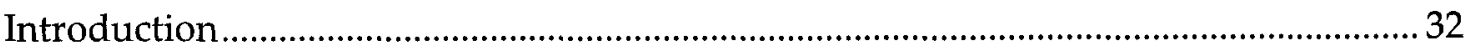

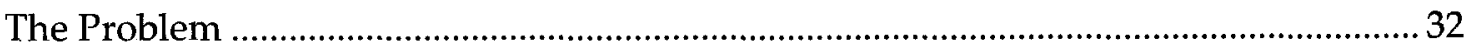

French Majority Cohesion and the Aging of the English Minority Communities of the

Estrie Region................................................................................................................36

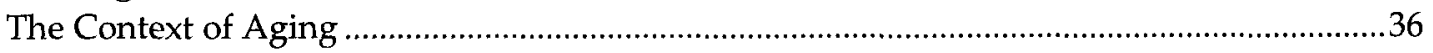

Quebec Nationalism, Globalizing Economies and the Era of Language Peace.........................42

Aging Minority Communities, Restructuring in Health and the State of Voluntary Labor...46

The Missing Middle and Voluntary Participation in Quebec....................................................4

Inter-generational Change in the Conditions of Volunteering ..........................................5 54

The Restructuring of Public Health Services: Government Provisions and Community-

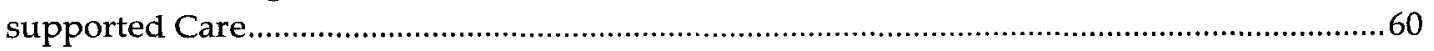

Political Disengagement .........................................................................................................67

Conclusion: A Neglected Absence ........................................................................................ 70

Chapter 3 - The Hidden Price of Care in Quebec's Era of 'Community'................. 72

Introduction .................................................................................................................

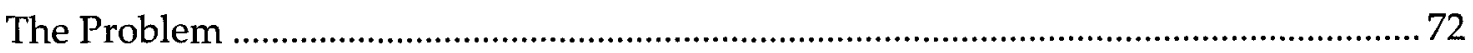


Aging Communities and Child-Centered Family Policy ….......................................... 76

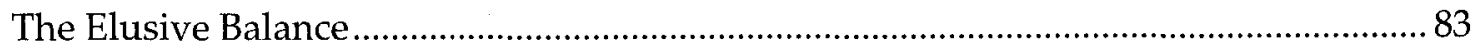

Community Vitality and Transformations in Health Care ...............................................92

Trickling Down: Faces at the Bottom of the Well........................................................ 102

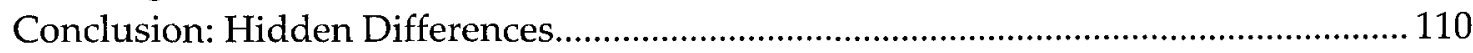

Chapter 4 - From Stewardship to Partnership: Mobilizing Rural Englishspeaking Voluntary Core ................................................................................. 113

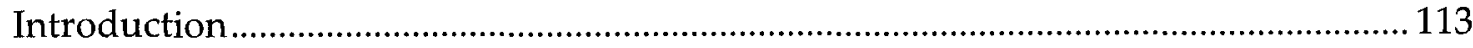

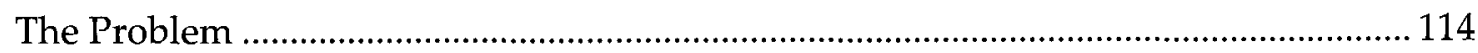

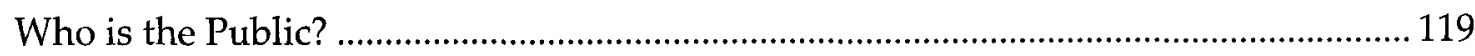

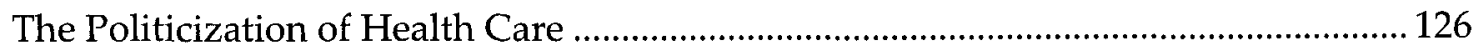

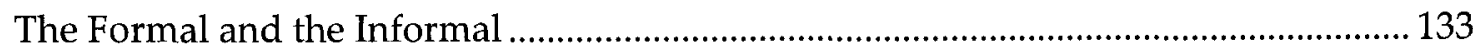

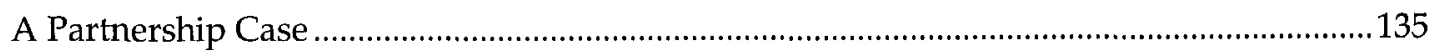

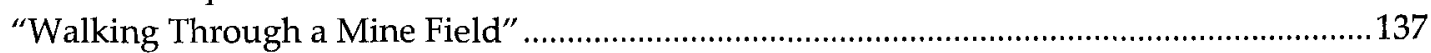

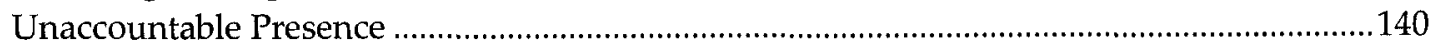

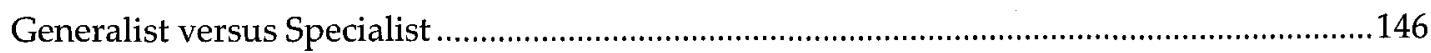

Mobilizing the Voluntary Core: Coordinate and Divide.......................................................152

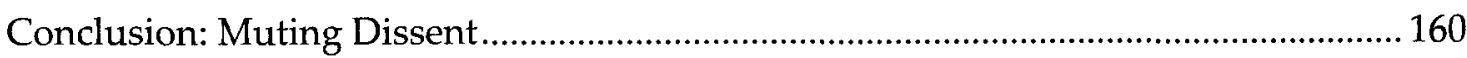

Chapter 5 - Conclusion: Lessons Learned from the Case of Estrie..................... 162

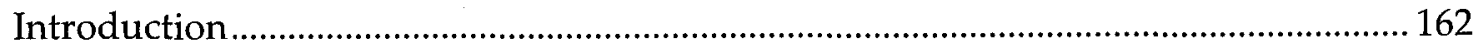

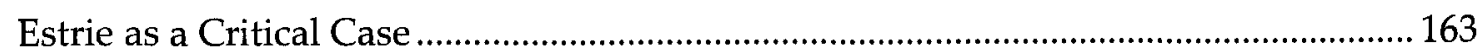

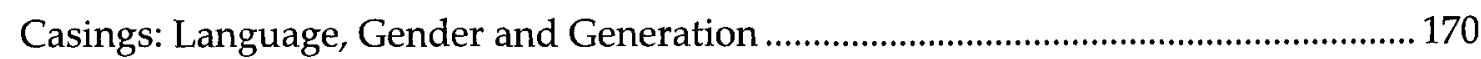

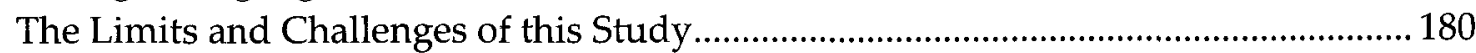

Appendix 1 - CROP/CHSSN 2005, Social Capital Questions, English .......................... 188

Appendix 2 - CROP/CHSSN 2005, Social Capital Questions, French ............................ 195

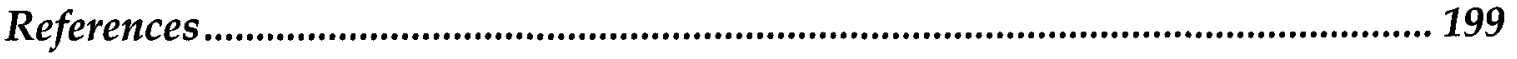




\section{List of Tables}

Table 1 - Key Socio-Economic Characteristics (p. 39)

Table 2 - Labour Force Activity (p. 87)

\section{List of Figures}

Figure 1 - Map of Estrie Region (p. 18)

Figure 2 - Volunteer Rate by Province (p.47)

Figure 3 - Traits of Canada's Voluntary Core (p. 51)

Figure 4 - Participation Health Care and Social Assistance Industry (p. 66)

Figure 5 - Unpaid Care to Seniors (p. 80)

Figure 6 - Population Employed in Government Services (p. 122)

Figure 7 - Representative Role of Government (p. 124)

Figure 8 - Timeline for Legislative Guarantees (p. 129)

\section{List of Appendices}

Appendix 1 - CROP/CHSSN 2005, Social Capital Questions, English (p. 188)

Appendix 2 - CROP/CHSSN 2005, Social Capital Questions, French (p. 195) 


\section{Chapter 1 - Social Economy, Health, and the Case of Quebec's Rural Minority Language Communities}

This chapter serves to lay out the general interest of my dissertation as well as the various tools and strategies that I have developed in order to explore this interest as a research problem. The chapter proceeds with a statement of the problem, a summary of the claims of this thesis, an overview of research methods and definitions of some key terms.

\section{The Problem}

My doctoral study explores the social economy approach (see definition of terms in this chapter) as it has emerged in the context of the Quebec model in recent years. It gives specific attention to issues regarding the conditions of health of the minority language communities located in the rural Estrie region. In light of the extensive social science literature, Quebec's rural English-speaking communities, noted for holding 'community' as a cherished value and a longstanding history of exemplary community capacity, could be predicted to thrive under the auspices of social policy where the participation of citizens in developing and delivering care through community-based organizations and local networks is increasingly critical to health. However, evidence from my doctoral study suggests the contrary. My research findings provide evidence of 
a link between Quebec's social economy era promoting 'state-supported community development' with excessively high levels of high intensity unpaid care by the women of middle and low-income minority language households, narrowing social support networks and intergenerational decline in the volunteer labor force of community-based organizations, increasingly mandatory private care services despite the rise of households unable to afford them and the increased fragmentation of this group as disadvantaged participants in the partnership approach between public health institutions and local communities. In other words, the capacity of this community to be a strong player in voluntary sector development has in fact weakened during a period of social policy where state strategy towards improved health is explicitly organized around supporting this same capacity.

Here, then, is the puzzle my study attempts to solve. How does the promotion of social solidarity, a defining principle not only of Quebec's social economy approach but of the unique social project of the only Francophone jurisdiction in North America, ${ }^{1}$ coincide with its elusion? When are strong social 
ties, such as those evidenced among Quebec's rural minority language communities, a weakness?

There is abundant and longstanding evidence that associates "social collaboration and solidarity" (Dekker and Uslaner, 2001: 1), "connections among individuals - social networks and the norms of reciprocity and trustworthiness that arise from them" (Putnam, 2000: 19), or "community capacity" (Gibbon et al, 2002: 485), with the health of individuals and general well-being of populations. The case of Quebec's minority language communities living in the Estrie region is worthy of interest in that they are well-versed in the use of the informal networks of family, friends and community-based organizations for the care of vulnerable groups like the ill and elderly, and would themselves no doubt perceive the option of "community development" as a culturally appropriate solution to their health needs (Saber-Freedman, 2001).

The emphasis on local empowerment suggests an alternative to a 'one size fits all' policy approach and the potential for greater flexibility with respect to the diversity of needs and resources of the geographically dispersed regional communities located outside of the Montreal area. As a population notably advanced in the aging process, the pursuit of an alternative to the hospitalcentered approach for the large portion of elders still able and willing to remain 
in their homes and familiar neighborhoods is appropriate. De-institutionalization is congruent with the desire to reduce the over-medicalization of women, both young and old, and generally empower patients with respect to their health. The shift in focus to the 'local' and the promise of increased health care support and decision-making power for the users and workers at this level suggests the arrival of the long-delayed recognition and support of the non-profit organizations and unpaid family workers, largely women, who are responsible for meeting the bulk of home-based needs.

On one hand, we observe an era characterized by social policy designed to support voluntary sector initiatives with particular focus on the inclusion and empowerment of marginalized groups. On the other hand, we see the seemingly well-positioned, predominately Protestant, rural English-speaking minority population noted for much higher rates of voluntary activity than the provincial average (Pocock, 2006b). Estrie emerges as a critical case ${ }^{2}$ in the sense that if the community development approach is not successful under such optimal conditions it is hard to imagine it succeeding in the event where such conditions are less favorable. How, then, are we to account for the weakened conditions of

\footnotetext{
${ }^{2}$ Flyvbjerg describes the generalization (in its negative form) that would follow from a critical case as "If it is not valid for this case, then it is not valid for any (or only a few) cases." (Flyvbjerg, 2006: 230)
} 
health of Quebec's aging minority communities, such as observed in the case of Estrie, as they emerge from the latest round of social economy policy?

My in-depth single case study employs both quantitative and qualitative strategies to explore voluntary sector participation and family caregiving on the part of Quebec's rural English-speaking population over the last few decades. One contribution of my work is in providing an argument for the analytic framework of language, gender and generation as an important measure of healthy social policy. While what is revealed through each treated discretely is of value I argue for greater focus upon the intersectionality of these social differences and enhanced clarity of the way they compound with one another in the complex experience of those who, like the English-speaking women of the Estrie region, live them simultaneously.

My findings support the claim that the lens of language is crucial in assessing the social economy approach in the unique context of Quebec even as it is conspicuously absent from the lively and ongoing debate among academics and policy-makers regarding the prevailing trend, in Quebec and elsewhere, toward third-sector development in the domain of health. While earlier policy periods are frequently referenced, typically as a contrasting period of social reform organized around working-class empowerment, the legacy of modern 
Quebec's language-based nation building is largely unconsidered as a continuing factor in the realization of recent social economy aspirations. Language is clearly a marker of social differences that pervade the lives of Quebec citizens and explains their distinct experience of the latest policy era.

Social economy policy in health is acknowledged as gender-sensitive in that it is designed, with the significant input of organizations representing Quebec women as stakeholders, ${ }^{3}$ to resist the twin tendencies of 'commodification' and 'familization' of care as its responsibility is shifted to the community. The case of Estrie offers evidence that this promise is unmet due in part to ignoring the way the situation of majority and minority women, as voluntary laborers and unpaid family caregivers, differ notably when gender is nuanced with language and generation.

Without attention to generation, both proponents and critics of social economy policy tend to be informed by a conception of Quebec's 'local communities' which diverges significantly from the current reality of the English-speaking aging voluntary core and the change in the socio- economic 
conditions which have historically supported their voluntarism. The current middle caregiving generation is highly implicated in the prevailing policy approach and a crucial health determinant of Quebec's low-income minority community households. The continuities and divergences of this group when they are compared with the middle generations who preceded them and with those who will soon take their place tell an important story about population health.

Undoubtedly, social economy initiatives, with their noted partnershipdriven approach, have produced improvements in care and general health status for some English-speakers. However, public partnerships are not guaranteed and tend to be as divisive as they are inclusive such that the 'shaky bridge' between majority health agencies and Quebec's English-speaking communities offers little basis for an optimistic diagnosis of the quality of the community's future health care.

Generally speaking, the lack of coherence between Quebec's current policy approach and the particular circumstance of minority language families and voluntary sector workers shouldering the greater burden of care demands means that health inequalities among Quebec's citizens remain far from resolved. It is argued that the third-sector approach disadvantages communities exhibiting 
traditional characteristics such as those observed in the case of Estrie despite the fact that such communities are, in many ways, the very ideal the model promotes.

\section{Summary of Major Thesis Claims}

(1) A major claim of my dissertation is that language does matter in the formation of social policy in Canada, particularly in the unique socio-political context of Quebec, and in social research which informs our understanding of community-based care in the area of health. Fundamental differences shaping the lives of Quebec citizens and altering the impact of policy measures, such as those observed in the experience of majority and minority language groups living in Estrie are disregarded when language is not given consideration.

(2) My thesis makes the claim that the equality of opportunity of minority language, low-income women is disproportionately undermined by virtue of their participation in the informal work of non-profits and families in providing quality care during Quebec's social economy era. Their concentration in high levels of volunteer activity and care networks - what may be described as their high levels of social capital - poses a health risk to themselves and the quality of care delivery in their rural communities. 
(3) A third claim is that the social economy approach is nostalgic. Social economy strategy rests upon, and seeks to recreate, what has been termed in recent literature as the "long civic generation" ${ }^{4}$ of an earlier epoch. An intergenerational shift in the pattern of voluntary sector participation has occurred alongside the rise of aging, 'missing middle', minority communities such as we observe in the case of the English-speaking communities of Quebec's Estrie region. Healthy social policy, for majority and minority alike, calls for a strategy which is congruent with the current experience of populations advanced in the aging process of globalizing democracies. The extent to which the social economy approach is organized around the presence of a robust middle-income, middle years group is revealed in the way it falls short of adequately supporting the marginal "missing middle" group observed in this case.

(4) I claim that while Quebec's social economy approach is heralded as an instance of health policy which is advanced in its explicit consideration of the situation of women, the privileging of gender as a health determinant undermines the solidarity of women and ultimately exacerbates the health inequalities which disadvantage marginalized groups. The focus on the

4 This term is borrowed from Putnam (2000) although it is now fairly widely circulated. 
intersectionality of language, gender and generation grants visibility to the middle-generation, English-speaking women of Estrie who would otherwise be obscured as the experience of the majority language group is treated as 'generic'.

(5) Finally, my research in the Estrie region supports the claim that trust is the pre-condition for the contractual partnerships between public health authorities and local communities promoted by the social economy approach and is unlikely to be fostered by these same partnering arrangements.

\section{Overview of Research Methods}

I have used a multiple methods strategy combining quantitative and qualitative techniques to explore the research problem of this dissertation. While the greater part of my data collection has produced findings at the regional level within the province of Quebec, comparisons are provided from the Canadian provincial and national levels to provide scale and clarity. Some international perspective has been gained through my review of the literature.

For the purpose of my study I focus upon the case of the historic Eastern Townships agricultural region, or Estrie as the administrative region is presently named. Generally, Estrie is fairly typical of the Quebec regions outside of Montreal in the socio-demographic characteristics it displays. Among Quebec's 17 administrative health regions, Estrie has a fairly sizable English-speaking 
population $(23,385$ Anglophones who comprise $8.4 \%$ of the region's total population of 279,695$)$. Its geographical location is within reasonable proximity to Montreal and Quebec City which means it does not have the same issues that can arise from the more extreme isolation experienced by some of its rural counterparts. As a region it claims a network of institutions in education that extend from elementary and high school (although the clientele for these are shrinking) through to an English-speaking CEGEP (Champlain College) and university (Bishop's). Until restructuring in Quebec's health sector in recent years and the transformation of the Sherbrooke Hospital, health and social services in English were fairly accessible. ${ }^{5}$ The present reality is that English-speaking Quebecers must seek services from the institutions of the Francophone majority in most areas, including parts of Montreal. Interestingly, international research underscores the fact that volunteer activity is strongly associated with Protestantism (Woolley, 2001) and the Estrie region is one of the two regions among official-language minorities across Canada that shows the highest levels 
of Protestant religious affiliation (Statistics Canada, 2003). Research also supports the finding that there is a long tradition of high rates of voluntary activity and strong community-supported family networks among the English-speakers of the rural Estrie region (Saber-Freedman, 2001; Pocock, 2006b).

I have explored four areas of inquiry in developing my thesis each linked with a distinct methodological approach and fieldwork strategy. I have employed demographic profiles, a regional survey, expert interviews, and intergenerational volunteer and caregiver interviews. One set of research questions concerns measuring and comparing quantifiable phenomena such age structure and certain socio-economic characteristics of selected official-language communities, both provincial and regional, across Quebec and Canada. These include an extensive questionnaire permitting comparison of the rate and type of voluntary sector participation and unpaid caregiving of these same populations. Expert interviews provide a first-hand look at the experience of those directly involved in a government initiative designed to build networks and public partnerships among local English-speaking communities in the area of health and social services. A final set of questions was designed in accordance with what might be called a genealogical approach measuring structural and normative change over time by comparing generations residing within this same 
regional population. The four fieldwork strategies and data sources I use are as follows.

\section{Demographic Profiling}

I have generated demographic profiles comparing the English-speaking population living in the Estrie region with the French-speaking population sharing the same territory, with the provincial Anglophone population, with other regional Anglophone groups as well as with other Canadian OfficialLanguage Minority Communities (OLMC, see definitions) across Canada. Estrie is one of 17 administrative health regions and is entirely contained within the historic Eastern Townships region.

A demographic profile of a population is organized to highlight a broad range of social and economic characteristics that describe and shape the lives of its constituents. For my dissertation research I considered such variables as income and employment, education, ethnicity, demolinguistics, unpaid care, caregiver-to-senior ratio, population growth, religious affiliation, marital status, household arrangement and health service provision. These also belong to the

list of key health determinants included in the Population Health Model used by 
Health Canada. ${ }^{6}$ These profiles consider the Quebec population at the provincial level, at the level of administrative health region and CLSC (Centres Locaux de Services Communautaires) $)^{7}$ territory. There are 8 CLSCs in the Estrie region. My main focus will be on the Estrie region (23, 385 Anglophones who comprise $8.4 \%$ of the region's total population of 279,695$)$ along with the CLSCs of Memphremagog CLSC (8, 475 Anglophones who comprise $20.6 \%$ of the territory's total population of 41, 200) and Richmond (2, 368 Anglophones who comprise $8.6 \%$ of the territory's total population of 27,655$)$, both of which are contained within Estrie.

Four main devices used for describing the variables collected for these various levels of the Quebec population:

Minority-majority Index: The Minority-Majority Index (mmi) compares the characteristics of the regional minority Anglophone population relative to the majority Francophone population which shares the same province, region or CLSC territory.

Relative geographic index: The Relative Geographic Index (rgi) refers to the relative value of a characteristic for the Anglophone population of a given region compared to the Anglophone population of the entire province of Quebec. This will also used be used to refer to the relative value of a

${ }^{6}$ See definitions section of this chapter for the various health determinants outlined by the Population Health Model used by Health Canada (Health Canada, 1998). The CLSCs were replaced by Centre de santé et des services sociaux in 2005 but the geographic boundaries of these institutions in the Estrie region did not change.

7 These are health and social service centres provided by Quebec's public sector (MSSS 2008a) 
characteristic for the Anglophone population of a given CLSC territory compared to the Anglophone population of the region.

Temporal Index: The Temporal Index compares the characteristics of a given regional community with its characteristics at a different point in time. It will be used to illustrate trends and change over time.

Gender Index: The Gender Index compares the characteristics of the female portion of the Anglophone population to the male portion of the same population.

\section{Survey Method}

As a research consultant for the Community Health and Social Service Network (CHSSN), a provincial health organization serving English-speaking Quebec, I designed a module on care, social support and civic participation that was featured in a larger omnibus survey conducted in the summer of 2005. To ensure comparability with broader national datasets this module draws heavily on the General Social Survey Cycle 17 (Statistics Canada, 2003) as well as the Survey of Volunteering and Giving (Statistics Canada, 1998). My contribution was to adapt the questions probing the general area of volunteering, caregiving and civic engagement in an official-language minority context.

The interviews were conducted by CROP, a Quebec-based research firm, for the CHSSN and administered to 3, 500 English-speaking and 1, 500 Frenchspeaking Quebec citizens. Estrie region was targeted resulting in approximately 250 questionnaires. The results were received in August of 2005 and analyzed. I received permission of the CHSSN to make use of this data in my doctoral 
dissertation. Copies of the French and English versions of the questions pertinent to my proposed project are attached (Appendices 1 and 2). The questionnaire was designed to follow up a survey conducted five years previously by CROP for the Missisquoi Institute with some questions remaining identical, some others added or modified and the addition of new questions concerning the voluntary sector.

\section{Intergenerational Interviews}

The twelve family interviews that I have undertaken are intertwined with the network analysis strategy outlined above and explore more deeply some of the questions from the survey. The choice of the three older generations means anyone under 18 years of age was not an interview candidate. Often by virtue of the narratives of the eldest generation, information regarding an older fourth generation was gathered. Families were selected from names offered by two community-based organizations involved in health and social services located in Estrie and by a local heritage association in the region. Family interview locations are indicated on the accompanying map (see page 18). All interviews were tape-recorded and the speakers were promised anonymity. The interviewees were selected to represent as closely as possible the nature of the group being investigated. This has entailed including a portion of family care 
situations characterized by a female relative from the middle caregiving generation with siblings who have departed from the region, a portion of elders whose care, and caregiving, does not involve co-present family members, and a portion of families where the elder generation is cared for by a middlegeneration male relative.

This aspect of my study is largely concerned with the extent and nature of change and continuity across the generations of a "missing middle" minority population with a focus upon caregiving, social support and civic participation. The questions I pursued were, for the most part, a further refinement of those asked in the questionnaire but more open-ended to allow for greater elaboration on the part of the respondent and designed to facilitate closer attention to generational variance. Of specific interest is the comparison of the experience of the middle-aged caregiver group across three and four generations. Changing contributions to unpaid care (especially eldercare), the nature of social support networks, employment patterns, geographical mobility, participation in the voluntary sector and health status were considered. 


\section{Expert Interviews}

As a research consultant for the Community Health and Social Service

Network (CHSSN) ${ }^{8}$ a provincial health organization serving English-speaking

Quebec, I undertook twenty semi-structured interviews with individuals who

play a leading role in their Health and Social Service Networking and Partnership

Initiative. The government-funded initiative is designed to improve access to

health and social services for Quebec's official-language minority communities

through the development of local networks and effective partnerships with

public sector agencies. The ultimate goal is to promote better health outcomes for

Quebec's English-speaking communities across the province through

partnerships which increase support to regional groups by Quebec's public

health and social service system.

Generally an hour-and-a-half in length, these interviews included paid

Network Coordinators and Executive Directors of associated regional

community organizations who had been involved in the initiative over the past

\footnotetext{
${ }^{8}$ The Community Health and Social Services Network (CHSSN) was established in September 2000 to create a network of community resources, associations, and public institutions dedicated to the development through partnership of health and social services for English-speaking communities in Quebec.
} 
five years. Their work gives them a unique first-hand perspective of the network and partnership approach in the health sector. They are also closely involved in the training and support of the voluntary core in their respective territories and have thereby acquired extensive knowledge on their nature and activities. Some have been involved in community development for many years and offer interesting insights into what they perceive to be the particularities of the most recent trend towards partnerships and network building.

Interviewees were provided with some general interview questions prior to the recorded telephone conversation. These served to guide the direction of the interview while also giving the participants ample opportunity to introduce topics deemed relevant to their particular experience and perception. All interviews were recorded with the consent of the interview participants and selectively transcribed. I was the author of a report based on these interviews entitled, Community Network Building, and published in 2007 by the Community Health and Social Service Network (Pocock, 2007a). All expert interview material used in my dissertation was drawn from this publication. 


\section{Definitions of Key Terms}

\section{a) Aging population}

Aging, at a societal level, refers to the proportion of age groups in a given population: young, mature, and aged. According to the United Nations a population is considered "aged" if $10 \%$ or more of its population is 60 years or over (Novak, 1997: 78). For Statistics Canada, the term "elderly" or "senior" refers to 65 years or over. Canada's population, for example, is one of the oldest in the world. To understand the aging trend in Canada and modern industrial societies in general demographers consider three conditions that affect a population's size and structure - namely migration, death rates, and fertility rates. In the case of linguistic communities, language transfer is also considered.

The two most significant forces in the case of Canada are the drop of fertility and death rates. The increase of life expectancy of its citizens over the course of the $20^{\text {th }}$ century means Canada has one of the highest life expectancies in the world. More people enter old age than ever before. The drop in fertility rate starting in the 1960s has meant a sharp decline in the proportion of young people in the population. By 1971, the fertility rate among Canadians had fallen below the replacement rate of 2.1. Statistics Canada projects the continuing decline in the portion of youth under 20 into the next century. Of course it is 
important to keep in mind the ratio of young, mature and elderly varies from region to region in Canada as these demographic features are shaped by various social, political and economic processes.

\section{b) Anglophone}

An Anglophone is an individual whose main or first language spoken is English. It should be noted that more than two-thirds of Anglophones living in Quebec in 2006 were considered English-French bilingual.

\section{c) English-speaking minority population}

In 2001, the total population of Quebec is 7.3 million and the size of the English-speaking population, its official-language minority, is estimated to be about 919,000 or $13 \%$ of the population (Statistics Canada, 2003).While a minority, this community is still larger than several Canadian provinces. Although the majority of Quebec Anglophones live in the greater Montreal area, there still remains a sizable proportion of the Anglophone community in the various outlying regions of Quebec. The Anglophone population outside of the Montreal area consists of approximately 140, 000 people (Pocock and Floch, 1999: 19). 


\section{d) Estrie Region}

Estrie is a territory established by the Government of Quebec to facilitate the planning and delivery of a broad range of government services including health and social services. (See map on page 18.) It is an administrative region entirely contained within the historic Eastern Townships which was mainly settled by Americans and British subjects from the end of the $18^{\text {th }}$ century forward. In 1996 it had 24, 770 Anglophones who comprise 9\% of the region's population of 273, 335 (Pocock and Floch, 1999: 20). The Estrie Anglophone community is among the most aged linguistic communities across Quebec. The region is predominately rural made up of small towns with a major urban center, Sherbrooke (population of 75, 000). Agriculture is the second largest employer of Anglophones in the region after manufacturing.

\section{e) Health Determinants}

National governments and health organizations around the world have identified a broad range of social, economic and environmental factors that have been demonstrated to have a strong influence on the health of populations and individuals. These influences rarely exist in isolation and it is usually the nature of their configuration which explains why some social groups enjoy a better health status than others. Health Canada outlines various determinants of health 
- some of which are social determinants - such as income and social status, social support networks, education, employment and working conditions, health services, physical and social environments, biology and genetic endowment, personal health practices and coping skills, healthy child development, gender, and culture (Health Canada, 1998).

\section{f) Official-language Minority Communities (OLMCs)}

To clarify, the Canadian Charter of Rights and Freedoms (1982) and the Official languages Act (1988) set official languages policy in Canada by which English and French are recognized as Canada's official languages. A consequence of this is the definition of Official-Language Minority Communities (OLMCs) which in 2001 included 988, 000 speakers of French outside of Quebec (4.5\% of the population) and 919, 000 speakers of English in Quebec (13\% of the population) (Statistics Canada, 2003).

It is important to note that the linguistic definition used here is First Official Language Spoken, which is a broad language concept, encompassing $99 \%$ of the Canadian population. Only those who can speak neither English nor French are not covered by the FOLS definition which is derived from responses to three Census questions (knowledge of official languages, mother tongue and home language). Both Official-Language Minority Communities (Anglophones 
in Quebec and Francophones outside of Quebec) show a higher rate of aging than do their respective majorities. Research also substantiates a high level of identification of individuals living in these official minorities with their linguistically defined communities (CROP/Missisquoi Institute, 2000).

\section{g) Social Economy}

For the purpose of my project, the term "social economy" refers to three different levels of meaning. First, the notion of the "social economy era" refers to a specific historical period distinguished by a policy initiative called "économie sociale" or social economy. While the social economy sector has a long history in Quebec, the social policy reforms of the Quebec government by that name have gained their popularity since the middle 1990s. An oft-cited defining event is the Economic and Employment Summit of 1996 where consensus was achieved among representatives of government, business, labor, the women's movement and community-based organizations on a new five element definition of social economy both as the model for, and mission of, state and government intervention (Vaillancourt, Aubry, Kearney, Thériault, and Tremblay, 2004).

Secondly, as a 'sector' of Quebec society social economy refers to an array of enterprises and initiatives mostly from the non-profit sector including advocacy groups, voluntary organizations, other community-based 
organizations and cooperatives (Vaillancourt, Aubry, Kearney, Thériault, Tremblay, 2004). As Vaillancourt underlines, the term is not as widely used in English Canada but is similar to such terms as "third sector", "voluntary or nonprofit sector", "community" with the exception that the cooperatives for which Quebec is well-known is frequently omitted when the latter are the case in point. Initiatives designed to enhance "social capital" and improve "community capacity" generally focus on development of this sector.

Thirdly, I use the notion of a 'social economy approach' to refer to the ideological climate that tends to be supported by public policy that promotes, in this case, the particular values and institutional structures attributed to this sector of Quebec society. Social economy is not a term used as commonly as social capital but as general approaches they share the common focus upon the democratization of social policy, the civic participation and empowerment of workers and users of the voluntary sector, and the formation of partnerships between formal agencies and the "local community" designed to facilitate them in addressing local health inequalities (Jenson, 1998; Vaillancourt, Aubry, Kearney, Thériault, Tremblay, 2004). Given my interest in the area of health care it is important to note that Quebec's social economy approach is distinct, as Jensen (1998) points out, in its focus upon economic participation as the central 
avenue through which social inclusion is achieved and in its explicit recognition that the state partnerships it promotes need to be designed to resist the twin tendencies toward the 'commodification' and 'familization' of care.

\section{h) Social economy debate}

As part of the ongoing and lively debate regarding the growing trend of 'voluntary sector' development among academics, policy-makers, as well as representatives of non-governmental organizations and advocacy groups, Quebec's unique économie sociale has been rigorously scrutinized with respect to its capacity to stand as a possible 'third way' and an inspiration for reconfiguring prevailing social hierarchies and structures of governance (Salée, 2003; Mendell, 2002; Shragge and Fontan, 2000; Comeau, Favreau, Levesque and Mendell, 2001; Vaillancourt-Rosenau, 2000).

While less attention has been given to Quebec's social economy approach in the domain of health, the theoretical links between social policy, the social economy and the determinants of health are nonetheless consistently drawn, and evidence of the consequences of the approach is increasingly the basis of argumentation (Vaillancourt, Aubry and Jetté, 2003; Armstrong, 2004; Bernier and Dallaire, 2002). There is abundant closely-related research in the area of health organized around the concept of social capital, a term more commonly 
used in English-speaking countries (Mackian, 2002; Muntaner, Lynch, Hillemeier, Lee David, Benach and Borrell, 2001 and 2002; Edmondson, 2003; Putnam, 2000)

For both proponents and critics alike much of the discussion hinges on Quebec's status, established through the radical activities of the 60 s and 70 s, as a 'counter-paradigm' within the Canadian social and political scene and a model for authentic social transformation. A central question for both sides of the debate is whether the current social economy approach represents a renewal of the Quebec model and the amelioration of the conditions of health promised in the notion of enhanced social solidarity and community empowerment, or whether it serves to maintain the cohesion that rests upon a managed accommodation to the dominant configuration of social relations inherited from Quebec's later modernization.

Curiously, despite language as a defining characteristic of Quebec society, and despite the proliferation of language policy and legislation during these same noted decades along with a substantial body of research organized around the comparison of linguistically defined communities by Quebec's intelligentsia, language is conspicuously absent from the current debate. I contend that evidence shows language to be a continuing factor in the social stratification of 
the population of Quebec and therefore the apparent 'language peace' characterizing the present period, and sustained by social economy analysts when language is placed beyond the parameters of their examination, can only come at the cost of the transformative potential sought in the model in question. The collaborationist, partnership-driven approach that has been emphasized in recent years, often argued to yield more beneficial results than the protracted confrontations of the past, is defended as having progressed beyond the issue of language. However, persistent language based inequalities among key health determinants suggests the silence surrounding the divide between Quebec's French-speaking majority and English-speaking minority in fact serves to grant it a level of legitimacy.

\section{i) Unpaid care}

This generally refers to the unpaid hours persons spend providing assistance to seniors, children or other dependents, and doing general household maintenance for one's own household, for other family members outside the household, and for friends or neighbors. This definition is one that is further elaborated in the course of my thesis as I explore the changing parameters of care for English-speakers in Estrie during the social economy era. 


\section{j) Voluntary Core}

The voluntary core refers to those who consistently devote a large number of unpaid hours to volunteer activities and often do so across several areas of activity. This is to be contrasted with individuals who volunteer fewer hours and volunteer on a temporary basis. A small fraction of Canada's adult population is responsible for a greater share of all volunteering, giving, and civic participation. In the case of volunteering, $10 \%$ of Canadian adults 15 years and older were responsible for $81 \%$ of all volunteer hours in 1997 (Reed and Selbee, 2000). Quebec has the smallest voluntary core (24\%) within which there is an even smaller primary core (5.2\%); Saskatchewan has the largest at $38.6 \%$ and $13.4 \%$ respectively (Reed and Selbee, 2000).

\section{k) Volunteer}

For the purpose of the present research project a volunteer is someone who, without compulsion, gives of their time and energy to an activity, or several, among a wide range considered to be of service to a larger community or group. This includes tutoring, coaching, front line service delivery such as wheels-on-meals, representative on a board of directors, sitting on a committee organized by a municipal town council and an array of similar others. 


\section{Conclusion: The Puzzle of Estrie}

The position of Quebec's English-speaking communities located in Estrie with respect to important determinants of health has declined in the recent policy era where voluntary sector development is the prevailing state strategy towards the improved health of populations and individuals. This chapter sets the stage for thinking through this change with an articulation of the problem, an overview of research methods, summary of claims arising from the research process and clarification of key terms.

The following three thematic chapters will use the findings from my study of the mainly rural Estrie region to demonstrate the ways that the promotion of social solidarity through Quebec's social economy approach has fallen short of its expected outcome. While all chapters draw upon a baseline of evidence derived from the interweaving of both qualitative and quantitative methods, each one is distinguished by a theme emphasizing a certain type of finding as well as a specific informant group.

The final chapter concludes with reflection upon the key lessons learned from various agents involved in producing community health as well as the possibilities and limitations of Estrie as a single in-depth case study. 


\section{Chapter 2 - The Missing Middle: Considering the Relevance of Third Sector Health Strategies for Quebec's Rural English-speaking Communities}

\section{Introduction}

In this chapter, the relevance of the social economy approach as a strategy for fostering the social inclusion and empowerment of aging minority populations will be examined. Findings will be introduced from the languagebased demographic profiles I have assembled using Statistics Canada Census of 2001, from the Survey of Community Vitality (2005) distributed to 250 respondents in the Estrie region (see Appendix 1$)^{9}$ and the 12 in-depth interviews conducted with members of English-speaking households located in Estrie.

\section{The Problem}

Of particular interest is the policy assumption that the alliance of state and community-based organizations in the domain of health fosters the democratization of health and social service policy, work, and service organization. Social economy policy is purported to promote the "empowerment of users and workers" and this is understood to be indicated in their level of

\footnotetext{
9 Throughout this and subsequent chapters "Survey of Community Vitality (2005)" refers to the questionnaire I implemented for my dissertation. For further description see methodology discussion in Chapter 1. Periodically, I also refer to this survey as my dissertation questionnaire.
} 
participation in the planning and management of health and social service organizations and initiatives. The catchwords are "full citizenship" and "sense of ownership" which are defined as "citizen-users", both individual and collective, who are not simply at the "receiving end" of public provisions but also "owners" of the process of production (Roeher Institute, 1993; Jetté et al., 2001; Vaillancourt et al, 2000).

In this chapter I claim that third-sector policy does not adequately conceptualize the experience of rural minority populations who, like Quebec's Estrie English-speakers, are typically advanced in the aging process of globalizing democracies. Evidence suggests the community development approach, either heralded as inherently positive (Putnam, 2000) or criticized for being heavily influenced by a model of community capacity typically associated with "traditional communities"10 (Mackian, 2002: 205), in fact disadvantages the very rural population to whom the model is generally attributed. In the case of Quebec's Estrie region, third-sector strategies tend to advantage a younger, more urban, French-speaking population who claim a greater proportion of local 
middle-income earners when compared with the older, more rural, and more geographically mobile English-speaking population who share the same territory. Restructuring in the health sector during the social economy era coincides with the widening of the gap between these co-existing populations in terms of their position with respect to key health determinants as well as their capacity to mobilize in terms of state-promoted tactics to improve the health status of their citizens.

An understanding of the distinct social network patterns of language majority and minority workers/users in the areas of voluntary participation and civic engagement, as they intersect with changing institutional arrangements in Quebec's health sector, clarifies how state-supported community development may undermine the basis for solidarity among the citizens of the Estrie region. The social policy, now some thirty years old, that has facilitated the ownership of the Quebec economy by its majority and promoted Francophone cohesion has simultaneously established the conditions for the growth of a bi-modal minority and the rise of a new Anglophone underclass. On the heels of this long-term erosion, the recent social economy era has targeted the community organizations and nonprofits of the third sector as candidates for state partnering, and in so doing, raised expectations of the voluntary and unpaid labor upon which these 
organizations depend. This has been done, however, without addressing the linguistically-differentiated nature of third-sector workers/users and their distinct challenges. In the case of Estrie's English-speaking population, the labor of their voluntary core may be recognized by social policy as a necessary component in overcoming barriers to health and reduced citizenship, but in ignoring language differences, the age and income structure of the majority language group tends to be presumed as the norm. In contrast to the majority population, the disadvantage these third-sector minority workers face by virtue of a 'missing middle' is even further compounded by the impact of the devolution from 'community institutions' to 'service access points' characteristic of health sector restructuring during this same policy period.

The case of the Estrie region in the domain of health suggests the recent decade of social economy policy is more aptly characterized by the notion of 'language pacification' than the currently popular 'language peace' given it has generally served as a period of unreasoned, and unhealthy, accommodation of Quebec citizens to their linguistically stratified positions with respect to the province's narrowing economic opportunities (Salée, 2003). 


\section{French Majority Cohesion and the Aging of the English Minority Communities of the Estrie Region}

\section{The Context of Aging}

While the aging of Canada's population is a well-known trend, Canada's unique feature as an officially bilingual nation remains a significant, yet unexplored, explanatory factor in determining the nature of its aging experience. In Canada, perhaps most apparently in Quebec, language matters. The accelerated pace of aging in the official-language minority communities of Quebec make them a uniquely fertile site of inquiry. The advanced rate of the aging process among English-speakers of the Estrie region means that, by the late 1990s, they were a generation ahead of the rest of the general Canadian population in terms of aging (Pocock and Floch, 1999).

Besides the significant difference in the rate of aging between the minority language population located in the Estrie region and the younger majority language group with whom they share the territory, demographic profiling reveals the Anglophone community is further characterized by a configuration of its generations which is unique compared to other linguistic communities across Canada. I refer to this characteristic as a 'missing middle'. Among the possible patterns that the age structure of a population may exhibit, the English-speaking 
community shows not only an over-representation of seniors but is notably marked by an under-representation of individuals in the 35-54 years age cohort generally known as the 'middle' generation. In the case of the rural Estrie region, Anglophones have $80 \%$ more individuals per capita in their senior years and just over half the proportion of individuals in their middle years found in the Francophone population of the region. This means that in relative terms, there are nearly twice as many English-speaking seniors women as French-speaking. In proportional terms, there are five times as many widowed women as widowed men in the English-speaking regional population (Pocock, 2003).

A comparative examination of the socio-economic features of both language populations in Estrie demonstrates not only the general absence of middle-generation English-speakers but the absence of Anglophones in the 35-54 years age cohort who by virtue of profession, education and income are typically referred to as 'middle-class'. This is in keeping with general provincial mobility patterns when measured by language group. When majority and minority languages groups are considered by Canadian province, Quebec's language minority has the lowest retention rate relative to their majority. This stands in contrast to provinces like Prince Edward Island, Nova Scotia or New Brunswick which show a stronger retention rate in the language minority than in the 
majority. Data analysis of the mobility patterns of English-speaking Quebec for the 1991 and 2001 census periods reveals, "the gap between leavers and stayers has grown quite considerably as those who leave are much more likely to be in the high income bracket and less likely to be in the lower income bracket than those who stayed." (Floch \& Pocock, 2008: 59) Those English-speakers who have stayed within the Estrie region have, over time, experienced a relative decline in socio-economic status with the result being a notable gap between a highly educated, high income group and an expanding group characterized by lower levels of education, low income levels and higher levels of unemployment (Floch, 2004).

Census analysis by the Department of Canadian Heritage reveals a decline across generations in the relative status of the Anglophone group when compared to their Francophone co-habitants in key socio-economic characteristics such as highest level of schooling, unemployment rates and tendency to be out of the labour market. 
Table 1 - Key Socio-Economic Characteristics

\begin{tabular}{|l|c|c|c|}
\hline \multicolumn{4}{|c|}{$\begin{array}{c}\text { Minority-Majority Index for Key Socio-Economic Characteristics } \\
\text { Anglophones Compared to Francophones } \\
\text { in the Eastern Townships Region of Quebec, Population 15+, 2001 }\end{array}$} \\
\hline & $\begin{array}{c}\text { Lacking high school } \\
\text { certification }\end{array}$ & Unemployed & $\begin{array}{c}\text { Out of the Labour } \\
\text { Force }\end{array}$ \\
\hline Pop. $15+$ & 1.02 & 1.11 & 1.26 \\
\hline $15-24$ & 1.27 & 1.31 & 1.29 \\
\hline $25-44$ & 1.07 & 1.18 & 1.55 \\
\hline $45-64$ & 0.93 & 0.93 & 1.11 \\
\hline $65+$ & 0.80 & 0.96 & 0.96 \\
\hline Notes: Table produced by author, based on data from Floch, 2004. \\
\hline
\end{tabular}

The above table uses a minority-majority index (MMI) to demonstrate

these three socio-economic characteristics across age cohorts. Comparing the minority Anglophone population relative to the majority Francophone, a mmi greater than 1.00 indicates the characteristic is more commonly found in the minority population. An mmi less than 1.00 indicates it is less present in the minority population. As one example, we learn from the above table that in 2001 Estrie Anglophones ages 25-44 were 55\% more likely to be out of the labour force than Francophones of the same age sharing the same territory. Overall, we can observe a trend across the different age groups of English-speakers residing in the Estrie region suggesting a growing gap between minority and majority populations.

When we compare Official-Language Minority Communities across the Canadian provinces, the heterogeneous composition of Quebec's English- 
speaking population stands out as a unique feature. ${ }^{11}$ The Quebec Anglophone provincial population is composed of a much greater percentage of members of visible minorities (20.8\% greater), a greater percentage of individuals of nonChristian religious affiliation (15.6\% greater) and more individuals born outside of Canada (30.9\% greater) than other Canadian language minorities. This is also the case when Quebec Anglophones are compared with the more homogeneous Francophone majority with whom they share the provincial territory. This pattern of diversity, while more marked in the urban Montreal region, remains consistent for the Estrie region with the added feature that English-speakers in the region are comparatively less urban than Francophones. Put differently, Quebec English-speakers residing in the Estrie region are much more likely to be living a reality associated with the advanced stages of globalization than their French-speaking counterparts. The often-cited characteristics of globalization such as an increased polarity between rich and poor, a highly mobile middleclass, a heterogeneous composition and an aging trend are present in the 
Anglophone minority population in this region to a greater degree than in the Francophone population (Pocock, 2004: 65-71).

In sum, the case of the Estrie region allows us to observe two language populations co-residing in the same provincial jurisdiction, under the auspices of the same social policy, and yet increasingly occupying two different positions with respect to the key health determinants of employment, income, and educational achievement. The weakening situation of the minority group with respect to social support networks, another important determinant of health given much attention in the social economy approach, will be examined in depth later in this chapter.

What can we conclude at this point with respect to the aging phenomenon in the case of Quebec? It is tempting to suggest that the advanced aging of Quebec's English-speaking minority communities allows them to stand as something of a predictor for those that are less advanced, like the Frenchspeaking majority, but this may be misleading. Unlike the life course of an individual, the aging of populations is not a linear process. In this case the youthfulness, if you will, of the majority population is maintained at the cost of the dismantling of the older minority group who displays its advanced aging as but one symptom of their interdependence. The continuation of this relationship 
into the future, under the same policy conditions, is likely to serve to maintain the superior conditions of health of the segment of the Quebec population who by virtue of this advantage, already enjoy a greater likelihood of good health.

\section{Quebec Nationalism, Globalizing Economies and the Era of Language Peace}

When seeking to understand the present state of health inequalities in Quebec, it is important to consider the English-speaking community as uniquely implicated in a globalizing economy on one hand, and Quebec's late period of modernization and language-based nation-building on the other.

The English-speaking population of Quebec was noted in the sixties for their location in the sectors of the economy most likely to be linked with larger Canadian and international markets compared to the smaller, more provincial markets associated with the sectors employing Francophones (Milner and Milner, 1973). This was actually underlined as an unfair advantage on the part of Quebec's Francophone majority, who viewed itself as 'an island in the North American sea of English' and in need of remedy by social planners. Some 40 years later, we can observe that this earlier trait in fact predisposed the Anglophone group to an increased incidence of market induced geographic mobility on the part of its educated, professional, middle-generation group in the present decade. This predisposition for high rates of mobility was further 
exacerbated by the much studied transformations of the seventies and eighties wherein the expansion of the Quebec state as a vehicle for structural change meant the rise of a new, distinctly Francophone, middle-class (Coleman, 1984; Fournier, 1984; Guindon, 1988; White, 1997; Shapiro, 1995). A telling example of the way this engineering is a continuing factor in the missing middle of this constituency of Quebec lies in the fact that among those employed by the provincial government in Quebec, less than $1 \%(0.7 \%)$ of the public service is drawn from the Anglophone community whereas over $96 \%$ are white Francophones (Secrétariat du Conseil du Trésor, 2003). Put another way, only $3.4 \%$ Quebec's public service is made up of individuals drawn from its aboriginal, visible minority, allophone and Anglophone constituencies. ${ }^{12}$

Despite the fact that apart from the 1986-1991 period, the fertility rate of Quebec Anglophones has always been lower than that of Quebec Francophones, the perception that immigrants were tending to join the Anglophone community rather than the Francophone majority inspired legislators to adopt a series of language laws designed to protect the French language and secure its continued

12 The groups of public service workers referred to here are those working directly for government departments. It does not include those working in para-public institutions such as hospitals or schools but would include those working for the Ministère de santé du Quebec or the Ministère de l'Éducation du Quebec. 
hegemony in the province. Low fertility rates combined with barriers to its inmigration means Anglophones now face particular demographic challenges. Consider also that during the 1976-1986 period, Anglophone Quebec experienced an unprecedented out-migration of its members from Quebec to other Canadian provinces. This entailed a net out-migration of 96,980 people aged 20-64 of whom 70, 035 had English as their mother tongue (Clugston, 1986). It has been reported that over 140 company head offices left Quebec during this period taking more than 14, 000 jobs with them (Clugston, 1986). Clearly, the adoption of the Charter of the French Language ${ }^{13}$ in 1977 and the rigorous program of Francisation especially in the area of commerce, business and the professions was a significant factor in the exodus. As a result of this period there is a marked absence of a middle generation which continues to influence the experience of this population in much the same way as the effects of the baby boom generation are still being widely felt.

Today, even in the face of the dramatic changes in the social stratification of Quebec's official-language populations, old stereotypes continue to persist as a rallying point for nationalist sentiment and justification of Quebec's language

${ }^{13}$ The Charter of the French Language, adopted by the Parti Québeçois in 1977, established French as the sole official language in Quebec. 
legislation. Recent social policy debate, both in the public and academic realms, tends to revolve around inequalities experienced by 'Quebec's cultural minorities' with little mention of language and no acknowledgement of the fact that the greater portion of racial and religious diversity is located among those who identify themselves as members of Quebec's English-speaking communities (see Salée, 2003 for example). A recent study prepared for the C.D. Howe Institute (Vaillancourt et al, 2007) tells us that the majority of Quebec Anglophones are now functionally bilingual, and bilingual Francophones now register the highest average income in the province. While for some the "clarification of the linguistic order" in Quebec has brought the benefit of "social peace $",{ }^{14}$ for others the silence surrounding the reversal of language inequalities attests loudly to the waning status of solidarity as anything more than an empty abstraction.

${ }^{14}$ In an article by Hubert Bauch, PQ MNA Pierre Curzi, the party's language critic in the National Assembly, is quoted as saying in reference to Bill 101 that, "The greatest benefit is the social peace and linguistic peace it has brought. Ultimately, it allowed for a clarification of the linguistic order in Quebec and reassurance to everyone." "Bill 101 Paved Way for Peace" The Gazette, Saturday, August 25, 2007. 


\section{Aging Minority Communities, Restructuring in Health and the State of Voluntary Labor}

As stated earlier, the social economy approach addresses health inequalities, and claims to promote the inclusion of marginalized groups, through the empowerment of community sector organizations and non-profits who rely largely on voluntary and unpaid workers. What is the situation of English-speaking workers and users of the voluntary sector in the context of the advanced rate of aging of this minority population located in the rural Estrie region? Do they meet the criteria of eligibility presumed in the notion of 'public partner'? And ultimately, is voluntary sector development a sustainable approach for the mobilization of Quebec citizens (who together are often viewed as an aging language minority within Canada and North America) in solving health problems?

My contention that social economy policy is increasingly irrelevant with respect to resolving health inequalities through the voluntary sector is substantiated primarily by findings from five aspects of the Quebec Anglophone case: (1) the reduced presence of a rooted, middle-aged, middle-income professional group with a commitment to community, (2) the nature of intergenerational change with respect to English-speaking voluntarism, (3) the impact 
of the restructuring of public health and social services on informal social support networks, and (4) the rise of both political disengagement (further discussed in Chapter Four) and (5) unpaid household labour during the social economy era. The situation of unpaid household labor will be expanded upon in Chapter Three.

\section{The Missing Middle and Voluntary Participation in Quebec}

It is important to underline at the outset that language matters when it comes to the workers and users of the voluntary sector. For both Anglophones and Francophones, language is an important consideration in the decision to become a volunteer. Despite high levels of bilingualism among the Englishspeaking population of Estrie, my dissertation questionnaire reveals the main language used in volunteer activities is English.

The accompanying graph illustrates that when comparing volunteer rates across the Canadian provinces, Quebec exhibits the lowest rate of

\section{Volunteer Rate by Province}

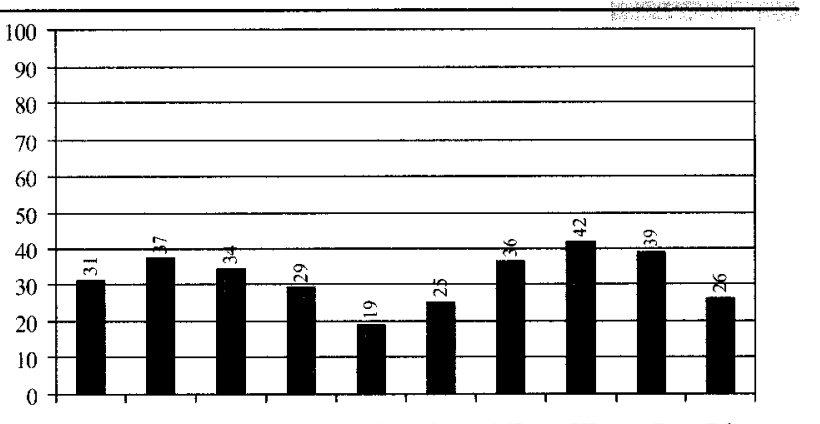

\begin{tabular}{lllllllllll}
$\mathrm{NL}$ & $\mathrm{PEI}$ & $\mathrm{NS}$ & $\mathrm{NB}$ & $\mathrm{QC}$ & $\mathrm{ON}$ & $\mathrm{MB}$ & $\mathrm{SK}$ & $\mathrm{AB}$ & $\mathrm{BC}$ \\
\hline volunteer rate &
\end{tabular}

Source: Canadian Centre for Plitanthropy and Statistics Canada. Caring Canadians, Involved Canadians, 2001 
volunteering whereas the highest rates are found in the Prairie Provinces and in Prince Edward Island whose rates are nearly or more than double that of Quebec. Quebec has the smallest voluntary core among all the provinces meaning the greatest concentration of volunteer activity among a few individuals. In other words, a small group is responsible for many hours and is volunteering in several organizations rather than volunteer participation that is widely dispersed throughout the population. Within the province at a regional level, Quebec Anglophones exhibit a higher rate of voluntarism than Quebec Francophones and many of Quebec's English-speaking regional communities, including Estrie, exceed the Canadian national average in their rate of volunteering. It was observed more than once in the course of interviewing English-speakers across the Estrie region that if you were to take away the volunteers from various organizations supporting small towns throughout the region there would simply be no community left (Pocock and Floch, 1999; Pocock, 2007b).

When we consider research underlining certain factors that tend to provide a warm climate for volunteer activity, along with the traits which have been demonstrated to characterize Canada's voluntary core, it is clear the extent to which there is a growing gap between optimal conditions and the experience 
of Quebec's aging minority communities. International comparisons tell us that extreme income inequality and voluntarism consistently show a negative relationship; that the high voluntarism of the countries of Europe and North America have the common feature of household units based on small, nuclear type, families; that there is a positive relationship between public expenditure and government provision of services, especially in health, and membership in voluntary associations; and finally, that the countries with the highest levels of voluntary activity are all predominately Protestant (Woolley, 2001). The optimal conditions for volunteer activity are increasingly less available to Estrie's English-speaking communities where the rise of income polarity, the emergence of 'crowded nests' and the increase in lone individual households, as well as recent cutbacks in the health sector jeopardizing access to services combine to challenge longstanding high levels of voluntary sector participation.

Consistent with the international pattern, the Canadian provinces with the highest levels of voluntarism, Saskatchewan and Newfoundland, have a majority of Protestants whereas the province with the lowest voluntarism, Quebec, is strongly Catholic (Woolley, 2001). Breakdown by religious affiliation of officiallanguage minorities across Canada at the regional level demonstrates that the Estrie region of interest to us, along with the Northern Quebec region, are the 
two which show the highest levels of Protestantism (Statistics Canada, 2003).

While neither minority nor majority language group are the churchgoing population today that may have been typical of their forefathers it is frequently noted, by interviewees and academics alike, that the groups clearly differ with respect to not only rates of volunteering but also in how their volunteer participation is organized and that this may be a remnant from the early establishment of their respective churches. The difference drawn is not necessarily at the level of ethical principle but refers to the fact that the conditions associated with the higher levels of Protestant voluntarism typically include "small, non-hierarchical and self-organizing" institutions as opposed to the "centralized and hierarchical" structure typified by the Catholic Church (Putnam, 1995; Knocks and Keefer, 1997; Vaillancourt et al., 1994). In the words of one interviewee,

In the small town where I grew up there were three Protestant churches and one Catholic church. The three Protestant churches relied very much on the volunteering of their congregation but the Catholic Church had the brothers and nuns. There was a residence for the 'sisters' in town and the 'brothers' just outside of town. The French-speaking children went to the Catholic school and it was taught by the brothers and sisters. Parents with children at the French school were not encouraged to participate in the school at all which was quite different from the English school that had a Home and School Association. The English school was considered a community center as much as anything and the parents did fund-raising to help the school. I 
grew up just assuming, as a mother, I would volunteer at my children's school but I enrolled my son in the French school. I was shocked to learn that parents, and not just English-speaking parents, were not really welcome. The French school, the only school now, isn't run by the brothers anymore but they still don't have a Home and School Association and parents still don't consider being involved the same way as you take-forgranted at the English schools. It was the same with the hospitals in Sherbrooke.

(Middle-generation, female, volunteer)

The traits of Canada's voluntary core as assessed by Reed and Selbee

(2000) are listed on the accompanying figure. Estrie's voluntary core, largely an

older group (65 years and up) with probably fewer children at home and often retired, exhibits many of the traits cited of Canada's voluntary core, however,

evidence suggests these

characteristics are

increasingly absent from the

younger English-speaking

generations who would be

candidates for volunteer

participation in the future.
Traits of Canada's Voluntary Core

1. Age ( 35 to 40 years and older)

2. Religious factors; religious youth group experience

3. Catholic (negative)

4. Other forms of helping and contributing

5. Education

6. White collar occupations, especially professional

7. Children $6-17$ yrs. at home

8. Household income (higher than average)

9. Expressed commitment to community

10. Positive assessment of Health and Life Satisfaction

11. Hours watching television (negative)

12. Non-metropolitan community

(Reed and Selbee, 2000)

'Missing middle' in this non-metropolitan region means precisely the reduced

presence of the local middle-aged, middle-income, professional group with an 
expressed commitment to community who tend to be the backbone of the voluntary labor force generally. In keeping with this assessment, the Survey of Community Vitality (2005) reveals that English-speaking respondents who are non-bilingual, born outside of Canada and/or claim neither French nor English as their home language exhibited lower levels of involvement in unpaid volunteer labour. When income groups are compared, those English-speakers whose annual household income is below $\$ 30 \mathrm{k}$ were the least likely to have performed volunteer work in the 12 month prior to the survey. This holds true for the Francophone respondents to the survey as well. This raises the question as to whether the appropriate focus of effective health policy for this population is support to its voluntary sector or working-class empowerment. ${ }^{15}$

More Anglophones than Francophones (Statistics Canada, 2003) reported youth activities/experiences related to volunteering in grade school or high school and having had one or both parents who were active volunteers. My dissertation interviews of highly voluntaristic individuals in English-speaking Estrie consistently revealed they had parents, and grandparents, who were active

15 This observation is explored further by authors such as Muntaner et al. who contend that social capital, and therefore the policy approach which builds on increasing its levels through community sector development, shows weaker associations with population health indicators than do economic inequality and working-class power. (Muntaner et al, 2002: 629-658) 
volunteers and passed-on important know-how and network connections in their chosen areas of specialization. Certain farming families, for example, had been volunteering on the board of directors for the local agricultural fair for generations. For several interviewees, sitting on the municipal council was in keeping with a father who had always been politically active. Joining the local Home and School Association was a natural extension of being a parent of school age children. Volunteering at the local hospital followed upon childhood models that, through their own voluntary sector involvement, even unconsciously, made that social environment familiar and accessible to their successors.

The 2005 Survey of Community Vitality tells us that Anglophone youth are active volunteers in their schools but demographic trends regarding their mobility patterns suggest they are increasingly taking that experience out of the province. For those youth continuing to reside in Estrie, the reduction of the voluntaristic 'middle' means they experience greater difficulty transferring their school experiences to the larger public arena given the informal apprenticeship and network connections the middle group historically offered have declined. The bridging capacity of Estrie's English-speaking voluntary core is weakened by the decrease in number that coincides with the decline of the small, local, 
institutions - churches, schools, and hospitals - strongly associated with their voluntary labour by virtue of scale, proximity and language access.

\section{Inter-generational Change in the Conditions of Volunteering}

Like the workforce in many areas, there is a bulging older group who comprise the English-speaking voluntary sector in Quebec and Estrie. The highest rate of volunteering among age groups in the Quebec Anglophone population is found in the $65+$ group and this group is also the most likely to be volunteering over 30 hours per month. The lowest rate of unpaid volunteer work among the English-speaking respondents to the Survey of Community Vitality was indicated by those in the 15-24 age group. In contrast, French-speaking respondents aged 45-64 years indicated the highest levels of volunteer activity within their language group.

It is eminently clear that the aging population of English-speaking Estrie implies a large proportion of seniors who are a tremendous asset when it comes to voluntarism. Their rich contribution is indicative of the greater capacity their generation has enjoyed in meeting the optimal conditions of voluntarism such as overall lower income inequality and greater availability of government services, particularly in health. When compared with the younger generation, the members of this civic-minded generation are more likely to exhibit the traits 
typical of the Canadian voluntary core such as a greater likelihood of high levels of education and (former) careers as white-collar professionals in this rural region.

The activities that claim volunteer time and energy have changed over the last few decades. The increase in sports-related volunteer participation (a pattern noted among the Francophone population as well) was observed in my dissertation interviews where interviewees suggested that it was the outcome of recent health promotion aimed particularly at children and youth, and an indicator of men volunteering more frequently than in the past. The Survey of Community Vitality tells us that $22.5 \%$ of Anglophone men residing in Estrie volunteer for sports organizations compared to $9.2 \%$ of women. Volunteering in municipal affairs, historically an area for English-speaking activity particularly among Anglophone men more than women, has declined. Generally Anglophone men and women show very similar rates of volunteering (considered here as distinct from unpaid care explored in the following chapter) although they differ in the types of organizations they choose to be involved in. Women are concentrated in schools, churches and community organizations while men volunteer largely through sports organizations followed by schools. 
According to interviews with the senior group, they joined a younger voluntary core in their early days of volunteering that had stronger institutional support and households with generally fewer combined hours of paid labour force participation then is presently available to their successors. Their perception is that the squeeze between household obligations and paid work outside the home has become tighter for the younger generation that tend to have children who are living at home longer, parents who are living longer as well as other family dependents. It was also frequently observed that the expectation regarding the degree of time and energy invested by parents in the organized activities of their children had escalated.

The change in social conditions from senior generation to the middle and younger age groups is often distilled into the issue of time. Not only as retired individuals, but also as younger parents and youth, this generation would claim greater access to the all important resource of time, and specifically, time for community. This was due, in part, to fewer dual earner families and more women who did not work full-time and therefore assumed primary responsibility for the household which included community service. Voluntary sector participation was not in addition to that of home and work but an integral feature, in many ways, of both professional and family life and therefore did not 
seem to demand time over and above these. The added value of volunteering for one's professional or family life has also become less clear which may contribute to the sense of time being lost. Is time spent doing community work time which benefits the worker or time without gain? Is time spent volunteering at the regional hospital, understood as a majority institution, time which benefits 'my community' and thereby my family and myself, or, is it time from which the majority community stands to gain at my cost? In other words, lost time? It is noted in Canadian research that most volunteers appear to share a concern for some common good (Statistics Canada, 2000: 4). Does the loss of a sense of common good affect one's experience of community time?

Contrary to Putnam's findings which point primarily to increasing levels of television viewing as the distinguishing factor between the older "long civic generation" and the lower rates of joining and volunteering among youth (Putnam, 2000), my findings underline structural barriers which challenge the volunteer sector participation of the youth of aging minority populations. The profile of the youth of the 'left-behind' population of Estrie suggests a group who are in a significantly different circumstance than that of their grandparents and even their parents. As the youth of an aging population, where the senior generation comprise a large portion of its voluntary core, there is less likelihood 
of their interests and concerns being expressed in the predominant types of organizations and targeted causes. For example, environmental concerns like global warming may be a cause to which hours of 'blogging' are devoted. Yet, this does not necessarily tend to lead to action through local organizations especially when they function largely in French. Interviews suggest that it is less obvious to these youth that voluntary sector participation, through the access to networks and practical knowledge it offers, serves as a means to social mobility or empowerment in Quebec to the degree that it did for their predecessors. This may be expressed in the fact that 40\% of Quebec's English-speaking youth (15-24 years) are volunteering some 15-30 hours per month and more, largely through their schools, but on an individual basis rather than as part of a group or organization (Pocock, 2006b: 32). This tends to raise questions regarding the potential of this activity for collective mobilization and solidarity. This distinguishes them from their seniors who are more likely to volunteer as a member of a group. Francophone youth volunteer largely as part of a group while those Francophones 65 years and over volunteer largely on an individual basis. Interestingly, the fact of this commonality between today's Englishspeaking youth and Francophone seniors reminds us that there are features of the predicament of English-speaking youth that may more closely resemble that 
of Quebec Francophones some 40 years ago than that of their Anglophone grandparents.

Intergenerational analysis suggests that while the policy climate enjoyed by the earlier years of the seniors of the Estrie Anglophone population was not organized around voluntary sector development, it was part of the prevailing socio-political conditions of a period that appears to have been more conducive to voluntarism than the recent decade. In other words, while the social economy era has explicitly promoted voluntary sector support and development to a greater degree than previous policy periods, it has been less successful in producing the sustainable volunteer participation that would ensure the vitality of this sector in the future. In many ways, the high levels of volunteering exhibited by the English-speaking voluntary core residing in the Estrie at present is being sustained by the community capacity generated under the more favorable conditions of an earlier epoch. Ironically, it was an epoch characterized by greater social unrest and overt language conflict than observed in recent years. To take this argument a little further, the rural communities of the language group in Quebec noted for its higher-than-average rates of volunteerism are witnessing the decline of these rates among the generation who would be expected to carry them into Quebec's future. 


\section{The Restructuring of Public Health Services: Government Provisions and Community-supported Care}

The interdependence between formal health and social service provisions and informal community-supported family care are easily misconstrued. It may be surmised that informal support networks will pick up wherever public institutions like hospitals and community health centres leave off or that cutbacks on the formal side can be compensated for on the informal side. In the area of health, evidence demonstrates that the presence of health and social services, a recognized health determinant, tends to be the basis for a stronger social support network. In fact, these services in the area of health are related to strong networks in other sectors as well. Woolley (2001) observes a positive relationship between public expenditure and government provision of services, especially in health and membership in voluntary associations; Winter (2000) points out that levels of social capital are higher where services are accessible, especially health services; and Luxton (2004) finds that there is a greater likelihood of informal care networks forming among friends and neighbors if strong core assistance is already in place.

The social economy era of the last ten years, and the shift of responsibility for care to community organizations and informal support networks, have 
coincided with restructuring and financial cutbacks in Quebec's formal health care system as in the rest of Canada. While potentially embraced as the deinstitutionalization promoted as being optimal for aging populations, I would contend that the impact has weakened the institutional base that has historically been a key feature of the volunteer networks so vital in the health care of English-speakers living in Estrie. While there may be evidence of increased home care services and local support for assisted living arrangements, health care restructuring has struck a decisive blow to the capacity of these language minority communities to use social economy means in achieving social economy ends.

According to the Survey of Community Vitality (2005), 84.6\% of Englishspeakers living in the Estrie region would turn to informal networks of family and friends and community organizations in the case of illness, $11.7 \%$ to public health and social services, and $3.7 \%$ would have nobody to turn to or would turn to other sources. They are less likely than their Francophone neighbors to turn to the public health system. Access to formal services is not simply a matter of geographic proximity although this is a factor worthy of consideration. Marginalized groups may also exhibit greater reliance on family and friends as the result of being excluded from majority institutions in various ways. These 
may include barriers to access due to policy that is indifferent to political, demographic or cultural differences, and importantly in this case, language barriers (Bowen, 2001).

In the Quebec model, institutions providing services in the English language may be "recognized", "designated" or "indicated". ${ }^{16}$ The greater number providing English services are 'designated institutions' which are institutions acknowledged by the Government of Quebec as required to make the institution's health and social services accessible in the English-language. This means that English-speaking Quebecers must seek health care from Francophone institutions in most areas, including parts of Montreal. This stands in contrast to the model for language minorities in other parts of Canada which is governed by the aspiration (not always attained) towards institutional completeness or 'community institutions', as the basis for encouraging the self-reliance of these collectivities. Montfort Hospital in Ontario, for example, is a 'community institution' with a clear mission to serve Ontario's French-speaking constituency

\footnotetext{
${ }^{16}$ A recognized institution is an institution that provides services to a majority of persons that speak a language other than French and that has obtained recognition from the Office québeçoise de la langue française, in accordance with section 29.1 of the Charter of the French Language. A designated institution is an institution that is acknowledged by the Government and required to make its health and social services accessible in the English language to the English-speaking population. An indicated institution is an institution that has had at least one department or service program identified in its regional access program to provide services in the English Language.
} 
in the Ottawa region. It is important to keep in mind that Quebec's Francophone institutions classified as 'designated' are operating in a province which lays claim to a provincial bureau, Office Quebecois de la langue Française, with the mandate to define and apply Quebec's policy pertaining to linguistic officialization and Francisation of public administration and where the union of the health workers has been particularly vigilant with respect to the right of their workers to work in French (further discussed in Chapter Four). With the latest round of restructuring, the Government of Quebec in October 2006 revised the list of designated institutions in the province such that they now number 42 with 29 located in Montreal (eight of which are long-term centres or residences).

In Estrie, the impact of the restructuring of the health system entailed the loss of the Sherbrooke Hospital, a recognized institution, during the 1990s. Many of my dissertation interviewees discussed this loss as an important turning point not only in access to services in English but in volunteer activity in the health sector as well. The hospital had been perceived as the 'English' hospital where services could be obtained in both the French and English languages. It had also historically been the center for an active English-speaking voluntary core. It was transformed into a geriatric institute and the only regional hospital then became the much larger Centre hospitalier universitaire de Sherbrooke (CHUS) situated 
outside the city. The volunteer activity on the part of English-speakers associated with the former Sherbrooke Hospital has not been reproduced at the CHUS nor at the Health and Social Services Centres (Centre local des services communautaires or CLSCs) more widely dispersed throughout the region.

In the words of one expert interviewee,

The CHUS rose to the challenge by trying to provide services in English, and tried to make English-speaking people feel that it was 'their' hospital in the way they had felt about the Sherbrooke Hospital. But there are constraints on such efforts because of the provincial language laws concerning signage and so on. It appears at some point someone from outside the Townships visited the CHUS and lodged a complaint with the Office de la langue française. The bilingual signs which had been in place had to be removed and replaced with unilingual French signs. As a result of all this many members of the English-speaking community were afraid to ask for services in English... they didn't feel they had the right.

Middle-generation Female, Director of Community-based Organization (CBO)

The Quebec model of designated health and social service institutions is problematic in many ways from the point of view of developing voluntary sector participation on the part of its language minority communities. Again, it is important to keep in mind that, for both Anglophones and Francophones, language is an important consideration in the decision to become a volunteer. The regionalization of hospital services means a change in scale, in this case the loss of geographic proximity for many living in the region, and there is ample 
research literature which underlines the fact that centralized, bureaucratic institutions are not conducive settings for the development of the communal and associational social capital which typically characterize non-profit and voluntaristic groups (Reimer, 2003; Mackian, 2002; Edmondson, 2003). The low rates of voluntarism typically associated with majority Catholic nations is attributed, at least in part, to the predominance of institutions that are "centralized and hierarchical" in structure as opposed to the more Protestant tendency towards "small, non-hierarchical and self-organizing" (Woolley, 2001). If these arrangements account for the low rates of voluntarism among Quebec's majority, how effective are they likely to be in sustaining the high rates historically noted among its language minority communities? Put differently, are Quebec's centralized, bureaucratic majority institutions in the health sector the appropriate vehicle for nurturing the development of minority community voluntary networks as the solution to their health challenges? 
The disconnect between the formal and the informal in this regard helps

to explain the generally high reliance of the communities on the informal support networks of family and friends. While $84.6 \%$ of Anglophones would turn to family and friends, only $5.6 \%$ would turn to community organizations. While the high levels of unpaid family care which characterize Estrie English-speakers will be explored in greater detail in Chapter Four, it should be noted that my dissertation survey reveals that these informal support networks are increasingly staffed by individuals who have very low levels of knowledge of public health

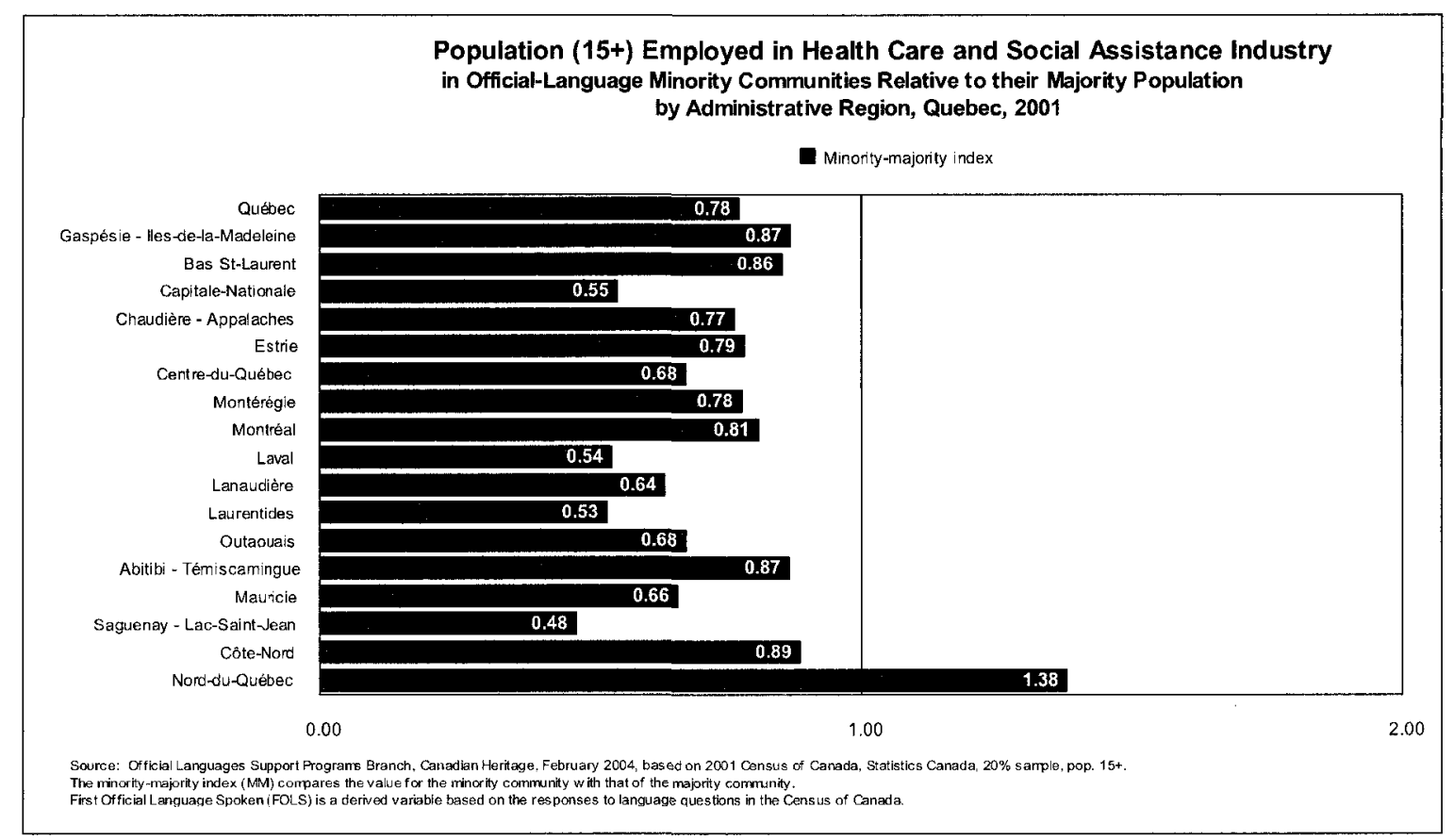

programming, or local health initiatives, aimed at their language group and few

are able to count a public health professional among their ranks. Estrie Anglophones, specifically, occupy $20 \%$ fewer positions in this sector than their 
population size would have predicted when compared to Francophones of the same territory. The added low tendency of Estrie Anglophones towards certification in the health professions means those who are employed in the health sector, a majority of whom are women, occupy the lower echelon of the industry. The impact of the disproportionate under-representation of Anglophones as health care workers in Quebec's formal health care system reverberates in the quality of the informal care delivery upon which they are highly reliant.

\section{Political Disengagement}

At a provincial level, Quebec's voluntary core is noted for its "aversion to civic engagement" as indicated in low rates of political participation such as voting behavior when compared with other provinces (Reed and Selbee, 2000: 10).

English-speakers residing in Estrie region exhibit notably low levels of political participation and related low levels of confidence in the structures of governance at municipal and provincial levels, even lower than their Francophone counterparts. This means Quebec's rural English-speaking communities, with the highest rate of volunteering and unpaid work on the part of their voluntary core, are likely to be those with the weakest rate of political 
participation. In the case of English-speaking volunteers, this means high levels of unpaid community and household labor with little influence, as a constituency, on the design, management and distribution of public provisions. Anglophones in the Estrie region are much less likely than their Francophone neighbours to be working in the government services industry (see Chapter Four). In the General Social Survey (2003), Quebec Anglophones showed the lowest sense of belonging to their province and their perception of the representative role of Government is exceptionally low when compared with other Official-language Minority Communities across Canada. In Estrie, the rate of volunteer activity by Anglophones in the area of municipal affairs was the lowest among six suggested possibilities.

According to my dissertation questionnaire, $77.4 \%$ of the English-speaking Estrie respondents agree that the future of the English-speaking community is threatened and this outlook is strongly shared by ages 25 through to 64 years. A notable feature of the tendency to agree that the future of the English-speaking community in their region is threatened is the fact that it is more strongly associated with the growing number of lower income (less than $\$ 50 \mathrm{k}$ ) households than with middle or upper income ( $\$ 50 \mathrm{k}$ and over). In the course of interviews this lack of confidence in the future of their community in Quebec 
emerged as a crucial factor in the weakened attachment among Englishspeaking youth and newcomers to the local collective and accompanying decline in local voluntarism. For many of the highly voluntaristic seniors interviewed their community service was, and to some extent still is, embedded in a narrative that defined their relation to the Estrie community, and the particular geographical place it had inhabited over several generations, as one of stewardship. In continuity with their ancestors they, in their turn, sought to make a contribution to the historical community they inherited with an eye to the future of the next generation that would someday take their place. For the middle generation, there is a sense of ambivalence about this same narrative and reluctance to nurture the same attachment to place among their successors as their prospects for the future in the region are increasingly perceived as bleak. Young and old alike agreed that the attachment to place, often to actual property such as the family farm inherited from their forefathers, was a necessary condition underlying the high levels of volunteerism in the region. When offered the hypothetical scenario of relocation to another province, for example, doubt was expressed regarding their likelihood of volunteering in the same way or to the same extent. 
At the risk of stating the obvious, it seems evident that the weak sense of belonging exhibited by Quebec's minority language communities and their tendency to be excluded from the largely Francophone public sector of the province in which they are citizens, impacts the sense of community ownership cited as a key objective of the social economy approach in health as well as the condition of trust which would lay the ground for durable partnerships between minority language communities and Quebec's public institutions. For the moment there is a sense of language peace but one that comes with a continuous awareness that the same machinery which has been used to successfully implement the Francisation of Quebec's workplace and public arena is everpresent and at the disposal of political leaders who, despite the altered position of the majority in the province and the concomitant change in its Englishspeaking communities, continue to advocate vigilance in barricading themselves against perceived threats, particularly internal dangers, to their social and linguistic cohesion.

\section{Conclusion: A Neglected Absence}

The case of Quebec's Estrie region offers us much insight with respect to the relevance of third-sector health strategies for aging 'missing middle' communities in the context of a globalizing Canadian nation. Under the auspices 
of social economy policy in Quebec in the last ten to fifteen years, the gap between English-speaking and French-speaking populations of the Estrie region with respect to their positions vis-à-vis key health conditions has widened. Using a multi-method strategy to investigate the situation of English-speaking workers and users of the voluntary sector, this chapter demonstrates that a problematic 'lack of fit' between the social economy approach, language policy and the English-speaking communities of Estrie underlies ongoing health inequalities. The findings presented in this chapter suggest that voluntary sector development in Quebec has not managed to prove itself as a sustainable approach in solving the health problems of Quebec citizens, particularly those whose community is characterized by a growing cleavage between rich and poor. 


\section{Chapter 3 - The Hidden Price of Care in Quebec's Era of 'Community'}

\section{Introduction}

In this chapter, I examine changes in the distribution and nature of unpaid care during Quebec's social economy era as these vary with respect to language, gender and generation. Put simply, when we send caregiving to the 'community', where does it go? For the purpose of this chapter, I draw primarily on findings from in-depth interviews held with members of English-speaking households located in the Estrie region (see map on page 18). I have included excerpts from all recorded family interviews. None of the individuals included here in their capacity as caregivers, volunteers and a few as employees of community-based organizations were interviewed as participants in my expert interviews. I also introduce information from my Survey of Community Vitality (2005) distributed to 250 respondents in the Estrie region (see Appendix 1).

\section{The Problem}

As noted earlier, Quebec's social economy approach in recent years is distinguished by its focus upon economic participation as the central means by which social inclusion is achieved and in its explicit recognition that the state partnerships it promotes need to be designed to resist the twin tendencies 
toward the 'commodification' and 'familization' of health care. This policy approach is generally considered a step forward as a health initiative in that it resists reducing access to quality care to those who can afford private services and it appears to acknowledge the powerful impact the conditions of women can have on the overall health of a population. It recognizes, in principle, the double bind that can arise from urging women to work even as the demand for family care, in which they are highly implicated, is increased. ${ }^{17}$ It is also frequently noted that women have been prominent in Quebec's policy process. At the Quebec Economic and Employment Summit of 1996, representatives of the women's movement were among the stakeholders who participated in formulating the five element definition of the social economy (Chantier de l'économie social, 1996 and 2001) along with business, government, labour, and community-based organizations (Vaillancourt, 2004: 312-315). Language, however, remains a mute issue in policy formation along with intergenerational change. 
Financial cutbacks coupled with the general restructuring that has taken place in the health sector during Quebec's social economy era has resulted in continued high levels of unpaid family care for all Quebec citizens. However, the downloading of responsibilities previously assumed by the state to communitybased institutions and families has, in recent years, resulted in the uneven distribution of high levels of unpaid care, particularly care to seniors, among Quebec's majority and minority language communities. In this chapter, using evidence from the case of Quebec's Estrie region, I claim that the third-sector health strategies which have characterized provincial policy in recent decades acknowledge gender but fail to take into account the manner in which the circumstances of women vary in accordance with language and generation. As a result of neglecting this "intersectionality" (Hankivsky, 2007) provincial policy has disproportionately disadvantaged the women of middle and low-income households of aging minority language communities. The demands of the unpaid family caregiving that these communities have long relied upon to meet their care needs, historically relying less on public provisions than the majority population (Saber-Freedman, 2001; Pocock, 2006a), have increased while their capacity to meet these demands has been reduced. The decline of accessible and relevant public services, the increase of low-income households who cannot 
afford to purchase private-care services, and the reduction of the financial and human resources that ensure adequate community-based support, place these unpaid family caregivers in a vulnerable position. Furthermore, this occurs in the context of the findings from the extensive Quebec Social and Health Survey (1998), much referenced during the latest period of restructuring, which tell us that when women are compared to men they are more likely to have health problems, are substantially more likely to suffer from anxiety and psychological stress, are more frequently hospitalized and consume higher levels of medication (Pocock, 2008).

While promoted as a measure to reduce the public debt the social economy approach in the health sector is not without its cost. In the case of Estrie, the hidden price of care in the era of 'community' is paid by those who are the most likely to have health problems, are the most reliant on community organizations and family for their care, and who comprise the greater portion of the unpaid workforce responsible for the provision of this same health care. In many ways, the price of care in the era of 'community' is community itself. 


\section{Aging Communities and Child-Centered Family Policy}

We see that there are English-speaking seniors who are vulnerable, many of them women. And the ones doing the caregiving, also mainly women, lack support. The Englishspeaking community is known to rely on family and friends. They haven't typically hooked into services the way they could have been. They don't make requests to the CLSC for services because they're not aware or afraid to ask or don't know whether they will have an English-speaking helper. We also find there tends to be a difference in family size when French-speaking and English-speaking families are compared and the children of the English-speaking families are less likely to be living in the area. The French-speaking families are more likely to be sharing caregiving among several households because there are more children closer by. We offer help with transportation and mealson -wheels in our area but there are many English families with nowhere to turn.

Middle-generation Francophone female, Director, Community-based Organization (CBO)

The experiences of both the minority and majority language communities of Estrie are consistent with the now vast literature which underlines the reality that women tend to shoulder a greater portion of informal caregiving responsibilities (both child-care and elder-care) when compared to men (Silver, 2000; Ward and Spitze, 1998; Marks, 1998). The situation of women as primary caregivers and purveyors of health knowledge within the traditional family remains a key predictor of the quality of care, and consequently level of health, 
which is likely to typify the communities in which they reside. ${ }^{18}$ For both language communities, the middle generation plays a pivotal role in family caregiving. Beyond this commonality, Estrie's language communities differ in terms of their rate of unpaid care, the type of care needs they are experiencing and the attendant expertise and knowledge required in responding to them, as well as in the relevant support and resources available to caregivers as determinants of the quality of their labour.

Among supporters of social economy, Quebec's program for universal daycare is heralded as a paradigmatic example of a state-supported intervention given it empowers both workers and users by giving them a voice in the operation of daycare service centres, empowers women by increasing their opportunity to participate in the labor market and generally upgrades the quality of care by reducing the provision of unregulated care provided in the households of friends and neighbors (Vaillancourt, 2004; Jensen, 1998; Jensen et al, 2003).The focus of Quebec's family policy on childhood development and the employability of young parents may be coherent with the demographic profile of

\footnotetext{
${ }^{18}$ In acknowledgment of a link between the status of women and health, gender is a health determinant recognized by Health Canada and other health agencies around the world.
} 
the majority group; however, it fails to capture the elder care needs of its minority language population as they arise from its advanced aging process. As mentioned in an earlier chapter, Estrie's English-speaking population have 80\% more individuals per capita in their senior years and just over half the proportion of individuals in their middle years than found in the Francophone population of the region. The proportion of senior women (65+) in the English-speaking population is nearly twice that exhibited by the French-speaking community. In relative terms, there are five times more widowed women than men in the English-speaking regional population (Pocock, 2003) many of whom find themselves without family in geographical proximity. This is noteworthy considering the substantial poverty of the unattached elderly, particularly women, in western democracies is alleviated by supports from co-resident family (Rendall and Bahchieva, 1998).

The reduced middle-aged and middle-income group which is a marked trait of the English-speaking population residing in rural Estrie has a significant impact upon its caregiving capacity. My doctoral interviews support the literature that contends that the middle-generation family caregivers have historically played a pivotal role in providing family care (Ward-Griffin and Marshall, 2003) as well as care that extends beyond the household. It is a 
generation comprised of middle-aged individuals who are primary caretakers of the elderly, of children, volunteers in community-based organizations and leaders in local civic affairs. When we single out the caregiver-to-senior ratio comparing the proportion of family caregivers (35-54) to seniors (over 65 years of age) we learn the majority Francophone population in Estrie has roughly twice as many caregivers per seniors as the Anglophone group. This low caregiver-tosenior ratio among English-speakers is problematic in a context where parents may have seen child-care services evolve, but little formal support established for the middle-aged men and women, notably English-speaking, who are caring for

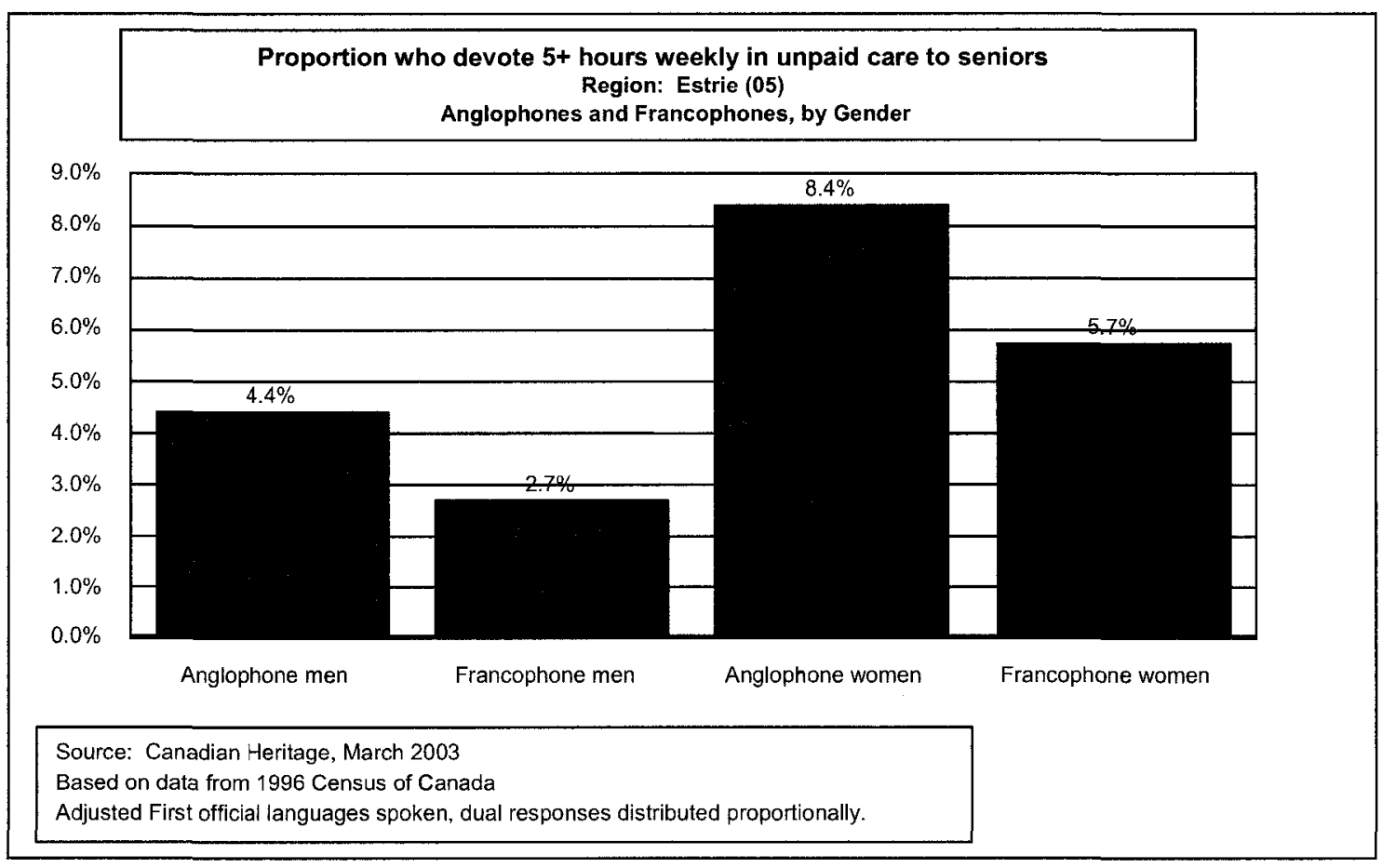


seniors and who, unlike former generations, are both expected to engage in paid employment. When it comes to unpaid assistance to seniors (the Statistics Canada definition includes more than 5 hours weekly of unpaid assistance to seniors in one's own household, family members outside the household, as well as friends and neighbors and excludes unpaid care through an organization) Anglophone women are carrying the heavier load by a significant margin. In Estrie, they are 50\% more likely than Francophone women to be doing more than 5 hours weekly of unpaid care to seniors, $91 \%$ or almost twice as likely as Anglophone men, and three times more likely than Francophone men to be so occupied. English-speaking men are $80 \%$ more likely than Francophone men to perform $5+$ hours per week of unpaid care to seniors (Pocock, 2004). The possible 20 hours or more monthly of unpaid elder care by women measured here is put into perspective when we consider it alongside other studies of caregiving. For example, Williams (2004), in her study of the "sandwich generation" - those middle-aged caregivers who are providing care to elders and still have children at home - draws a distinction between low-intensity care ( 8 hours or less monthly on elder care) and high-intensity care (more than 8 hours monthly on elder care). Drawing on data from the Canada-wide General Social Survey (Statistics Canada, 2002) she finds the high-intensity group is much more likely 
to experience health effects (such as increased stress), work-related problems (such as reduction of work hours) and curtailment of their social activities compared to the low-intensity group.

The current focus on 'community care' is defended as less costly in that it reduces hospitalization and, like the program for universal daycare, as beneficial to the public at large by offering clients increased control over their state of health and less reliance on experts. It follows upon a trend towards "deinstitutionalization" originally aimed at improving health care for psychiatric and elderly patients by providing them with the opportunity to remain in their familiar environment and, particularly for the latter, to extend their decisionmaking capacity over their affairs (Desjarlais \& Moisan, 1999). The logic of the change from 'centralized' to 'community-driven' solutions to care presumes a system that is capable of being more responsive to the cultural and linguistic differences which shape the health care needs of local populations as an outcome. The problem in the case of health is that the people we are asking to be autonomous and take charge of their health care are the ones in need of help. While the caregivers of children are automatically considered as clients in the design of childcare services, the caregivers of our elders have figured less prominently in the restructuring of health care services. The English-speaking 
community is noted for its low reliance on services and there are disproportionately low numbers of English-speaking health professionals compared to Francophones working at the hospitals and CLSCs (community health centres) who are responsible for government-supported, home-based services (GMCDI, 2007). While Anglophone women are almost four times more likely than Anglophone men to be employed in the area of health care and social assistance they are highly unlikely to have postsecondary education in the health professions (Pocock, 2004: 71). In the case of the seniors of the English-speaking population - and for many patients who have been healthy most of their lives they are not regular users of, nor workers within, the system they must negotiate in order to have their needs met. And this must be done in a language they may not feel competent using and while under the stress of suffering physical and mental symptoms they may not comprehend.

While a greater proportion of seniors does not necessarily mean a 'sicker' population it does imply an increased tendency towards health needs that are more characteristic of individuals in their later years. Chronic diseases such as arthritis or rheumatism, diabetes and heart disease are more prevalent among older individuals as well as activity limitations which, we learn from the Quebec Health and Social Survey (1998), are due primarily to mental health and 
osteoarticular (bone/joint) problems. The fact that women outnumber men in the senior group means that their health profile may influence the profile of health needs which characterize the senior group. English-speaking respondents to the survey reported a higher rate of activity limitations than Francophones and English-speaking women exhibited a higher rate than Anglophone men. Relatively speaking, Anglophone women, who also form the majority of caregivers, were substantially more likely to report anxiety and psychological distress than men and Anglophones as a group were 58\% more likely to report such mental health problems than Francophones (Pocock, 2008). While the aging Anglophone population would appear to be an ideal candidate for home-based care the persistent problem, even at this late date, of lack of communication and 'partnership' between institutions and community/family care providers undermines its success (Moisan, 1999). These are strongly supported by my interviews in Estrie where the missing bridge between hospital services and home care was a dominant preoccupation.

\section{The Elusive Balance}

If you can afford to pay for services then perhaps a balance can be found. Otherwise, it's just not possible.

(Middle-generation female, family caregiver) 
In many ways the aging Estrie English-speaking population resembles the much discussed sandwich generation (Anderson 1999; Immen 2004; Kleiman 2002; Rosenthal and Stone, 1999) defined as individuals, typically 45 to 64 years of age, looking after children (15 years, sometimes 25 , and under) while providing care to a senior. Delayed marriage, postponement of children and decreased fertility rates coupled with increased life expectancy means a greater number of older family members requiring care by working couples while children are still part of the household.

The advanced rate of aging of the English-speaking communities in the case of Estrie when compared to the overall Canadian average offers an occasion to consider the projection that caregivers will increasingly find themselves to be members of the sandwich generation in the near future. While the overall number of Canadians in the sandwich generation is still relatively small, evidence supports the claim that these will grow with the aging of the baby boomers. If this is the case then we could also expect a growing number of midlife women, given these women are more involved in elder care and more likely to perform the most intensive tasks (Williams, 2004), who struggle with the contradictions of social policy that renders the balance between work and family, in their view, as impossible to achieve. Does the growth of the sandwich 
generation explain the rate of high-intensity caregiving among Quebec's

minority language communities?

Evidence from my research suggests the situation of mid-life caregivers denoted in 'sandwich generation' does exist in Estrie. I listened to accounts of working middle-generation women who are implicated in managing two, sometimes three, households: the one shared with their husband and their children and another where their parents or parents-in-law reside. However, the selective out-migration of the English-speaking professional middle-aged group indicates that this situation may not be as widespread as it is within populations, like the Francophone majority, who benefit from a different mobility pattern. It is also more of an urban than a rural phenomenon therefore more typical of Montreal, for example, than the outlying regions.

The 'sandwich generation' exists in both the English and French communities but for the English they are largely living away from the region. Many left because of the political upheavals in the province a few years ago so they're not here to provide care or to volunteer. Their help comes from a distance and often it is financial assistance. They come to us for help finding a private nurse and we keep a data bank of graduates from Englishlanguage caregiving programs. We also receive a tremendous amount of donations - we don't need fund-raising events.

Middle-generation Francophone female, Director, $C B O$ 
The delayed marriage and postponement of children is often a characteristic of men and women who have pursued years of education or time to establish a career. For many, to say that Francophone mid-life caregivers in the region are both more likely to be members of the sandwich generation and doing less unpaid care than Anglophones sounds like a contradiction in terms. The problem is that the literature does not always draw the distinction between 'professional couples' and 'dual-earners' although the difference in income and working conditions of caregivers when the two households are compared may be substantial. As underlined in my interviews with the 'left-behind' minority population of Estrie, the capacity to pay for private services is more characteristic of sandwiched professionals than dual-earners and this has a great effect on how caregiving demands are managed. Being able to hire a nanny as opposed to keeping a place at the local daycare, or hiring a private nurse to spend nights with a convalescing parent as opposed to facing sleep deprivation on top of child care and work, can make a significant difference in time invested in unpaid care and related levels of stress for caregivers. A more extensive social support network by virtue of the co-presence of the households of siblings in the region, relevant community-based services and a lower caregiver-to-senior ratio also figure in the mix. 
Table 2 - Labour Force Activity

\begin{tabular}{|l|l|l|l|}
\hline \multicolumn{5}{|c|}{$\begin{array}{c}\text { Minority-Majority Index for Labour Force Activity } \\
\text { Anglophones Compared to Francophones } \\
\text { in the Estrie Region of Quebec, } \\
\text { Population 15+, 2001-2006 }\end{array}$} \\
\hline \\
\hline \\
\hline
\end{tabular}

The assumption that the numbers of sandwiched professionals will grow among English-speakers in Estrie is also cast in doubt in light of the intergenerational trend toward an increase in lower-income households, growing levels of unemployment and the ongoing departure of young professionals for destinations outside the region and the province. The above table uses a minority-majority index ( $\mathrm{mmi}$ ) to demonstrate socio-economic characteristics comparing 2001 and 2006 across age cohorts. Comparing the minority Anglophone population relative to the majority Francophone, a mmi greater than 1.00 indicates the characteristic more commonly found in the minority population. An mmi less than 1.00 indicates it is less present in the minority population. We learn, for example, that for the total population $15+$ the relative gap between the majority and the minority in the rate of unemployment grew 
substantially between 2001 and 2006 and the gap is the widest among those aged 15-44 years. English-speakers of the 25-64 age group are more likely to be out of the labour force than French-speakers and their numbers grew between 2001 and 2006.

While aging baby boomers form a large cohort we need to be mindful of the fact that neither they nor their caregivers are a homogeneous group nor are they evenly distributed among geographic and socio-economic constituencies. According to the 2001 census, the 45-64 age group of English-speakers residing in the Estrie region are much more likely (around 40\% more likely) than their Francophone counterparts to be living below the low-income cut-off. The situation is not much better for the $25-44$ age groups as they are about $30 \%$ more likely. This stands in contrast to the $65-84$ years age Anglophone group where the gap between themselves and the same age group in the Francophone population is basically nonexistent (Pocock, 2008).

Based on evidence from my doctoral research I would argue that there will continue to be a middle generation among Estrie Anglophone engaging in high levels of unpaid family caregiving to both younger and older age cohorts. This will be much higher levels, as mentioned, than the standard measure for the high-intensity caregiving typical of the most vulnerable women of the much- 
discussed sandwich generation. Often this group of caregivers is not captured by the census data used to study the sandwich generation in Canada because they do not satisfy the criteria of children still living at home. As I learned from my interviews, however, the households of this group are still very interdependent both financially and in terms of day-to-day care and the interdependence can continue as such for an extended period. In fact, we might question whether a separate address is in fact an adequate indicator of a separate household.

My son, 23, lives with me and is working. My daughter (18) and her boyfriend were living with me until their baby arrived. Now, they have their own apartment but they don't have a car so I drive them when they need to go shopping or to doctor's appointments. My daughter still comes over to my place during the day while I'm at work and her boyfriend is working. I often cook for all of us here or I take meals over to their place and help with the baby. My parents are still managing on their own right now but it is getting harder for them. They have more health problems and they don't like to drive anymore.

(Middle-generation female, family caregiver)

The successors of the aging, highly voluntaristic, senior cohort of Englishspeaking Estrie are more likely to be dual-earner couples or members of lowincome households. They are more likely to spend more years in a social context where the gap between rich and poor is wider than that experienced by their elders. The weakened social support network that accompanies this economic polarization means that for them the 'balanced life' is increasingly the 
prerogative of those who can afford the cost of private services. For a significant portion of English-speaking Estrie couples this prerogative is attained through their participation in an economy exterior to the region and the province and reduced co-presence with the family members they financially support. For the portion that chooses to stay in the region and offer family support the world of work is increasingly a challenge to access. In 2001, English-speaking Estrie women had the highest rate of unemployment (14.1\%) combined with the lowest average income $(\$ 11,124)$ among male and female Anglophone and Francophone groups. Estrie Anglophones are 39\% more likely than their Anglophone peers across the province to have no high school leaving or additional training and Estrie Anglophone women are $23 \%$ more likely not to complete a post-secondary degree compared to men (Pocock, 2004: 67). Of course, unemployment and low income levels are associated with a low likelihood of health care costs covered by a private insurance plan.

The perspective of the parents of the baby-boomers I interviewed is that the push and pull of caregivers, often women, between the labour market and the household is longstanding and dependent in many ways on the level of statesupported provisions in the heath sector. They frequently likened the situation of their seniors, in a period when health services were not as developed, to the 
situation of families today. They also provided personal accounts that tended to support the literature arguing that it is largely women in families who compromise their own opportunities to support elderly relatives (Aronson, 1991;

Keating et al., 1999; Myles, 1991) although grandsons, sons and husbands were never without acknowledgement.

My two aunts had gone to New Hampshire as young women to learn dressmaking. When their mother was confined to a wheel chair because of polio they returned to the farm to help out. Their father was not well either. Their brother stayed in New Hampshire and helped to support the family with his earnings for many years. Neither of my aunts ever married. One died at a fairly young age and the other went on to be a caregiver in the home of elderly women after her mother passed away.

(Senior generation female, family caregiver)

I had moved to Ottawa and was in my first year at Carleton University when I decided to come back and look after my grandmother. I wasn't really happy at Carleton and my family was finding it harder to look after my grandmother.

(Youth, female, family caregiver)

My mother took in both my grandmothers and they both eventually passed away living at our farm. My Dad died first and we were seven kids ranging from one year to about 12 at the time. My Mom hired a man to look after the day-to-day operations of the farm and went out to work. My oldest sister, who was about four years older than me had to quit school to stay at home and look after the house while my mother went to work. My sister always did domestic work once she left home.

(Senior generation female, widowed family caregiver) My cousin was fairly young, a teenager, when he moved in with his bedridden grandmother. He and his siblings had lost their 
mother so they had been farmed out to different families. When he moved into his grandmother's home he made all the meals and did everything that needed to be done until he went off to serve in World War II.

(Senior generation female, widowed family caregiver)

\section{Community Vitality and Transformations in Health Care}

Many people become involved in a number of volunteering activities but they still want to be able to take care of their family members and they become stretched in too many directions.

(Middle-generation female, volunteer)

The English family members who left are not coming back so they aren't here to volunteer. We're discovering that as individuals retire or partially-retire they are not becoming as involved in organizations on a volunteer basis as they once would have. The average age of our volunteers right now is 70 so we have a situation where many of our volunteers could actually benefit from the services we offer. We're looking at the picture in the Estrie region and trying to figure out how we can survive. It's scary. We certainly can't do it without volunteers.

(Middle-generation Francophone female, Director of a $\mathrm{CBO}$ )

There has been much recent discussion, both academic and popular, concerning the collapse of civic participation and associational relations in America and elsewhere (Putnam, 1996 and 2000; Fukuyama, 1999). Much work has also been devoted to demonstrating the importance of social capital to the health and well-being of individuals and communities (Kawachi et al., 1997; Berkman, 2000; Shiell \& Hawe, 1996). This, in turn, has provided the rationale for the promotion of community development approach by governments and health organizations around the world. My in-depth case study of an aging minority 
community situated in the rural regions of a globalizing democracy does not necessarily disprove the broad generalizations offered by such discussion. It does suggest, however, that a close look at the factors that are significant in community vitality as they inter-relate in a particular context raise questions regarding the policy approach fueled by social capital research.

Both the literature and my interviewees agree that community sector success depends on a volunteer workforce. Rates of volunteerism are widely accepted among researchers as an indicator of social engagement and civic participation. Putnam's findings demonstrate that increased female participation in the paid labour force and the emergence of the dual career household has not contributed significantly to the decline of voluntarism (Putnam, 1996: 6). Women in the labour force are members of more voluntary associations than are homemakers. Amongst workers, those who work longer hours are more civically engaged (Putnam, 1996: 7). Higher levels of education, an absence of economic hardship, successful marriage and the presence of children are associated with high levels of social capital. It follows that lower levels of education and economic hardship are associated with lower levels of social capital and unattached individuals tend to be less civically engaged and trusting. Besides the rate of volunteerism, the type of networks formed differ according to these 
conditions with the former characterized by more 'bridging' opportunities and the latter with the type of connections referred to as 'bonding'. ${ }^{19}$ The presence of elders is not mentioned. Income polarization (Putnam, 1993: 224, Kawachi et al., 1997: 1495) is discussed as contributing to community decline but is treated as yet another discrete factor alongside the former rather than their descriptor. The interdependence of the two realities, distinguished by high and low levels of civic engagement, goes unexplored as do the problems which arise when they are governed by the same social policy particularly in the area of health.

Like these studies, the case of Estrie, noted for its large portion of seniors, demonstrates that the rise of lower levels of education and higher levels of unemployment which characterize the younger generations of the Englishspeaking population are linked with a decrease in the levels of civic engagement. The out-migration of young educated professionals, such as the much storied and photographed members of the families I interviewed in Estrie, fit among those who are both working and involved as volunteers in the schools and sports organizations of their children in their Montreal or Toronto neighborhoods - 
neighborhoods where they may very well live among other middle-class professionals whose elderly parents are also 'back home'. The French-speaking majority population of Estrie fulfills the conditions associated with high levels of engagement and bridging relations to a greater extent than its linguistic minority counterpart although stable common-law arrangements are more prevalent among the majority group than marriage. It is important to note the degree to which volunteers for community organizations tend to work along linguistic lines. The often retired senior group involved in community-based support to English-speaking households are themselves primarily English-speaking and often bringing services to those they would consider to be members of their informal network of neighbors and friends.

The revitalization of community where decline is evident may be a worthwhile end and a contribution to the overall goal of improved health but is this effectively achieved through community means? If both groups are required to pursue the strategy of government supported community initiatives, largely partnerships with public health agencies, to improve the health status of their members, is the group which displays the conditions associated with 'bridging' support networks or 'bonding' connections the most likely to succeed? (Under the auspices of the community development approach to what extent does the 
voluntarism of the latter continue to qualify as voluntary?) While the volunteerism of groups with high levels of social engagement may under certain conditions assist in building community among those living under less optimal conditions, does this occur where the haves and have-nots are geographically and administratively, or linguistically, divided? Also, health sector restructuring in Estrie and Quebec as a whole has entailed the loss of jobs in a field where women figure prominently and the subsequent weakening of their earning power as a group. According to research findings on women and work, it is a contradiction in terms to implement a health strategy organized to build community vitality while also reducing the opportunities of women in the paid labour force as has taken place in the health and social assistance industry in Quebec.

From the point of view of the small rural communities dispersed across the Estrie region it is misleading to talk of 'sectors' as discrete entities each with their own resources to supply citizens with varied support in achieving quality health care. The idea of alleviating the increased demands of family caregiving, such as we see with the example of unpaid care to seniors in the case of aging Estrie, through community sector development casts the illusion of shifting responsibilities from one area of the workforce to another. In reality, the social 
economy approach in the health sector simply places pressure for more on the same small, 'stretched-thin,' core of workers. Whether the paid workers and volunteers of community-based organizations, or of formal health and social service agencies, or unpaid family caregivers, the bulk of policy shaped demand tends to fall squarely on the women of these communities. The community development health initiatives intended to support unpaid family caregivers in meeting their demands in fact depend on these very same family laborers as both their volunteer workforce and paid workers. If reducing government supported health and social services in a population with a low caregiver-to-senior ratio amounts to an increased demand on family caregivers, it also means reducing the unpaid workforce of the community-based organizations intended to support these families. Frontline community volunteers acknowledge this problem in their frequent remarks upon the danger of the isolation and withdrawal from the outside world that overwhelmed family caregivers are susceptible to experiencing. When faced with trying to balance family, work and social participation, which includes volunteering for a range of community organizations, community is the demand that is likely to go unmet. Significantly, historically speaking and even more the case in the domain of health and in this aging context, we are speaking of community by women for women. 
Community development has meant cutting professional positions in public health and social service institutions and promoting work that, if measured by rate of pay and benefits, amounts to reduced opportunity for women. According to a survey carried out by the Centre de formation populaire et Relais-femmes (Comité sectoriel de main-d'ouevre, 2006), $80 \%$ of the jobs in community organizations in Quebec are held by women and that $80 \%$ of employees in the community sector earn less than $\$ 20$ an hour despite higher levels of education than those in other employment sectors. The average hourly wage in the 1, 354 community organizations surveyed was slightly more than $\$ 15$ an hour. One quarter earned less than $\$ 10$ an hour and more than one-third earned between $\$ 10$ and $\$ 15$ per hour. In the 35 years and over group $37.9 \%$ of employees in the community sector have a post-secondary diploma compared to $14.3 \%$ of Quebec's labour force overall. The study also revealed that there is a relatively high rate of turnover in community organizations. For example, 57.2\% of the workers in organizations in the health and social service sector had less than three years of seniority (Bourdon and Deschenaux, 2002: 4). “Data available on SEEs (Social Economy Enterprises) in the home care industry shows that their workforce is primarily made up of women earning between minimum wage and $\$ 8.30 /$ hour and, in 4 cases out of 10, employed on a part-time basis" (Moisan, 
1999: 5). There appears to be a pattern of educated community workers, largely women, using their experience in the community sector as a 'stepping stone' to employment in the public and para-public sectors. While comparisons of English and French speakers are not available for the community sector alone, the low rate of Anglophones working in Quebec's public sector would suggest this is a stepping stone used by very a small portion of the minority population. ${ }^{20}$

The illusion of community sector development as filling the gap left by the reduction of formal health services not only conceals the extent to which unpaid family caregivers of minority communities are without options but also the extent to which the era of 'community' has normalized the paid services of a private nurse (or near equivalent) as an inevitable feature of quality home-based care for frail elders. When compared with Francophone majority, the Englishspeaking Estrie population has fewer individuals per capita who are certified health and social service professionals which means that they are more prone to rely on less qualified individuals in order to have care in their language. Nor can

${ }^{20}$ According to the 2001 Census of Canada, 2.2\% of Anglophones in the labour force living in Estrie were employed in the government services industry. Nearly double $(4 \%)$ that proportion of Estrie Francophones were so employed. 
these households generally afford the rate of pay a trained health professional would typically demand in public health settings.

I am a trained nurse and worked in a home for the elderly here in the region for a short time. When my daughter was born I wanted flexible hours so I began taking work in the homes of elderly women. Compared to working in a hospital or CLSC the pay is generally less, there are no benefits or security and you're never sure where your next job will be. On the positive side, you can have some control over your workload and I don't have to worry about language problems.

(Youth, female, paid caregiver)

We have many situations where our bank of volunteers have to step in because someone is ready to be discharged from the hospital, but needs care, for example to dress themselves but does not have the financial means to hire someone to do this. There are agencies that will do these things, but they charge $\$ 25$ an hour, and will not go to someone's home for less than that so people can end up spending $\$ 50$ or $\$ 75$ a day just to have someone help them for two or three hours. If we have a volunteer in that individual's locale, he or she might be willing to spend an extra hour or so helping out and only charge $\$ 10$ or $\$ 15$.

(Middle-generation Francophone female, Director, $C B O$ )

From the point of view of users of community-based organizations, my

research indicates that where English-speaking regional community-based organizations and third-sector initiatives are present they do alleviate the care demands placed upon some minority language families, and in many communities these are a crucial mainstay of family support. For example, for healthy elderly men and women living alone without traditional family support 
within geographical proximity community initiatives can play a supporting role. There is a significant gap in English-speaking health professionals such as psychologists and social workers who would be targeted by the support needs frequently nominated by caregivers of the elderly such as counseling, elder health literacy and respite care (Williams, 2004) and community-based organizations attempt to address the need for relief for caregivers through their volunteers. However, these initiatives are neither sufficiently robust nor widespread to stand as a sustainable solution to the overall situation of the primary caregivers of Quebec's aging language minority. Where communitybased organizations are present, as in some parts of the Estrie region, they are not an option commonly used by newcomers to Quebec or by low-income caregivers who tend to be located in households with the highest rate of illness (Pocock, 2006b). Both of these groups are increasingly represented in Quebec's official-language minority population. In light of the predicament of Quebec's aging minority language communities it is not surprising to learn from the Canadian Community Health Survey (2005) that they express the lowest rates of satisfaction with health care services as well as home-based care when compared with other minority language groups across Canada (CCESC, 2007). 


\section{Trickling Down: Faces at the Bottom of the Well}

There is a trickle down effect. There is a shortage of doctors at the CLSCs and the nurses cannot meet the need for homecare services. The care facilities that used to have clients who were fairly autonomous are now seeing an increase in those who need more intensive care and this pushes the more autonomous individuals back onto families. There are not enough nursing homes and they are now telling us that the people they see are in need of critical services at a fairly constant level. Dr. Lowry, an English-speaking doctor who would make visits to these homes in the Sawyerville area passed away recently and this has made the services of the nurses from the CLSC less available to private homes. The appropriate convalescing facilities for people who have been released from the hospital are often private ones and those facilities are expensive. You often have people who have been released going right back into the hospital.

(Middle-generation female, Coordinator, $\mathrm{CBO}$ )

One of the major ways that caregiving has changed during the social economy era is the extent to which family caregivers are expected to provide medical expertise, to be 'pro-active' with respect to the health system and exercise a general level of 'health literacy'. Studies of world poverty and health have long confirmed findings like those of Lappé who found the literacy rate of women to be the most significant factor in explaining the varying mortality rates of industrial and non-industrialized nations (Lappé, 1977). Aside from general levels of education, as the key caregivers and keepers of practical health knowledge in traditional families the empowerment of women through access to 
basic health principles and 'know-how' can have an important impact on the

health and well-being of their communities as a whole.

The impact of the "trickling down" of responsibilities in the social

economy era is an increased demand on family caregivers as the weavers of the increasingly fragile "social safety net" (McDaniels, 2002) at the bottom of the hierarchy of paid and unpaid care provision but with few corresponding measures taken to prepare them to cope.

Often family members are shown by hospital staff how to change bandages, give injections and so on but you're never sure that you're doing the right thing and often people don't know where to go to get the right information or to find someone who can perform these procedures properly. One problem that arises, for example, is volunteers who drive people to the hospital are then asked to stay and help the patient after treatment (e.g. to have drops put in their eyes or to stay if someone is having day surgery). This is something a volunteer should not have to deal with - there are even questions regarding legal responsibilities if something happens to the patient who is in the volunteer's care. This is when a trained professional is needed but it costs.

(Middle-generation male, volunteer)

Patients are discharged from the hospital earlier and family caregivers have to take over the medical care. They expect you to pick up where they left off but without making sure you are comfortable that you have the knowledge you need to do the job properly. You sometimes have to make decisions in situations you don't feel qualified to handle and the back up is not always there.

(Middle-generation female, family caregiver) 
I looked after my late husband after he was discharged from the hospital and it was very stressful. I was especially worried that something would happen at night that I didn't know how to deal with. You want to care for your loved ones but you want to feel safe doing it. I was grieving because my husband was dying of cancer and at the same time I became responsible for his case. My neighbours were there ready to help if I needed it but I was reluctant to ask. There are limits to what you can ask of them. And I guess I wanted to protect my husband's privacy as he would have wanted.

(Senior generation female, family caregiver)

The shortcoming of Quebec's social economy era is that in sending care to the 'community', primarily middle generation and senior mothers and daughters, the quality of care has been made to increasingly depend on broadening the dissemination of health knowledge but the avenues for access by minority family caregivers who have the heaviest demands have in fact been reduced.

While Anglophone women are much more likely than men to be employed in the health and social assistance industry they are highly unlikely to have postsecondary education in a health occupation. For English-speakers in the rural Estrie region, the disproportionately low number of English-speaking health professionals compared to Francophones and the centralization of hospital services which entailed, for example, the loss of Sherbrooke hospital as a more proximate and historically English-speaking institution amounts to an increased 
likelihood of reduced communication with the key purveyors of health information. Aside from the ratio of English-speaking health professionals per Anglophone patient a Health Canada study of language barriers indicates that obstacles to communication can reduce recourse to preventative services where health information is transferred and affect the quality of services which emphasize effective communication such as social services (Bowen, 2001). The high rate of mental illness in the English-speaking population including symptoms commonly associated with the frail elderly and the notably low number of English-speaking psychologists and social workers has made the acquisition of knowledge in this area by family caregivers a pressing concern. Caring for individuals suffering from dementia or Alzheimer's, often men giving care to a spouse with some assistance from children in the case of my interviews, represents a challenging learning curve.

Besides access to health professionals another way that information is relayed is through informal networks. Reliance on families, friends and neighbors is not simply about day to day practical assistance but this local English-speaking network is also the primary means for circulating health information whether about services or acquired medical techniques. Interviews with families and individuals involved with community-based care strongly 
supported the finding that the transfer of knowledge, particularly for a minority language group coping with majority language institutions, was a matter of 'word-of-mouth'. "We've done publicity, we've developed English-language pamphlets, but word- of- mouth is often the only way people learn about what's available. A referral from a friend or neighbor based on their experience is more likely to be trusted." (Middle-generation female Director, $\mathrm{CBO}$ ). Comparative analysis of Estrie's linguistic majority and minority populations with respect to their informal support networks shows that Anglophone networks include a high number of seniors, are less likely to include a health professional, include households that tend to have lower levels of knowledge of health services and programs in English, include a high level of unattached individuals and a portion of the population which tends to exhibit low levels of civic engagement (Pocock, 2006b).

The findings of my dissertation survey indicate that $70 \%$ of Estrie Englishspeakers had not received information from public health and social service organizations regarding services in English in the last two years and $80 \%$ did not obtain information on health promotion and prevention programs. Health information was more likely to be received from a community organization, school or newspaper than through public health organizations. When 
information was received it was generally through flyers (64.7\%) followed by a telephone or visit $(13.3 \%)$, an information meeting $(11.7 \%)$ or website $(2.7 \%)$. Anglophone men are more likely than Anglophone women to receive information regarding health care through a website while Anglophone women who are more likely to obtain information through a telephone call or visit. Websites were a more likely source of health information for the 15-24 years age group. When household income is compared, those earning less than $\$ 30 \mathrm{k}$ as well as those who are non-bilingual are the most likely group to obtain health information from a telephone call or a visit and those earning $\$ 70 \mathrm{k}$ and up and claiming bilingual status are much more likely to than other household income groups to obtain information through an information meeting. Those who assess their health as below average are more than twice as likely as those of better health status to obtain their health information by telephone or through a visit (Pocock, 2007b).

Low income households with the highest rate of illness and coinciding high levels of unpaid family care show a preference for face-to-face or oral communication in their acquisition of health information and yet this opportunity with CLSC nurses or doctors has been reduced and they are less likely than high income groups to turn to community-based organizations. 
Shortened hospital stays and overloaded CLSC nurses, largely responsible for public education and health promotion programs, are frequently noted as contributing to reduced access to health information.

When I had my babies I stayed in the hospital for a week to 10 days. The nurses spent that time teaching us how to breastfeed and care for our babies. Now mothers are expected to go home the next day. When it comes to your second or third baby you have experience to draw on but when it comes to dealing with your father's heart surgery it is always a first time. The CLSC nurses are great but the wait for follow-up after someone is discharged from the hospital is way too long. Sometimes the follow-up just doesn't happen

(Middle-generation female, family caregiver).

As in most communication, the face-to-face encounter is an opportunity to build networks, establish some familiar perhaps English-speaking contacts and generally establish a comfort level in what is not always perceived by the minority as a welcoming environment (Pocock, 2005). The community approach in health explicitly promotes networking and the mobilization of community members as the route to information and influence over the allocation of resources. As research on social capital points out, the density of a social network is not given once and for all but corrodes through time if not properly maintained. In order to maintain his or her social connectedness an individual or group has to devote scarce resources such as time and money to social interaction (Bolin, Lindgren, Lindstrom and Nystedt, 2003). There are settings 
where this has proved successful - parents in schools are often cited - but we need to consider the predicament of the clientele of health organizations when it comes to health. Are the sick or high intensity middle-aged and senior minority language family caregivers, appropriate candidates for the mobilization that the community development approach promotes as their strategy for empowerment within majority language institutions?

People are exhausted. They wait too long to ask for help partly because there is a lack of resources or lack of awareness of what's available, but it's also accepting the fact that they need help fulfilling the mandate that has often been thrust upon them, not by choice. They're often extremely exhausted by the time they seek help. The fact that people become isolated because they have to cut back on their activities in order to act as caregivers around the clock and seven days a week is a real problem.

(Middle-generation female, volunteer)

The case of Estrie clearly illustrates the impact of social policy in Quebec which takes gender into account but ignores the crucial ways it intersects with language and generation. The rationale of downloading responsibilities from hospitals to the CLSCs more widely distributed throughout the region is to bring services 'closer' to local communities. However, some CLSC territories such as Memphremagog and Sherbrooke have higher concentrations of English-speakers and are the 'oldest' populations among the region's CLSCs. Accordingly, the demand for home care services is higher in these areas but the financial and 
human resources allocated are not adjusted in accordance with these variances.

Despite the dispersal of services to CLSCs many English-speaking seniors tend to relocate from the more rural settings of the region to be closer to the hospitals, community organizations and public transportation offered in the more urban areas. The critical mass of English-speakers tends to mean an increased likelihood of health care workers and community volunteers who can speak English. Ultimately, however, this compounds the strain placed on formal provisions in these areas and increases the trickle down to family caregivers. The result of not considering the logic of language is that CLSC services in these cases are in fact more difficult to access rather than 'closer' to the communities they are intended to support.

\section{Conclusion: Hidden Differences}

One of the most profound insights of my investigation of paid and unpaid care in the era Quebec's social economy approach is the extent to which genderbased analysis, in research as well as policy, conceals significant inequalities in health and health care among the diverse groups of Quebec society and most apparently among women. While Quebec is heralded for health care and policy which is advanced in its explicit consideration of the situation of women, the privileging of gender as a health determinant carries the risk of ignoring the way 
it intersects with other forms of social difference in shaping women's lives. While gender neutrality may treat men and women the same and result in overlooking the unique needs of women in the area of health (CIHR, 2004; Marks, 2002; Rogers, 2004), the notion of gender as the dominant category of women's experiences "flattens out important differences" (Marshall, 2000: 47) and may "downplay diversity among women" (Weisman, 1997, 183). Alternatively, "Intersectionality refers to the idea that gender is experienced by women simultaneously with their experience of class, ethnicity... and other forms of social difference... and in ways that are complex and compound with one another" rather than merely "added on" (Varcoe, Hankivsky and Morrow, 2007: 19).

In this chapter, my in-depth case study of caregiving in the rural Estrie region using the lens of gender, language and generation allows insight into a world that would otherwise be hidden by rendering the experience of women in the households of the majority language group as 'generic'. The fact that Englishspeaking women are located in a population that is more advanced in the aging process, displays a different pattern of participation in the local economy and occupies a different position with respect to the state apparatus distinguishes their family caregiving experience from their Francophone counterparts in 
significant ways. It reveals the extent to which a gender-based social economy approach may unwittingly undermine the solidarity of women and contribute to the formation of social policy that exacerbates the existing disadvantage of marginalized groups with respect to access to quality health care and ultimately, health. If there is agreement with the logic that says the status of women has a powerful impact on the overall health of a population then recognition of the barriers to realizing that collective potential is a necessary first step. Grappling with the inequalities in health that make women invisible to one another seems like a good place to begin. 


\section{Chapter 4 - From Stewardship to Partnership: Mobilizing Rural English-speaking Voluntary Core}

\section{Introduction}

In this chapter I examine the engagement of community-based organizations working on behalf of rural English-speaking minority communities with public health agencies during Quebec's social economy era. How do inter-agency partnerships work in this context? And, serving what interest?

For the purpose of this chapter I will introduce findings from the twenty interviews I conducted with the directors and coordinators (two men and 18 women) of community-based regional organizations serving Quebec's Englishspeaking, primarily rural, population. All of them are engaged in the CHSSN Health and Social Service Networking and Partnership Initiative funded jointly by Health Canada, the Public Health Agency of Canada and Canadian Heritage for the purpose of improving health service access and community-based support for the English-speaking communities of their regions. For further details on the expert interviews, see Chapter One. 


\section{The Problem}

Of interest is the promotion of 'partnerships' as a marked feature of the social economy approach towards reducing health inequalities and improving the health status of disadvantaged populations. The social economy era has seen growing support for inter-agency "partnerships", "alliances" and "joined- up solutions" which include infinite permutations from various levels of government (Mackian, 2002: 204, 207; Hudson et al., 1999; O'Keefe and Hogg, 1999), to public agencies like Quebec's CLSCs and community organizations providing home-based services (Vaillancourt, Aubry, Kearney, Thériault and Tremblay, 2004) as well as between health professionals and patient groups (Hamilton, 1998). Current policy guidelines advocate the use of partnerships as the optimal way to draw policymakers, health managers, health providers and lay groups into meaningful dialogue and to support "local communities" in mobilizing to respond to their particular health challenges (Fafard, 2008). Strengthening the influence of communities on the policy process is reputed not only to improve the effectiveness of policy and program choices in meeting health needs but also to foster a sense of inclusion by those increasingly occupied with their impact. While improved "community capacity" (Gibbon et al, 2002), "greater social inclusion" and "the development of full citizenship" 
(Vaillancourt, Aubry, Kearney, Thériault and Tremblay, 2004) are the much discussed outcomes of partnering, less attention is given to the complexities underlying these arrangements themselves as an achievement and the way the health inequalities these proposed partnerships are intended to solve can make the formation of the partnership itself problematic.

In the case of Quebec, the partnership approach of the social economy era has been introduced in a very specific socio-political context. Far from the benign setting images of health care agencies may conjure up, Quebec's latest partnership strategies follow on the heels of many years of fiery contestation over language rights which have featured Quebec's public health institutions as a key battleground (Silver, 2000). Population sub-groups, historically defined along linguistic lines, vary markedly with respect to their links to the public institutions of the province and in the nature of their relationship with the government which, as funder, has the greater power to set the terms of a 'new' alliance. While the partnering approach is often about supporting lower-level groups (individuals, communities, agencies) in their efforts to negotiate and influence higher-level aggregates (larger institutions and formal structures of policy and government) (Mackian, 2002), I claim that the higher -level process through which support is negotiated disregards the way the position of Quebec's 
language minority and majority communities differ. This difference affects the opportunity each has of establishing a partnership and is the basis for variance in the limits and possibilities of the engagement when it does occur. Evidence from my interviews with experts involved in third-sector organizations working within the present framework to improve access to health-enhancing resources for Quebec's English-speaking minority communities suggests this indifference to history undermines efforts to close the gap and join the negotiating table as a legitimate potential partner among others. Evidence such as the notably low representation of Anglophones as employees in Quebec's public sector, the lowest levels of confidence in the representative capacity of the provincial government among all of Canada's official-language minority communities (OLMCs), a weak sense of belonging and the widespread perception that they have no recognized place in Quebec's future plans suggests the preconditions for the type of engagement promised in social economy partnerships are far from within equal reach for all citizens (Pocock, 2006b). 
Using the example of the Community Health and Social Service

Network, ${ }^{21}$ I contend that some organizations have achieved improvements in the level of health resources for their local populations. Health Canada evaluations indicate the CHSSN partnership initiative is held as a paradigmatic model among OLMCs similarly funded across Canada. Still, the proportion of the English-speaking population benefiting from this approach is small (15-18\%) creating a gap between participants and non-participants in the new alliance and the sustainability of government investments is not secure. In Estrie, the benefits of pursuing 'bridging and linking' partnerships with provincial public health institutions have coincided with the emergence of antagonistic relations between minority community sector actors. Overall, the precariousness of these initiatives in Quebec, aptly described by one $\mathrm{CBO}$ coordinator who likens the partnering process to "walking through a minefield", underlies the general understanding that success in partnering requires the voice of the community to be unified and accommodating and that dissent must be muted as it risks ever-tenuous future investments. In other words, the absence of language as an issue or 'language

${ }^{21}$ The Community Health and Social Services Network (CHSSN) was established in September 2000 to create a network of community resources, associations, and public institutions dedicated to the development through partnership of health and social services for English-speaking communities in Quebec. (www.chssn.org) 
peace' is the current price to be paid in return for federal government funding in support of provincial partnerships intended to bring about improved access for minority language communities to public health resources. In this context, partnership is not the solution to the political disengagement of the minority but rather is formed on the promise of its perpetuation.

I claim that the partnership approach in health during the social economy era has targeted community organizations as the training ground for the bureaucratic management of a captive and low-cost source of labour. Where partnerships have been established the representatives of community organizations, largely women, have assumed the task of coordinating an exceptionally dedicated local unpaid English-speaking voluntary core, the majority being mid-life and senior women, at a fraction of the cost of comparable work by a public employee located in formal health structures. While it may be argued that these "street-level bureaucrats" (Fafard, 2008: 13; Checkland, 2004: 951-975; Walker and Gilson, 2004) wield more power than generally portrayed with respect to their impact upon the decision-making of higher-level agencies, their situation of lower pay, increased responsibility and location within organizations with few paid employees widely geographically dispersed across 
Quebec's rural regions results in a fair rate of turnover and a weak basis for concerted action to improve their situation.

\section{Who is the Public?}

Who is the public and how are Quebec's official-language groups positioned with respect this prospective partner?

Edmondson (2003) makes the important point that a given type of social relatedness may react with different social settings to yield contrasting outcomes. Or conversely, different types of relatedness in different settings may produce the same end results. Broad public policy which promotes 'partnership' as the favored vehicle for the improved health of local populations and is, in turn, implemented on the 'apply the same standard to all' basis typical of large-scale public institutions can produce varying results by virtue of its "reactivity" with diverse circumstances (Edmondson, 2003: 1726). So too, different forms and meaning of partnership may be needed to yield the same desired outcome in different social contexts.

Previous chapters have demonstrated that while Quebec's Frenchspeaking and English-speaking populations share the same geographical and administrative territory there is remarkable variance in many aspects of their 
social circumstances. The inter-agency partnerships of the most recent decades of social economy policy were not introduced in a vacuum. The community organizations of Quebec's English-speakers have a long-standing relatedness with public health organizations and government structures that co-exists with that of French-speakers and the nature of this relatedness is one of the differentiating features of their distinct social realities. In keeping with Edmondson, the case of Quebec, and Estrie specifically, demonstrates that given their different points of departure the prevailing partnership approach in health to which both language groups are subject is likely to achieve contrasting, and unequal, outcomes for each. Aspirations to redress health inequalities may need to consider that different forms of collaboration are needed for different groups to bring about the same outcome for all citizens.

It is important to keep in mind that in Quebec the larger institutions and formal structures of public policy and government are considered to be Francophone majority enterprises. It is common parlance to use the terms 'public services' and 'Francophone' or 'majority services' interchangeably in this setting. This no doubt stems in large part from radical social change that occurred during the Quiet Revolution (roughly 1960-1966) which included the expansion of the role of the new welfare state and alterations in the relations between Quebec and 
the federal government. The expansion of the size of the state bureaucratic apparatus meant, for example, that between 1960 and 1971 the number of people employed in Quebec's public and para-public sectors grew from 36, 000 to 350 , 000 increasing government employees from $2 \%$ to $15 \%$ of the total labour force (Renaud, 1984: 151). Not only did the Quebec public sector become the major employer of the new Francophone middle class but also much of Quebec's language majority came to equate the promotion of their collective identity with the empowerment of the state (Fournier, Rosenberg, White, 1997: 7). Still today, among those employed by the provincial government in Quebec over 97\% are white Francophones. Less than three-quarters of one per cent of Quebec's public service is made up of individuals drawn from aboriginal, allophone and Anglophone citizens (Jedwab, 2008: 16). This represents an expansion of employment positions but an extreme narrowing of population groups hired to fill them.

In the case of Quebec's English-speaking communities their exclusion from the public sector is not the unintended result of majority indifference but is in fact the outcome of strategic efforts enshrined in legislation to empower the majority by making French the official language of la nation Quebecoise and to curtail the use of English within the workplace and public sphere. Quebec's 
official-language minority community is unique when compared to those located in other Canadian provinces in that it is a minority within a provincial population that views itself as a minority within Canada and hence the rationale for employing language legislation to protect its unique status. As the accompanying graph illustrates, Anglophones in the Estrie region are much less likely than their Francophone neighbors to be working in the government services industry. As mentioned in earlier chapters, their relative representation among workers in the health and social assistance industry when compared to

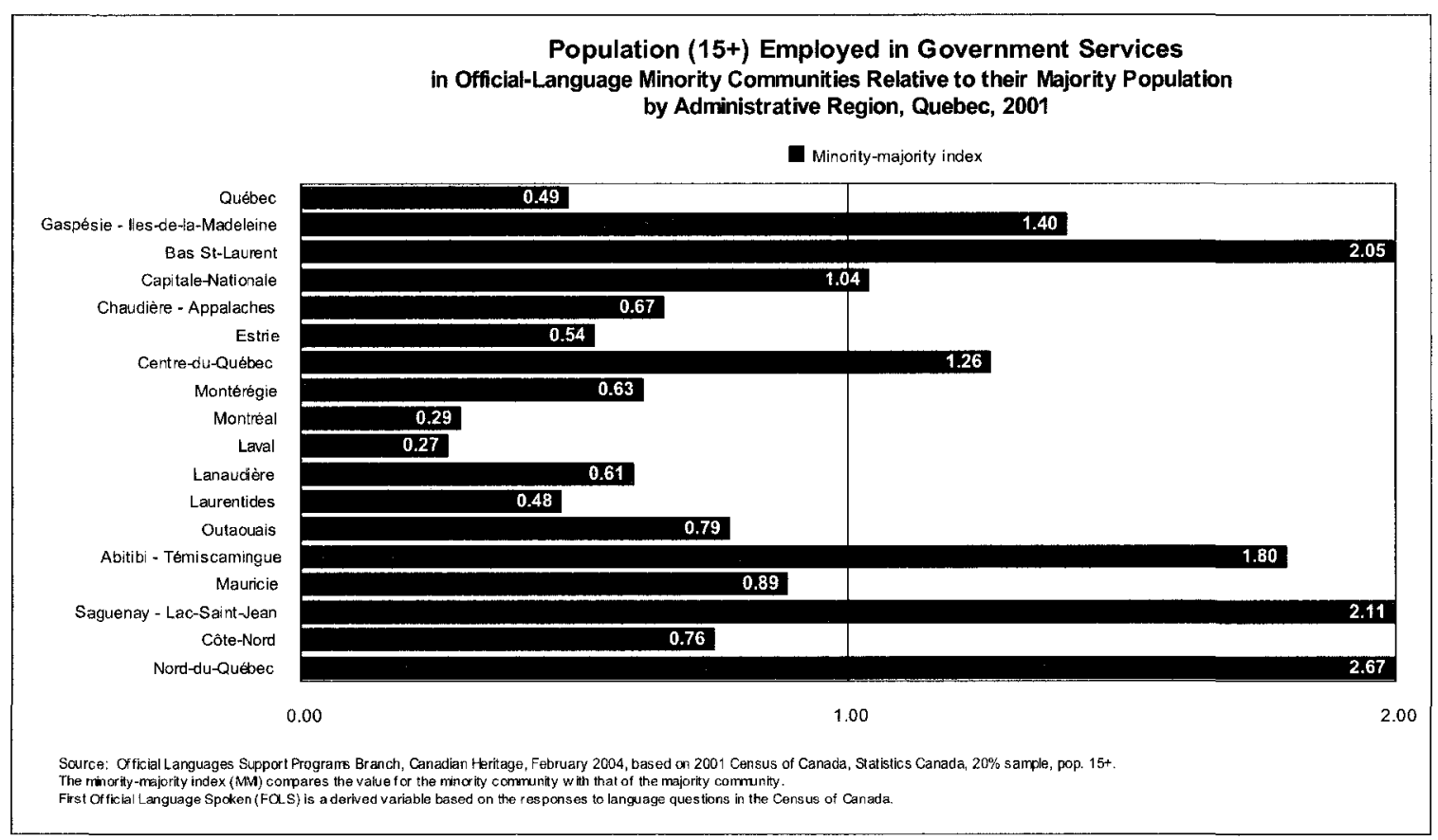

Francophones is notably low. In a study done of the health occupations in the

Montreal where there is likely to be the greatest concentration of Englishspeaking health professionals per capita, Anglophones had substantially (30\%) 
fewer professionals who were government mangers, working in health and social development policy and in program administration (GMCDI, 2007).

Community-based organizations representing Anglophone minority communities, or more popularly known as "les Autres" during the 60s and 70s (Cullen, 1992; Rudin, 1985), face the paradox of being required to partner with agencies that in many ways have helped to generate the health inequalities their alliance is now expected to eliminate. Years of reforms in the health sector have, from the point of view of these community organizations, brought about the sometimes radical reduction of the health and social services with which they have historically played a complementary role. In the General Social Survey (2003) respondents were asked to rate their trust in various institutions and Quebec Anglophones exhibited substantially less trust in the health care system than the Francophone group (Pocock, 2006b). In the words of one CBO director, “How far can we really expect provincial government agencies to go in eliminating the inequalities that benefit the group whose position of advantage is their stated priority?" In contrast to the minority, Francophone community actors who have been historically more reliant on state provisions are more likely to already have established arrangements with these agencies; to find the work of policy-making and that of implementation of services already have a level of 
coherence that Anglophone groups do not experience; and a greater basic trust that their collective interests will be championed by the provincial public sector.

In the General

Social Survey

(Statistics Canada,

2003), Quebec

Anglophones

showed the lowest

sense of belonging to

their province

\section{Representative Role of Government}

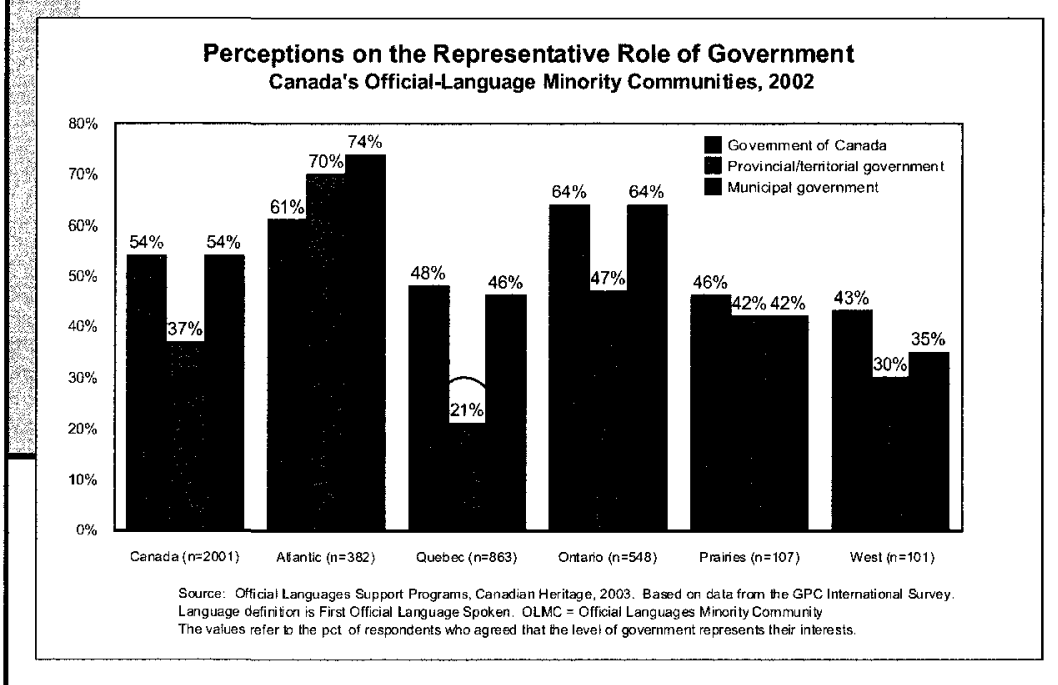

(Pocock, 2006b) and as the accompanying graph illustrates, their perception of

the representative role of government is exceptionally low when compared with other official-language minority communities across Canada.

Consider also that the notably high percentage of individuals born outside of Canada who compose Quebec's English-speaking communities compared to its majority results in a greater likelihood of sub-groups whose relatedness to the state, established even prior to living in Canada, may not be conducive to partnership (Pocock, 2006b). For example, the sense of entitlement to public resources that partnership tends to build upon may not be as present for 
newcomers as those Canadian-born. In many ways, Quebec youth are like newcomers to the current reality they have inherited in that they may not have access to the minority memory which would invite them to view their present as something that could be otherwise, or, is their refusal to put their hopes in the formal avenues available for influencing public authority testimony to an alternate vision of political activity? It is argued that popular measures of civic engagement (see those used by Putnam for example) are narrow and overlook the fact that in some contexts political activity is defined in terms which include disengagement from, and distrust of, formal state strategies (Edmondson, 2003). Where political engagement or mobilization is defined in terms of resistance to state power, the notion of government-supported community development may be heard as false benevolence. By invoking competition among local populations for the opportunity to influence public policy, it may be perceived as threatening solidarity rather than nurturing its development.

In sum, the promotion of partnerships between formal policy and government structures and local communities as a strategy towards improved population health, in the case of Quebec, tends to advantage the group with higher levels of trust in provincial public institutions and provincial leadership and greater control over health-enhancing resources. 


\section{The Politicization of Health Care}

Aside from the absence of members of Quebec's English-speaking community from among the ranks of public agencies and provincial ministries, the destabilizing effect of successive years of restructuring stands out as a determining factor in the inter-agency partnerships that are being promoted as themselves a feature of the latest round. Highlighting the contradictory character of the social economy era, the directors and coordinators of the communitybased organizations (CBOs) I interviewed as part of my doctoral research recurrently cited the context of reforms and financial cutbacks as, in many ways, undermining the potential for effective partnerships. In this section of this chapter I will trace the politicization of health and social services in Quebec in the 90s and the 'shaky' ground that emerged for the ensuing years of interagency engagement. I will argue that the promoted 'joined up' solutions to health concerns distorts the political nature of the gap between the relatedness of 'lower-level' community groups, health agencies and care providers and their engagement of the 'higher-level' policy and government structures they are 
intended to influence. ${ }^{22}$ The following chapter sections will consider the impact of internal organizational restructuring on the ability of public agencies to engage effectively and the general exacerbation of long-standing areas of incompatibility in the joint ventures of large-scale bureaucratic agencies and small traditional community associations.

Before the Castonguay ${ }^{23}$ reform of the health and social services system in the early 1970s, the organization of services for the English-speaking community differed from that of the French-speaking majority. On the one hand, services in English reflected to a great extent a tradition of small, non-hierarchical associations, volunteer commitment, and self-help (Silver, 2000). Institutions and community organizations relied on financial support from private corporations and foundations, and on individual gifts and bequests. On the other hand, the Catholic Church assumed an essential role in founding institutions providing services to French-speaking Quebecers. In the period leading up to the reform, the provincial government assumed an increasing part in providing and financing services to both communities. After the Castonguay-Nepveu Report,

\footnotetext{
${ }^{22}$ I place these terms in quotations because my research and analysis suspend the ranking they impose as itself a matter of debate and product of the bureaucratic structures under consideration.

${ }^{23}$ The Castonguay-Nepveu Report is otherwise known as the Rapport de la commission d'enquête sur la santé et le bien-être social, Gouvernement du Québec, 1967-1972.
} 
the government created a network for which it assumed all the costs. Institutions originally founded by the English-speaking community, including several of Quebec's most prestigious hospitals, were absorbed by the public network and today, especially in the regions, are staffed almost exclusively by Francophones (Silver, 2000: 684-685). Although English-speaking communities continued to use local volunteer-based community organizations, their link with the public network has dramatically declined along with access to services in English (Jedwab \& Maynard, 2008).

Events of the 1980s and 1990s specific to the health sector are still fresh in the memory of English-speaking Quebec along with the loss of good faith in high-level government process that followed in their wake. The text box below lays out the evolution of the right to English health and services enshrined in legislation in 1986 (Bill 142) and the politics which reduced the impact of the efforts of the Regional Councils over the subsequent decade of its controversial and much delayed implementation. 


\section{Timeline \\ Implementation of Legislative Guarantees \\ for Access to Health \& Social Services in English}

1986 The Liberal government introduces Bill 142 concerning existing health and social service legislation. It gives the Minister of Health and Social Services the responsibility to ensure services reflecting the linguistic and socio-cultural character of each region. The government must designate by regulation which institutions recognized under the Charter of the French Language (those with the right to function in both French and another language) are bound to make their services available in English

1988 At this time there are 79 designated institutions 55 of which are located in Montreal representing $9.2 \%$ of the total 858 institutions.

1989 With the implementation of Bill 142 Regional Councils develop access programs in collaboration with regional health institutions and the number of designated institutions increases to 170 or $29 \%$ of the total.

1991 Another major reform of the health and social service system and new administrative regions are formed

1994 The Parti Quebecois gain power and the Regional Councils are asked to revise their access plans. The English Services Committee request intervention and matters heat up between mobilized English-speaking communities and the Parti-Quebecois government including a media campaign and public meetings in several regions At this time the number of designated institutions is reduced to 68 with fewer than 20 providing services off the Island of Montreal leaving some regions with none at all. For example, no hospital is designated in the Montérégie region for more than 100, 000 residents. No youth protection services are included outside of Montreal and no specialized services.

1997 The Office de la langue française is formally included in the process to review revised access plans submitted by Regional Councils. Their concern is that hospitals have exaggerated the need for English services. Regional Councils are asked to justify their modifications. Protests arise against access plans by Société Saint-Jean Baptiste de Montreal and le Mouvement estrien pour le Français in the Estrie region. While the Regional Councils receive much pressure to counter "rampant institutional bilingualism" they maintain their humanitarian position

1998 By the end of the mandate of the Parti Quebecois in 1998 the revised access plans have not been implemented.

1999 Upon the filing of court proceedings by Alliance Quebec, a Montreal-based citizen's group, regional access programs to English services are finally approved. The Canada-Quebec Agreement that provided the means, to a great extent, for the regions to implement their programs is not renewed in 1999. The English Services Committee is dissolved.

2006 Government of Quebec revises designated institutions to 42 with 29 located in Montreal (8 of which are long-term centers or institutions. 
Questions were raised by the Parti Quebecois with the introduction of Bill 142 in 1986 with specific concerns regarding the directives of the Charter of the French Language regarding the integration of immigrants. The Minister defended the Bill with the argument that the language of work and education were the tools favored by the government for the purpose of integrating newcomers. The Minister argued that aside from the historic rights of the English-speaking community permitting members of the different cultural communities who comprise this provincial sub-group, and are more comfortable expressing their needs in English, to avail themselves of English services for humanitarian reasons would not threaten the use of French in Quebec. Bill 142 was to be seen as legal recognition that the needs of the vulnerable and sick should come before the promotion of the ideology of language.

Subsequent changes to access plans flowing from Bill 142 during the reign of the Parti-Quebecois (1994-1998) were defended on the basis that providing English access to services contributed to institutional bilingualism and threatened the right to work enshrined in the Charter. Protests calling for the repeal of Bill 142 and the access plans proposed by the Regional Councils (formed in the late 80s) called for the end of discrimination among health workers based on knowledge of English. It was the stance of the PQ government 
that knowledge of French should be the prerequisite to obtaining access to public services and individuals should adapt to institutional structures, not vice versa. There was still concern that this could become a means for introducing immigrants into the English-speaking minority and promoting its growth.

CHSSN founder, James Carter, advises that history has taught the Englishspeaking community that they must be "fire hall ready" and "ever vigilant" as any gains made through cooperation with regional agencies with respect to health resources is always vulnerable to the politics of the day (Carter, 2008). Trust and good will may exist at the lower level of the hierarchical policy process between English-speaking communities and the regional public agencies that are in contact with their health needs but this doesn't necessarily translate into effective influence of higher level decision-making. As this case illustrates, even legislative guarantees may fail to offer firm ground as their administration is subject to the priorities of the political party that happens to be in power. In response to Jensen's query, ${ }^{24}$ social capital does not necessarily 'aggregate up' from the local level and as can be seen in this case alliances intended to bridge

\footnotetext{
${ }^{24}$ Jane Jensen proposes the following research question, "Does social capital constructed in local communities aggregate to the level of the country or even the province?" (Jensen, 1998: 34)
} 
beyond the frontlines of health care program delivery are rickety affairs.

Community-based organizations are caught between the urgent health care needs of Quebec's rural minority communities and the potential of being the target of punitive tactics by a government seeking the cohesion of the electorate in a time of cutbacks and job loss. Knowing the extent to which these aging rural populations rely on the funding they are able to procure to improve their quality of health care, the risk of losing further ground in any sort of resistance or confrontation of "high-level" policy has become too great. The social economy approach has made the role of the community sector essential in its health care strategy but what is essential, in this case, is left vulnerable to political bargaining. It is not surprising that the activism of recent years has disappeared from the town halls and the media and "accommodation" has become the new catchword.

Interestingly, language is the device used to contain the potential solidarity surrounding the issue of health care access from gaining greater clout under the guise of an appeal on behalf of "the workers". The summons to protect French as the language of the workplace is but a veiled warning to maintain the linguistic divide that seemingly grants the majority group an advantage with respect to the conditions of employment. It essentially deflects attention away 
from the issues of health and health care which are a preoccupation for frontline health care workers and revives a well-worn pseudo-solution for Quebec's poor record of job creation in recent decades, namely, to reduce the claim to public resources of an apparently over-reaching Other (Cullen, 1992). Silver notes that the work of the regional councils formed to create access plans for English services was undertaken largely by Francophone health agencies and health providers which means it was in large part majority 'lower-level' health sector mobilization that was neutralized not simply minority unity. I learned from my doctoral expert interviews that the English-speaking community is marked by this past in the health sector as public providers still associate their dealings with them as potential ground for further language feuding.

\section{The Formal and the Informal}

As discussed in the previous chapter, the current focus of the social economy approach on sending health care to the community is justified, in part, as being part of a trend towards de-institutionalization which is supported by a long-standing critique of the large-scale formal organizations that hospitals and related health organizations have become in much of the modern world. The ability of formal organizations to serve as an appropriate setting for procuring 
the general physical and mental health of individuals has been the subject of much discussion and research in social sciences literature. How, then, are these same formal organizations suited for engagement with small-scale traditional community associations or lay communities in fostering community capacity and social inclusion? How does the critique of the standardization and monitoring typical of bureaucratic hierarchical institutions warrant the shift of health related responsibilities for seniors to home-based care, for example, but fails to apply when it comes to partnering with small-scale rural organizations which are building social support organized on a more inter-personal basis? There is a powerful critique of modernity across the social sciences which tends to support the assumption that the effects of formal structures on traditional local cultures are essentially negative. Does it make sense, in this context, to presume that local rural groups can acquire influence over the health policy generated largely by these formal institutions through partnerships with them?

Caution has to be exercised around these questions as it is all too easy to fall guilty to the very abstraction that these modern institutions are charged with exercising to ill-effect. Weber himself exhorts us to be mindful of the fact that his study of bureaucracy is of an "ideal-type" and not likely to exist in such perfection in reality (Weber, 1978). Nor are the rural networks of the community 
sector simply havens of neighborliness and related humanitarian practices. In fact, the very notion of "inter-agency" is itself something of a generalized construct that, at the level of practice, boils down to interpersonal relations and networking which according to the literature these small-scale groups are especially skilled at accomplishing. In the pristine setting of a laboratory we might be able to take a measure of the relatedness of these two social forms in their pure state but instead what we have is a 'case' where they are inseparable from the particular socio-historical context in which they are embedded.

\section{A Partnership Case}

The expert interviews I conducted were held with the directors and coordinators of CBOs working on behalf of Quebec's English-speaking, primarily rural, population in the health sector. They are directly involved with a CHSSN initiative funded by the federal government (Health Canada, Public Health Agency of Canada and Canadian Heritage jointly) where they are to forge partnerships with designated provincial health agencies (CLSCs, CSSS) in their regions to improve health and social service access and community support for the local English-speaking population. Community organizations located in 8 
different regions including Estrie, ${ }^{25}$ most of which had received government funding in the past, were subject to a selection process that required they comply with specific application guidelines. Anglophone communities located in regions without the benefit of such infrastructure, or which for other reasons did not manage to apply, are not participants in the partnership initiative. Given the large geographical territory designated by an administrative region usually only a segment of the region's total population is targeted by those with successful 'bids'. As a result, some $15-18 \%$ of the English-speaking population is considered to be served by this initiative. The vast majority of the coordinators of the partnership initiative in Quebec's regions and in OLMCs across Canada are women. Like those observed by Jutras (1990), the partnerships are easily likened by the interviewees to those which typically form as a business enterprise. In their words,

We approach them with a win-win proposition. We want services and they want access to the community to fulfill their mandate. We come to the arrangement offering resources and this way we are not a burden on the system. Partnering means both sides bring resources to the relationship. Both sides need to feel they're getting something out of it. In many ways, we are helping our partners help us. They are required by their access 
plan to offer support to the English-speaking minority and we are offering them a way to do it.

(Female, Francophone, $C B O$ Director)

\section{“Walking Through a Mine Field"}

The destabilizing environment of ongoing restructuring in Quebec's

health sector over the last 30 years laid out in the previous section of this chapter has not simply seen the decline of access to health resources for rural minority communities but also a climate of stress and frustration among public health employees at all levels. While the notion of restructuring tends to be thought of as a temporary period of change followed by a return to some kind of stable routine and improved atmosphere, the now long-term unsettled state of health sector organizations and institutions suggests this may be more accurately understood as a permanent condition. Cutbacks have further removed such agencies from geographical proximity to these rural communities which, according to Reimer (2003), already have a low rate of bureaucratic type of engagement. While community inexperience is nominated by interviewees as a barrier to forming effective public partnerships, administrative confusion poses an even greater challenge. This fragile and potentially explosive situation, combined with the fact that there is no precedent to which partners can appeal, makes the planning and implementation of community support a precarious 
endeavor and a matter requiring continuous maintenance by $\mathrm{CBO}$ coordinators.

Put bluntly by one coordinator, "this has not been an easy concept to sell". The stability and coordination of public partners cannot be assumed nor an established protocol towards community-based organizations whose demands do not appear to readily align with the job description of any specific agency employees.

We sort of got lost being shuffled around among various administrative people at the CSSS at the start. They had had little contact with the community and suddenly we showed up asking for a number of things. It wasn't a question of them not wanting to help but more a matter of time constraint. We fell outside of 'work to rule'.

(Female, Anglophone, CBO Program Coordinator)

Our work has taken place in an atmosphere where people are losing jobs and management and bargaining units are changing. This has meant a challenging context. Just when you think you're making some headway personnel change and you have to start over. It's like walking through a mine field. And, we can't assume our public partners are one big cozy group. There is a lot of tension and turnover. On one side our public partners are in chaos, and on the other side, the volunteers we depend on also means people coming and going. One day we're making progress and the next day it has all" blown up". I feel like an old time switchboard operator trying to keep everyone connected but I keep losing the parties at the other end of the line.

(Female, Anglophone, CBO Program Coordinator)

You may have developed a good working relationship with a partner only to have to start all over again due to staff changes. The CSSS I work with is the largest in the province. It has gone through significant changes and is facing challenging times. They are preoccupied with their own internal workings. This 
makes it very difficult to establish partnerships for community

support. It is hard to feel you're making headway.

(Female, Francophone, $C B O$ Coordinator)

In many ways progress is an uphill struggle not simply because of the atmosphere of change but because partnership for the purpose of community support, while an important piece of the overall social economy approach, has low priority - if any - among its managers. The fact that inter-agency relations are so vulnerable to changes in administration simply underlines the fact that they are not a part of the core priorities and easily removed from the agenda when it is overbooked. The increased scrutiny and monitoring of the public service in recent years indicated in the implementation of greater frequency of government program evaluations would suggest that being pushed aside is more than simply the outcome of temporary upheaval. When the Director General of the regional CSSS is accountable for more objectives than he has the time or manpower to fulfill he will no doubt prioritize with consideration as to how his department will be evaluated. While it is clearly a challenging time to gain community support from public agencies, it is also an opportune time to learn what is considered fundamental to the mandate of public agencies and what is considered peripheral. 
Partnerships are usually promoted as the strategy through which provincial public health institutions extend support to regional communities in need of capacity building and inclusion in decision-making in order to improve their health status. The image is of a benevolent and egalitarian gesture from health policy experts and system planners to disorganized and disconnected communities (Muntaner, Lynch and Smith, 2001). But who in fact is mobilizing whom? In the case of these CBOs working on behalf of Quebec's language minority communities, it is a strategy for communities which, thanks to winning funding primarily available from federal sources (Health Canada and Canadian Heritage) and through access to Anglophone volunteer manpower, are able to negotiate a deal that mobilizes their reluctant provincial partner to live up to his mandate. Without these resources it is not obvious in this case that a mechanism for community support, so essential in the social economy approach, would even make it to the agenda of public agents.

\section{Unaccountable Presence}

The administrative machinery of complex societies is often portrayed in the literature, both popular and academic, as at odds with building the trust and social solidarity crucial to community (Edmondson, 2003: 1730). The notion of these very organizations as the setting for the production of community capacity 
intended to benefit those located beyond their walls is not unproblematic. How did the very mass organizations considered to reduce men and women to mere numbers become settings for the production of social relatedness and trust? Is a community a community without community capacity? How does its capacity to be a community come to be something external to itself and available to be redistributed according to the most winning proposal? Can it be given such capacity if in its absence it ceases to be a community? Informal networks and connectedness exist among those assigned formal positions within such settings and lay communities are not without their regulatory mechanisms. It is hard to imagine a Director General of a regional CSSS who is not also a neighbor, friend or family member and being any one of the latter has its strict formalities. Inviting the lay community to participate in the formal production process, and therefore to be more than a passive consumer of its products, nonetheless sustains the dichotomy between the two. It distorts the way "community" arises in company with or, in resistance to, formalized processes in general and while an inseparable feature of them is not their end product (De Certeau, 1984). Bringing the lay community into the formal production process may be an attempt to marry community know-how with more efficient modern techniques 
but what if its ad-hoc, informal and seemingly disorganized character is what

makes it what it is?

Keeping your contacts everywhere is important because you really need this. We often meet informally with our contacts to bring them up to date, to check out what is taking place, and to verify that we are proceeding as we should. You have to be a constant presence and build strong personal relationships with the people you work with. This takes time.

(Female, Anglophone, CBO Program Coordinator)

One challenge posed by the approach, is that the partnerships boil down to individuals, and when you have someone in a key position with no understanding of your needs, or is 'anti-anglo', you can face a real barrier. This can be very frustrating and hard to resolve. You have to find ways of working around your partners as much as with them to get things done.

(Female, Francophone, CBO Director)

Partnerships are essentially personal. You start on a personal level and then you try to build in structural commitments to see you through changing times. This all takes time. Community time-frames and public partner time-frames differ. The community coordinators are expected to do a great deal in a short period of time (12 months and quarterly reporting) but their public partners are located in bureaucracies which work far more slowly. This can create frustration and put pressure on partnerships.

(Female, Anglophone, CBO Program Coordinator)

The required participants in a successful partnership are generally

determined by the funding agencies and in accordance with their affiliation with an institution, professional order or regional community organization. In the case of CHSSN, for example, Health Canada evaluations of their partnership 
initiatives consist of an assessment of the composition of the partnerships and the frequency of meetings among partners. ${ }^{26}$ Interviewees point out that getting the right people in the same room several times a year may mean success from the point of view of government monitoring but the relation between this opportunity for influence and its manifestation in subsequent action is weak. Change attempted through such formal channels is slow to trickle down to those engaged in actual support activities. Despite the fact that the partnership approach demands time the emphasis on "results-based management" means CBOs are pressured for tangible outcomes in a short period. Funding is never secure and this pressures CBOs to enter into an action phase quickly so as to deliver as much as possible in a short period of time. Their funding contracts tend to be for a 5 year term with often a substantial amount of time devoted to the administration of the contract itself. From the point of view of CBO coordinators this time -frame ( 4 to 5 years) fails to take into account not only the slow pace of bureaucracies but also the time invested in ongoing face-to-face networking. The focus on the mechanics and structural arrangements of public partnerships leaves the crucial role played in building informal connections and

\footnotetext{
${ }^{26}$ CHSSN evaluation documents are the source of this observation.
} 
being a "constant presence" unaccounted for. As addressed above, without this undervalued networking time the accomplishments of a formal partnership would very likely not materialize. The work of "moving from the personal level" to "building in structural commitments" is not only time consuming but appears to be never-ending.

Besides the many hoops of public partner decision-making which tends to slow things down, interviewees point out that this formal alliance may not include the individual (s) who, in the end, are the most likely to " make things happen". The "doers" at the level of public agencies are not always appropriately identified by formal position and interviewees agreed that having someone on the "inside" who is willing "to pick up the ball and run with it" was a key to moving forward. A health provider such as an English-speaking nurse is often cited as the contact that makes the difference between a partnership that is primarily a formality and one that leads to effective community support. In fact, the joint efforts of nurses and CBO volunteers were frequently cited by directors and coordinators alike as the most fruitful thereby lending credence to the opinion that cutting back on professional nursing positions while proposing a health program using community support as its key component is poor planning. When Anglophone nurses and doctors were "insiders" of public health 
institutions by virtue of being on staff, the network needed as a bridge between health planners, health care providers and the local Anglophone population was no doubt fashioned as part of their daily interactions and without the pressure of being evaluated as an "add-on" venture with only short-term funding.

For community-based organizations representing Quebec's Englishspeaking rural communities the standard partnership approach does not stand alone and they tend to operate on at least two fronts - formal avenues for engagement and informal networking. The latter does not replace the former but the configuration of the two is subject to variance with each new context whether different regions, different time periods or even between agencies in the same region. In their words, "you never know what you'll be handed and it can always change". There is no standard way of networking. It is easy to learn who occupies the key institutional positions the contract with Health Canada requires public partnerships to include but it takes time to decode the informal lay of the land and then to create a place for creating community support within it.

Sometimes the formal avenues are simply pretexts for getting the real work done as in "They give us a legitimate entry point", sometimes the formal alliances do turn out to include the "doers" themselves and sometimes they constitute major obstacles that have to be "gotten around". The conditions for the latter are not 
well considered in the design of the partnership approach but they are perhaps even more important in contexts like that of Quebec's language minority who are notably absent from the health sector labour force. But then, is that not the external position that all "lay" communities and community sector players must by definition assume in order to be eligible for social economy partnerships to improve their health? This is far removed from the ideal of public health care as universally accessible.

\section{Generalist versus Specialist}

Unlike the specialized nature of the health agencies with which they are to partner rural community-based organizations are small and diversified. Aside from health and social services they work in a variety of sectors - education, culture and heritage, economic development - and at a number of levels and therefore tend to view the community holistically. They are something of a microcosm of the larger regional population in which they are situated. Provincial health and social service agencies, on the other hand, work strictly within the jurisdiction of health and medicine as does Health Canada as well as the Public Health Agency. They are a specialized sector of a larger bureaucratic structure and largely preoccupied with hierarchical linkages within the sector such as provincial, regional and local aggregates to take one example. Regional 
community organizations also have an advocacy role which is a feature of their mission and an important aspect of being representative of the English-speaking minority. The CBO where I conducted interviews in Estrie was part of the coalition of English-speaking community organizations that joined forces to pressure the government for the implementation of Bill 142 outlined in the previous section. From the perspective of the CBO, their stance as advocates of the English-speaking population of Quebec is quite consistent with a health initiative designed to further the regional access plans which ensued, in large part, thanks to pressure from the coalition and others. From the point of view of the provincial health agencies approached for partnership, however, the association of these CBOs with the activism of the late 1990s may be considered a deterrent to a joint health intervention. In the words of one coordinator,

We started out organizing a one-day forum to bring together local non-profit organizations, our public partners in health and social services and the community. We wanted to present the results of a community survey and health needs assessment and initiate discussion of partnership strategies for improving health and social service access. I had no idea the attitude at the Centre de Sante would be one of reservation and apprehension. This blind-sided me at first. Their contact with Anglophones had not been overly-positive in the past and they reacted quite strongly against the proposed forum. Years ago, the Anglophones had come to be associated with an advocacy approach which had sometimes led to a hostile-sounding community voice. This made it difficult for partners to imagine a positive and productive 
working relationship. The public agencies were apprehensive given their past experience and the community was skeptical as they felt the Centre de Santé had never taken their mandate to offer services in English seriously.

(Female Anglophone, CBO Program Coordinator)

In Estrie, in particular, the general lack of activity in the health sector is attributed to the events of the late 1990s surrounding the closure of the region's English-speaking hospital and the backlash to Bill 142 which included a hardline stance among several CLSCs. According one interview subject, "the result of all of this is that members of the English-speaking are afraid to ask for services, even from designated public institutions, and feel that 'making waves' could result in less likelihood of getting any services at all" (Female Anglophone, CBO Director).

Similar situations across the regions generally lead to the same reaction by $\mathrm{CBO}$ representatives, namely, that partnership is only possible upon the agreement to leave the role of advocate at the door. "We try to be as accommodating as possible". "We have to be non-confrontational and try to reduce the fears of the community". "The language issue must remain in the background". Distancing their endeavors from the activism of the past, without which they would not have the policy framework which provides the grounds for present negotiations with public agencies, means splitting off the role of 
advocate from that of partner. The problem here is that the social economy approach in health has resulted in increasing the responsibilities of community organizations and this has meant the general expansion of the space occupied by health among their other concerns. Many interviewees spoke to the raised profile of their organization in the area of health in recent years and increased funding targeting health specific programs. It follows from this trend that advocacy becomes downplayed within the organization across the board under the pressure to engage public health agencies and assume their newly defined service role. This would be a contributing factor to Quebec's new language peace.

This has created antagonistic relations within the larger Anglophone community between those accused of being the "lamb lobby" and those denounced as the "angryphones" (Westmount Examiner, March 3, 2008). For some the representative capacity of the organization is at stake in the diminishment of its activist role; for others the potential to influence public policy and gain headway in engaging public institutions and agencies promises to be more effective. While the business-like model of partnership appears to offer something of a neutral ground by sidelining contentious language issues, to what extent should CBOs assume an accommodating pose and accept that for the sake 
of the health of their constituency they should downplay their advocacy responsibilities? Or can they? At the level of Health Canada and the provincial Ministry it may be easy to compartmentalize and assume that advocacy is an obligation that belongs to another jurisdiction. From the point of view of community-based organizations, it is not a responsibility they can simply hand over to another domain. For many of the experts I interviewed this poses a difficult dilemma. If they don't fulfill their mandate in this regard, in most regions, no one else will. And yet, what option do they have to accepting the conditions of the favored partnership approach when the plight of the sick and vulnerable among their constituents is at stake?

Health policy makers and managers are located in specialized organizations that require them to think vertically and to seek links among those of every level of the hierarchy from provincial policy, to regional health management, to health providers through to community non-profits and lay communities. In many ways partnership is about the extension of this alignment to include "local communities" (Vaillancourt, Aubry, Kearney, Thériault, and Tremblay, 2004), or put differently, the extension of government bureaucracy reach into the community sector. From the point of view of formal agencies, 'development of the community sector' is about making links between 
community sector actors and public health authorities more effective. For the directors and coordinators located in community organizations, "community development" is consistent with its view of the community as many-sided and growth is improvement that sustains the balance of all of its intersecting parts. While $\mathrm{CBOs}$ have always pursued relations with public institutions to some degree, alliances are typically likely to be more diverse and cross-sectoral and policy which supports their development plan is guided by a 'bird's eye' point of view of the whole..$^{27}$ The community's development plan is informed by "the big picture" while from the point of view of the formal health agencies development of the community sector players means assisting them in influencing, and aligning with, current public priorities. The lack of confidence among Quebec Anglophones in the ability of local leadership to reflect their interests may stem from the fact that in the social economy era their community organizations are increasingly pressured to organize around demands in health, or adopt the 
partnership approach as the general community development model, and this jeopardizes the "big picture" that has traditionally inspired their champions.

\section{Mobilizing the Voluntary Core: Coordinate and Divide}

What may be described as the most profoundly telling, and disturbing, fissure in the partnership approach of Quebec's social economy era is one which community organizations must confront in mediating between the demands of higher-level health organizations and the nature of the local workforce they depend upon to meet those demands. The rhetoric around the promotion of partnerships tends to draw a deceivingly unproblematic connection between inter-agency alliances and improved health outcomes. My expert interviews revealed that for those who must operate in the obscure area between the two there is a complex labyrinth of factors that challenge any such passage. In the case of my interviewees the logic is that improving the position of the community with respect to access to quality health and social services, a key health determinant, will result in improved health status. This is consistent with the logic of Health Canada funding. Public partnerships are promoted as a vehicle for greater "social inclusion" and "full citizenship" both of which imply improved availability of public health resources. The problem is that the actual labor of closing the gap between services and the targeted community is to be 
largely undertaken by that same community. In other words, those who are most vulnerable by virtue of their disadvantaged position with respect to the conditions of health are those who must undertake the labour to improve health care access (Desjarlais \& Moisan, 1999).

Thus far in this chapter I have demonstrated that the partnership itself, and the realization of the influence of local communities upon the decisionmaking of health policy makers and managers, is the precarious outcome of much labor. Still, if successful, this is only the starting point in supporting communities to "mobilize"28 in response to their particular health challenges. As mentioned earlier, the idea is for partners to help the community help themselves. This is justified with arguments borrowed from both the supporters of de-institutionalization and feminists supporting the empowerment of women in health (Armstrong, 2007, Conseil du statut de la femme, 1999). But what if the community consists of the physically and mentally ill, the aged, members of lowincome households, and exhausted unpaid family caregivers conscripted ${ }^{29}$ long

${ }^{28}$ This term is placed in quotations because it is borrowed from popular terminology and its meaning is in the process of clarification in course of this section

${ }^{29}$ For further discussion of conscripted nature of unpaid family caregiving see the (1997) National Forum on Health (Ottawa: Minister of Public Works and Government Services), "Values Working Group Synthesis Report", p.19 
ago by virtue of the long-term scarcity of public services? What if their marginalization from public health institutions means their general health information has been compromised and this includes competence with administrative procedures typical of formal organizations? Far from the empowerment promised, in their case, the exhortation to "mobilize" and to rally around self-service in health may be the tipping point which sends their health status into further decline. And, of course, the ultimate irony is not merely that they are expected to pay more for the self-serve opportunity than for the fullservice they once enjoyed from public health institutions, as after all, that is fairly widespread among all citizens. Even more difficult to come to terms with is the fact that the segment of the citizenry who are the most marginalized from public health resources must compete with each other for this reduced offering and some will not gain entry through partnership initiatives. Those who either already enjoy superior access to public resources or can afford to pay for private health care will likely benefit both in terms of health and social cohesion.

The state of community human resources is a crucial consideration when it comes to CBOs undertaking actual activities (activities such as a directory of services in English, monthly sessions with professionals on diverse health related topics, an English language caregiver support group) to extend the reach of 
public provisions to their underserved population. For the community-based organizations serving English-speaking Quebec in the regions participating in the CHSSN partnership initiative, this means turning to the one paid coordinator they gain and their bank of community volunteers drawn from their target population. The smaller rural community groups the CBOs coordinate often have little experience with bureaucratic procedures and tend to be motivated to use their volunteer time for "people work" not "paperwork". Partnership means training in these higher-level procedures and modes of communication.

We (coordinators) were given training sessions to learn how to
deal with applications and negotiations with public partners.
Writing strategic action plans is not something everyone knows
how to do. We had to learn this and then pass our training on to
our groups across the region.
(Female, Anglophone, CBO Program Coordinator)

The key observation of CBOs with respect to this aspect of partnering for health is that any attempt to tighten the coordination of their unpaid workers and streamline their productivity around formal requirements is plagued with the rise of antagonisms among them. Frustration with evaluation procedures, for example, is expressed in the surveys of CBO staff conducted by the evaluators of the CHSSN Networking and Partnership Initiative. Evaluation and increased accountability means less discretion and leeway to adjust to the diverse 
situations and health concerns that face coordinators and volunteers on the front line. Tensions arise around the gap between government priorities and procedures and pressing community needs. And generally, in the small world of local community organizations evaluation and monitoring are not tools for generating trust but in fact have the opposite effect (Edmondson, 2003).

The coming and going of an overextended volunteer labor force represents a challenge to CBO's which by virtue of their contract with public partners must plan and coordinate the efficient production of measurable and fundable outcomes.

The networking approach means individuals who are not earning huge amounts, who may or may not have special qualifications, are expected to sit down with DGs and negotiate tough stuff. Our quality of health as a minority is depending on this. There is the question as to whether what is expected of these coordinators is in line with the salary and conditions of work. And the off-loading of health care responsibility to the community, especially to women, appears likely to accelerate in the near future. We also manage our volunteers who are wonderful but they are vulnerable to burn-out and there are no fresh troops to relieve them.

(Female, Anglophone, CBO Program Coordinator)

There is also the larger problem of the depletion of the workforce altogether as the largely senior volunteers that CBOs are so dependent upon are not being succeeded by newcomers (Pocock, 2006b). 
As outlined in the previous chapter, and supported as a general trend by extensive research literature, the robust volunteer base that Anglophone community organizations have enjoyed in the past is not a renewable resource they can assume will be endlessly available in the future. As a scarce resource so crucial to the health outcomes of the partnership approach, access to the volunteer core can become a point of struggle between community organizations within a region where both are engaged in inter-agency health partnerships. In Estrie, where the English-speaking population is advanced in the aging process and characterized by an absent middle generation among their volunteers as well as few youth joining in the footsteps of their elders, antagonism between community groups is evident not only in the competition for funding but also over a shrinking unpaid labour force.

We met a lot of resistance and resentment at first from some other groups in the region. I think part of it was that we needed to take more time to do the groundwork initially. People needed to understand that we were not trying to expand our territory or interfere. One community organization, for example, felt that our program would interfere with their mandate even though this particular group was not a regional association, but rather a local one covering a much smaller geographical area.

(Female, Anglophone, CBO Program Coordinator)

As interviewees explain, at one end much depends on "having the ear" of your public partners and the rise of competing groups sending different 
messages may lead to an impasse. There is much concern about controlling the message at the level of public health policy. At the other end, community organizations may find themselves with distinct jurisdictions according to administrative levels but in fact overlapping in terms of the geographical territory from which they draw their volunteers. In other words, volunteer concentrations do not necessarily align with administrative boundaries. An English-speaking doctor, nurse or social worker willing to volunteer to attend an information meeting for Anglophone seniors, or a family caregiver support group, is a contact who is in high demand and one for whom groups may feel they must compete for access.

In the struggle over human resources the missing middle is a stumbling block. The fact of fewer family members in proximity as the result of mobility patterns as well as middle-income professionals in the public health sector employed as health providers, managers and directors than in the past affect the volunteer workforce available to community organizations. Volunteers tend to obey fairly strict linguistic lines in their choice of volunteers activities and the participation of youth outside their schools is a challenge for both the language 
majority and the minority..$^{30}$ The more concentrated the voluntary core, the more likelihood of too few doing too much, and the lowered likelihood of sustainability. The need to diversify the sources of human capital is suggested but the prevailing situation of dual-earners already overbooked with familybased care leaves few options to explore.

While the past involvement of Quebec's English-speaking community organizations in confrontations around language issues in the health sector can be seen as a disadvantage in pursuing public partnerships, in important ways the memory of its senior volunteers who are the keepers of this same past offer a valuable critique. Their long view of the present situation of their community and community organizations points to the way different meanings of "mobilization" have come to be collapsed into one in the latest social economy era. As the interviewee points out below, there is the mobilization that is "joining forces to bring about change" and the mobilization that is "working hard" as opposed to a state of passivity or inactivity and the latter should not be taken for the former.

${ }^{30}$ According to the CROP/CHSSN Survey on Community Vitality (2005) the main language used in volunteering among Anglophone respondents was English at $68 \%$, both French and English at $16 \%$ and $15.9 \%$ of respondents reported using French. (Pocock, 2006b: 29) 
When we stood to lose our schools we gave of our time and came together to do all we could. We really had something to lose. But, what are we fighting for now? We've lost our institutions; we've lost our health professionals; now we have some majority institutions which may or may not offer English services. Of course we're willing to work hard to provide some health care for our family and friends but this is not about joining forces to bring about change so things will be different in the future. If our loved ones were not at stake we would refuse the volunteering because in a way the more we are willing to do it for free the less likely any change in health care is going to occur.

(Senior Anglophone Male, volunteer)

As this volunteer points out, if recruiting volunteers has become a challenge maybe it is not because of apathy or indifference but a critical resistance to the exhortation to work harder disguised beneath the facade of new activism in health. ${ }^{31}$ It is one thing to live in a world where care for the suffering and vulnerable is predicated on their level of productivity; it is another to invite our youth or new arrivals to perpetuate such a world as an instance of a social movement towards a more just society.

\section{Conclusion: Muting Dissent}

A close look at the proposed partnership between Quebec's public institutions and the English-speaking communities of its rural regions occasions

${ }^{31}$ Smith and Kulynych (2002) are among others who demonstrate how terminology may be used in such a way as to blur important analytic distinctions such as we see in the case of the term 'mobilization' in policy documents promoting the partnership approach.. 
what is perhaps the clearest demonstration of the incompatibility between the legacy of Quebec's years of language-based nation building and its recent social economy approach in health. The partnerships they are required to form for community support and empowerment are with the very same government bodies that have participated in their marginalization to begin with and in relation to whom their disadvantage is most apparent. Evidence from my research supports the claim that the trust and empathy that are the preconditions for contractual partnering relations between majority health organizations and local communities are not met in the case of Estrie's minority communities nor are these conditions necessarily transformed when the much promoted vehicles for influence are undertaken. Cutbacks and restructuring in health increase the pressure upon local communities to conform to partnership criteria (determined largely by francophone public agencies with whom they must partner) for much needed community support with the result being the muting of dissenting voices and new local internal oppositions. 


\section{Chapter 5 - Conclusion: Lessons Learned from the Case of Estrie}

\section{Introduction}

The case of Quebec's aging minority language communities located in the rural Estrie region has proven to be fertile ground for the testing of a number of important propositions shaping current health policy. It has also been an opportunity for lessons concerning case-study research and its particular value in working through the problem animating my doctoral study. To restate the problem from my dissertation proposal, what happens to Estrie's minority language communities in Quebec's social economy era? And later from Chapter One, how does the promotion of social solidarity in health, a defining principle of Quebec's social economy era, coincide with solidarity's decline? Or put differently, when are strong social ties, such as those evidenced among Quebec's rural minority language communities, a weakness?

While an in-depth single-case study my inquiry is also 'multiple' in a number of ways. Rather than exploring a single aspect across several cases, family caregiving for example, my study is multiple in the sense of exploring several aspects, and the internal linkages between these aspects, of a single case. It is also multiple in Ragin and Becker's (1992) sense of several research techniques, including statistical profiles, survey findings as well as interview 
narratives, which result in "ideas and evidence that may be linked in many different ways" (Ragin and Becker, 1992: 225). Each research procedure I employed played an important role in yielding a "field" with sufficient "disciplinary force" (Geertz 1995) to result in what Flyvbjerg (2006) refers to as the "falsification" of preconceived views, assumptions and hypotheses. Some of these are views maintained by a widespread research and policy community, others are views which tend to be more restricted to those sharing the particular milieu of my case subjects and still others are common to both. The result is a single study that offers different insights to different audiences.

The contribution of my doctoral project to current debate with respect to the social economy approach in health as well as the state of research upon which it rests will be elaborated in the course of this chapter.

\section{Estrie as a Critical Case}

Personally, as researcher, health policy analyst and having lived a greater part of my life in the Estrie region, casing this case has meant something akin to what C. Wright Mills describes as being "suddenly awakened in a house with which they had only supposed themselves to be familiar" (Mills, 1959). The hypothesis with which I initially embarked on my study of Estrie's English- 
speaking communities required revision quite early on in the process of gathering observations. The frame I fashioned using language, generation and gender strongly resisted the account that I had anticipated would be confirmed. Rather than support my thinking, this frame shed light upon a corner of "the house" generally left in the shadows and its observation has served as a point of resistance to any attempt to return to my original position. Case studies are replete with recorded moments of such "awakenings" and I reacted with a genuine audible gasp on more than one occasion, not only to raw findings, but to the surprise that emerged in producing a narrative constrained by their intersection.

At the outset I presumed that the rural minority language communities of Estrie would be an example of a constituency that would thrive under the auspices of social economy policy. To me, Estrie was a critical case in the sense of if the propositions of the social economy approach in health are not validated in this case, they are not likely to be validated in many other cases. Estrie appeared to offer the optimal conditions for the success of the community development approach therefore if it did not work in this context it was hard to imagine it succeeding in the event of less than optimal conditions. 
My original thinking was reinforced in a number of ways. There is burgeoning interest among academics and policy-makers concerning the role of social capital in healthy communities and how it can be addressed by public policy (Putnam, 2000; Baum, 1999; Muntaner, Lynch and Smith, 2000; MacInko and Starfield, 2001). Critics of the social capital approach ${ }^{32}$ in health claim it is heavily influenced by a model of capacity as "part of 'traditional communities' characterized by civic engagement in voluntary organizations, good neighborliness, and often churchgoing population" (Mackian, 2002: 205). While critical of what could be called a 'bias' towards traditional communities, this school of thought claims that the approach advantages these communities over other types. The privileging of traditional communities typically exhibiting the characteristics cited suggests, albeit in a back-handed way, that there is more likely to be an alignment between this health policy approach and rural communities such as those located in Estrie. In other words, while seeing thirdsector development as limited in that it fails to be relevant to non-traditional social groups, this school of thought actually supports the assumption that the

\footnotetext{
${ }^{32}$ As explained in Chapter One, while the terminology differs the initiatives in health designed to enhance "social capital" share the same principles as the social economy approach. "Third-sector development", "non-profit or voluntary sector" and "community development" are terms used more widely in English Canada.
} 
rural communities of Estrie, insofar as they exhibit traditional characteristics, should be suited for such a model.

Many of the characteristics of Estrie's minority language communities with which I was intimately familiar, and are confirmed by research findings, appeared to dispose them to being model participants and partners within the community development approach. As explored in earlier chapters, these include a long- standing ethic of self-reliance among a primarily Protestant population, a history of voluntarism and membership in voluntary organizations including those in the health sector that exceeds that of the majority, 'community' and 'neighborliness' as cherished values and a tradition of community- supported family care for vulnerable groups including the elderly and the ill. All of this suggests the level of community capacity and preparedness expected of a community well-disposed to benefit from prevailing policy principles and the restructuring of public health institutions. Even the greater likelihood to be married compared to the majority population is taken as an indicator of a greater likelihood of community sector participation.

The current approach in health is also consistent with research which advocates deinstitutionalization and this further supported my original hypothesis. There is a substantial sociological literature (Goffman, 1961; 
Gubrium, 1997; Illich; 1975) which may be understood to support proponents of social economy in seeking to empower "users and workers" to be more than consumers of public provisions by also being "owners" of the process to which they are subject (Roeher Institute, 1993; Jetté et al., 2001; Vaillancourt et al., 2000). Offering psychiatric patients and elderly clients with special needs the opportunity to remain in their environment, and putting an end to hospitalcentered health care while promoting patient autonomy, is seen as a cure for a host of health problems which actually stem from institutionalized public care settings. There is a substantial literature which draws a link between the quality of social support networks and aging well (Cannuscio, Block and Kawachi, 2003; Keating, Otfinowski, Wenger, Fast, and Derksen, 2003; Stobert and Cranswick, 2004; Fast, Keating, Otfinowski and Derksen, 2004; Nocon and Pearson, 2000; Zunzunegui, Kone, Johri, Beland, Wolfson and Bergman, 2004). The notion of shifting responsibility from centralized public agencies to the small community organizations and families of local communities, accompanied by increased community level support, appears to be an attractive proposal from the point of view of Estrie's English-speaking population in several ways.

First, increasing the influence and decision-making of local communities who are geographically dispersed and often relatively diverse with respect to 
their socio-economic circumstance offers an alternative to a 'one size fits all' approach in policy. The health needs and resources of the English-speaking communities of Quebec's rural regions, for example, are not presumed to be identical to those living in the urban Montreal region. It is also assumed that this approach would extend the reach of health and social services to more isolated populations and to populations targeted for high levels of home care.

Second, community-supported family care offers a solution to the need for culturally appropriate care particularly for the large cohort of Anglophone seniors who face intimidating language barriers in seeking care through majority Francophone public institutions. The point here is well made by a story told by a former director of a community-based organization in Estrie. The director and a number of other representatives from the community were being given a tour of a facility for the elderly in the region and throughout the tour questions and answers were exchanged in both languages. At one point one of the elderly residents of the facility began speaking quite loudly in English. This was received with shock from the health professionals who had not heard the patient speak for a long period of time and had in fact presumed the patient to be incapable of speech. It was concluded that the rare event of hearing English-speaking voices had stimulated communication. 
Third, the social economy approach is in many ways consistent with feminist literature which calls attention to the "medicalization of women", and the need for women to take charge of their own bodies (Sherwin, 1992; Morrow, 2007; Desjarlais and Moisan, 1999). Also, from the point of view of Estrie's English-speaking communities, the shift in focus to the 'local' and the promise of increased health care support and decision-making power for users and workers at this level suggests the arrival of the long delayed recognition of unpaid family workers, largely women, who are responsible for meeting the bulk of homebased needs. Given the extent to which women are implicated in formal and informal health care, both as patients and as workers, logic suggests that the improvement of the situation of these minority women is a certain route to improved health literacy, health care and health for their communities.

Despite what seemed a solid and well-supported hypothesis my research procedures detected weaknesses which necessitated a shift in my position. Estrie continues to stand as a critical case. However, analysis of the evidence that has emerged supports the argument that Estrie's minority language communities are disadvantaged by the prevailing policy of recent years. The alteration in my position is expressed in the change of question statements from that of my dissertation proposal to Chapter One of this document. The shift from what 
happens to Estrie's minority language communities in Quebec's social economy era? to the later how does the promotion of social solidarity in health coincide with solidarity's decline? indicates my growing preoccupation with the discovery that these seemingly ideal candidates had in fact been disproportionately disadvantaged with respect to certain key conditions of health in recent years. The hypothesis that such rural minority communities would thrive under the latest round of social economy policy, a logically solid assumption held by both critics and supporters of social economy alike, has been shattered largely due to the heavy blow exerted by first-hand observations of the practice of community care. In fact fashioning an in-depth look at the state of informal caregiving ranging from Canadian census data and broad-based national surveys comparing officiallanguage groups, to interviews with family caregivers, volunteers and $C B O$ workers serving English-speaking communities in Estrie, has led me to view prevailing policy as itself a health risk.

\section{Casings: Language, Gender and Generation}

Casing: any frame or framework around an opening such as a door or window. The action of framing openings.

\section{Oxford Dictionary}

In the course of my work I have found drawing the similarity between the operation named by the term "casing" in the world of architecture, or "framing 
openings", and that of social research to be useful in a number of ways. One use of the analogy is as a reminder that the production of a case is an achievement in and of itself. Much discussion around the value of case studies revolves around the subsequent use to which they may be put, for example, do they lead to generalizations? Is a single-case study sufficient or are broad- based random samples required to meet the criteria of scientific validity? When are cases comparable? (Flyvberg, 2006) It is all too easy to forget what is entailed in the production of a narrative and finding the thread that links the pieces of sometimes radically diverse types of evidence. Framing openings or "gaps" in what would otherwise be opaque and impenetrable; altering the play of shadow and light within a structure; offering inhabitants an altered position with respect to old partitions. The narrative is not simply a means to an end outside itself but "is itself the answer". (Nehamas, 1985: 163-64) The intersection of language, gender and generation leads to insight into an otherwise ignored world and the case of Estrie stands as a point of resistance to the use of framing which permits its ongoing neglect.

One of the claims of my dissertation, strongly supported by both qualitative and quantitative findings, is that language matters in Quebec when it comes to third-sector development in the health sector. The distinction between 
the French-speaking majority and English-speaking minority in terms of their participation in the voluntary sector, both today and historically, is noteworthy and a crucial factor in attempting to account for their different experiences with respect to health sector restructuring in recent years. What is astonishing is the extent to which language has disappeared in the last decade or two from Canadian social research and policy formation in general despite the fact that it exerts such a determining influence on the experience of different social groups. This conspicuous lacuna is most evident in Quebec considering the proliferation of language-based research that emerged in the 60 s through to the 80 s that served as the foundation for legislative and institutional change and which continues to exert definitive power in the daily lives of citizens today. The few reports that have emerged, such as that of the Commission des États généraux (Quebec, 2001) testify to the improved state today of the French language and French speakers across Quebec. A recent study for the C.D. Howe Institute provides ample evidence of the reversal of the economic inequalities that have long been the central issue in the language conflict in Quebec and Canada (Vaillancourt, Lemay \& Vaillancourt, 2007). Very little attention has been given to the exacerbation of the bi-modal character of Quebec's minority and the rise of the growing Anglophone underclass that has coincided with the empowerment 
of Quebec's majority. Anglophones figured largely negatively in the narratives that emerged during the years of the Quiet Revolution as captured in such generalized terms as "capitalist", "colonizer", "Les anglais", "les autres", "Westmount Rhodesian" which for many English-speakers, perhaps particularly those located outside of Montreal, storied a life bearing little resemblance to their own. The disappearance of language-based research in Quebec's latest era of language peace has meant the old stories have lingered on despite the radical change in the circumstances of the characters. One contribution of my work, particularly my use of demographic profiles, has been to provide evidence of this change.

Federally, the Department of Canadian Heritage conducts research mandated by Canada's Official Languages Act through its Official Language Support Program. Their regional profiles project, developed in the last 7 years, has been indispensable in allowing me to conduct comparisons of official-language minority communities (OLMCs) across Canada. The Office for the Development of Official-language Minority Communities at Health Canada has little research capacity but offers programming for improving access to health services for official-language minorities across Canada. Their approach to improving the health of these populations is built primarily on knowledge of language barriers 
at the level of patient-clinician communication, their impact on health service access and the efficacy of linguistic access service interventions (Jacobs, HM Chen, Karliner, Agger-Gipta and Mutha, 2006; Bowen, 2001). Some research has emerged in recent years using a health determinant framework but issues that fall outside of communication barriers at the point of access to health services are largely viewed as beyond their official mandate.

Both of these government agencies rely on research built around largescale provincial aggregates using national census samples which are invaluable in drawing out the unique position of Anglophones in Quebec and that of these Canadian minority communities vis-à-vis the majorities with whom they share their provincial territories. ${ }^{33}$ The regional profiles project at Canadian Heritage has taken steps to break provincial aggregates down into smaller geographical and administrative units, Health Canada less so. These national samples tend to conceal sub-provincial realities which may differ radically from a provincial average. Quebec's official-language minority is an interesting case in point as its high level of concentration in the Montreal region means the characteristics of

${ }^{33}$ The majority/minority index used in the course of my research is borrowed from the "Communities in Context" regional profiles initiative of the Department of Canadian Heritage's Official Languages Support Programs Branch. 
this group figure predominately in any averaged picture, resulting in a distorted portrayal of the more rural regions. Even English-speaking Montreal itself is far from homogeneous such that the population of certain parts of the region vary notably from a regional portrait. It may be presumed that sub-provincial portraits are the responsibility of provincial agencies who are more engaged with services but in the case of Quebec, for example, official-language minority communities are not granted recognition nor is language a typical variable in targeting vulnerable groups in health. The choice of designated access points for health and social services in English points to the fact that consideration of language is the exception rather than the rule. Social economy policy focuses on the empowerment of the local but being included among the local is problematic without sub-provincial and even sub-regional level findings nuanced with a language lens. My multiple method case study approach exploring a single region uses language as a vehicle to link observations from the level of family household and to those of a more aggregated provincial collectivity.

As demonstrated in Chapter Five, the omission of language is tantamount to denying the history of a segment of Quebec citizenry which parallels, but also diverges, from that of the Francophone majority. Majority and minority language groups, long defined along linguistic lines, vary markedly with respect to their 
links to the public institutions of the province and in the nature of their relationship with the government with whom they are required to form partnerships as the favored strategy for improving health outcomes in the social economy era. Absenting language in the name of "language peace" does not produce a level playing field among local communities in bargaining for state support but in fact entrenches the gap between those included and those marginalized with respect to entitlement to, and use of, public resources. Where health is dependent on the most successful bid those most in need are likely to be the ones forced to get by on reduced offerings.

The aging of the Canadian population is widely acknowledged in social science research and health policy through increased attention to the growing number of seniors and their particular health and health care needs. Seniors are recognized as a vulnerable group among others and there is widespread awareness of the need to adjust health and social service access in accordance with the demands of this age cohort. Our habit of mind is to isolate this group as an age aggregate rather than as a generation whose life experience stems (at least in part) from, and has consequences upon, other related generations. The social economy approach in health is itself promoted as an attempt to improve community support to home- based care for elders but often 'elders' in the 
abstract without the nuance of particular context. My doctoral questionnaire was important here in providing an understanding of the state of social support in which Estrie seniors are located including support from family, the community (individual and formally organized) and the increasingly rickety bridge between public health institutions and marginalized Anglophone households. My interviews taught me the extent to which support, even so-called voluntary support, is increasingly provided with a price tag attached.

The intersection of language and age in Estrie reveals not only different rates of aging between majority and minority groups but notably different age structures and inter-generational experiences co-existing within the same regional territory and subject to the same health programming. The nature of inter-generational relations is all important in family-based care and key insights emerge upon considering how language specific aging processes are different yet inter-dependent as well as changing over time. The two most significant forces which explain aging in the case of Canada and Quebec's majority are the drop in fertility and death rates. These are at work in the aging of Quebec's minority language communities in Estrie as well with the added dimension of the notable selective out-migration of its middle-class, middle-generation, Anglophone group. This has implications for how they fare under social economy policy 
considering the key historical role of this group in the voluntary sector and in family-based caregiving. A view across generations suggests the conditions which supported the "long civic generation" of an earlier epoch in Estrie, and which they in turn provided, has changed quite radically in the last 30 years. The critical situation of Anglophone youth residing in Estrie speaks volumes in this regard with respect to voluntary sector participation, capacity to pay for health care and likely health status. According to the 2006 census, they face rates of unemployment higher than Estrie Francophones of the same age and higher than the youth of other regional OLMCs across Canada indicating a generation that is much more dependent on government transfers than their predecessors were at the same age. The fact that today's youth were more likely to participate in a virtual global network than their elders was acknowledged in family interviews but generally accompanied by the wry observation that this would not be a likely source of support if they were to fall ill or need home-based assistance in their later years.

One of the most compelling insights afforded by the case of Estrie, and strongly supported by evidence gathered through each of the research methods applied, is the extent to which provincial health policy has disproportionately disadvantaged the women of middle and low-income households of aging 
minority-language households. The excessively high level of high-intensity unpaid care performed by mid-life and senior women, particularly unpaid care to seniors, coincides with the shift of caregiving responsibilities from public institutions to non-profits and families. Their well-being, and the quality of health care their households and communities rely upon them to provide, is clearly compromised by existing arrangements. As discussed in Chapter Two, this is due in part to misrepresentation of the interdependency between formal health institutions, voluntarism and unpaid caregiving. The notion of developing a volunteer work force that "fills in" where cutbacks in public institutions have occurred ignores the way the vitality of the informal and the formal coincide. The predicament of the primary caregivers of rural minority households, such as those observed in Estrie, is a critical but neglected indicator of the contribution or shortcoming, in this case shortcoming, of the social economy approach.

One contribution of my work is in providing an argument and an analytic framework - language, gender and generation - for the development of this indicator as an important measure of healthy social policy. While the recommendation for gender-based analysis is well made by both academic and government research, and even language and aging are topic areas in their own right, I contend that the intersection of these themes has not received adequate 
attention. What is revealed through each treated discretely is of value but may cover over the complex experience of the women who live them simultaneously. The neglect of this complexity results in policy which is alert to the unique predicament of women as primary caregivers and the danger the familization of care poses for them but conceptualizes both the problem and appropriate intervention without consideration for the way this situation is compounded by language and inter-generational change. Instead of creating public sector employment for women, the government has offloaded responsibilities onto community-based organizations that operate largely on the strength of volunteer work by women along with a few low-paying and unstable positions. From health professionals of public institutions, community sector volunteers and workers, to family caregivers one cannot ignore the gendered implications of Quebec's restructuring in health in recent years. However, the notion of gender as the dominant category of women's lives falls prey to the assumption of a "generic" female experience which itself becomes a barrier to mutual understanding and genuine mobilization among women for women.

\section{The Limits and Challenges of this Study}

My case study of Estrie is not qualitative work that rejects research that concentrates on large-scale samples with related quantitative analysis. The 
breadth that such samples permit in their broad-based comparisons has provided insights that gave focus and sharpened my face-to-face interviews with experts and families. The detailed observations of the latter provide depth to the former as they explore a practice in all its lived complexity. The different rates of aging and types of age structures of language populations, for example, are a quantitative discovery whose explanatory value is deepened through observations of family households in their routine practice of senior care. And vice versa, broad comparison can transform a seemingly idiosyncratic practice into a collective matter and social issue. The narrowing world a woman from the regions may experience in managing family care, even the exhaustion and stress related illnesses, does not reflect a personal inadequacy but in fact the expression of her membership within a particular social group in a specific time and place.

The multiple method approach lends itself to a study which is able to address several audiences. This is not an attempt to be all things to all people but rather the attempt to come up with a toolbox adequate to the demands of the problem. Restructuring in health during the social economy era is about shifting responsibilities and redefining the relations between sector actors. Fafard points out that the policy-making process involves different decision-makers at different stages (Fafard, 2008). The "breadth and depth" (Flyvbjerg, 2006: 241) 
character of my approach emerged in the attempt to focus on the nature of the "in between" as much as the situation of any given actor. In exploring different aspects of a single case I have been able to draw out the interconnectedness (or lack thereof) of different domains of responsibility in health from public health institutions, the community sector, family household and to a less extent, private sector care services. With respect to the latter, I have been able to frame the gap enlarged by recent restructuring and increasingly filled by paid service providers as the broken bridge between public institutions and minority families referred to as "community support".

While I have made use of a provincial profile of health professionals distributed by language and region my interviews did not include health professionals except when they happened to be included in my conversations with families or $\mathrm{CBO}$ workers and volunteers. This was due mainly to time constraints. I am not aware of work done on this in Estrie but there is no doubt broader Quebec-based work which would supplement mine. I would recommend the Armstrong study for a closer examination of the impact of restructuring in health upon nursing in Canada using extensive consultation and interviews (Armstrong \& Armstrong, 1996). I decided to give priority to the English-speaking families in Estrie and community-based organizations serving 
them as it was apparent their voices were relatively unheard and in need of the forum that I could supply. From the regional profiles I constructed using majority and minority comparisons, along with knowledge of their particular history in the community sector, I observed that Estrie's English-speaking health sector actors were uniquely positioned in the social economy mix and made the decision to make them and their circumstance the target of my interviews. The Survey of Community Vitality (2005) included 3,500 Anglophones and 1,500 Francophones province-wide with 250 respondents in the Estrie region itself. Although I feel confident face-to-face interviews with Francophone families living in Estrie would not have changed what I have learned from my doctoral work, and my interviews with directors of community-based organizations with knowledge of both language groups tend to support this, it is an acknowledged limitation of my case.

Despite my familiarity with the Estrie region achieving access to families for inter-generational interviews, particularly low income households, proved very challenging. In fact, out of concern that my familiarity might unwittingly lead me to select interviewees sharing the same support network I took precautions to target households from different geographical areas of Estrie and different CBO's. The difficulty stems from the fact that senior care is a very 
sensitive issue rife with fear of judgment and often emotional pain. Interviewees were quite willing to share stories of volunteering and much more reluctant to make their unpaid caregiving a topic. As an elder, finding oneself increasingly dependent without family nearby or knowing those who are in proximity are stretched thin both financially and in terms of time and energy, can be frightening and humiliating. This response is exacerbated when one feels abandoned by the public system. Elders often expressed the sentiment that "becoming a burden" was their greatest fear and clearly the policy climate does little to allay their dread. Volunteers and $\mathrm{CBO}$ coordinators supported this in their stories of the great lengths to which their clients would go to conceal their difficulties from their families and friends. Caregivers, on their side, are struggling under working conditions that are unlikely to nurture their desire to offer their lives up for public scrutiny. They often express great regret that the standard of care to which they aspire is placed beyond their reach. I am certain my interviews only touched the surface of the private hardship many Estrie households are living through.

Strictly speaking, my case study of Estrie does not include a class analysis. However, the link between income and third-sector development unfolded within my research through the investigation of generation. The missing middle- 
aged, middle-income group of the generation of caregivers deeply implicated in the latest round of the social economy approach in health distinguishes them from their predecessors. Their absence is felt in many areas that are crucial to the success of the social economy model and explains, in part, the decline of the community with respect to certain conditions of health. Their disappearance as health professionals involved in the planning and service provision of public health institutions, their inclusion in local community support networks as a source of health information and general leadership, their high levels of volunteerism and civic engagement, to name a few, results in a weakening of the community capacity that is valued in the social economy approach. I would underline, however, that the point of comparing generations is not to invoke nostalgia for an earlier epoch. If, as a thought experiment, we were to imagine an economy that could support the return of this absent group it is clear not all the challenges the community is facing would be solved. My interviewees point out, for example, that the position of women as primary caregivers in traditional lowincome minority households is a constant through time and has rarely been ideal. While their responsibilities have been eased at times by better access to public health and social services and a more vital social support network their lives have long been vulnerable to the flux and change of the labour market. 
They have benefited from the presence of a robust local "middle" group in former years but as something of an unintended consequence of their prosperity and activism. Estrie's minority language communities may have gained from the spirit of working class empowerment which characterized the activism of previous generations of both language groups but it is outlived by language barriers which were re-enforced during the same epoch. The return of the "long civic generation" might make Quebec's social economy policy in health 'fit' the English-speaking communities better but it would still do little to directly address the status of the minority women of the regions who continue to play an essential role in the health of their rural households and communities. The lesson of the case of Estrie is more about the fact that Quebec's social economy policy is not organized around the experience of lower-income households to the degree that it must to be effective in resolving health inequalities and less about reestablishing the class distribution of a longed for past. In many ways, the case is about making the past the past not by ignoring or idealizing it but by using it to bring the present into focus. What future are we building today for the young women who will someday soon be the caregiving generation, and crucial health determinant, of Quebec's minority community households? Where will we stand tomorrow with respect to the measure of language, gender and generation? 
Finally, I would like to draw attention to a matter that presently remains a sub-text in my analysis but is deserving of more explicit attention, namely, the uneven distribution of the experience of death and dying associated with the changing patterns of eldercare. In marginalizing aging, left-behind communities such as find in Estrie we also push death to the sidelines and limit access to the encounter of men and women with their mortality and the mortality of their loved ones. On one hand, we have self-contained neighborhoods that are predominantly urban and often composed largely of relocated middleincome families who live with relatively little day-to-day contact with their elders. On the other hand, we have communities for whom attending to the human frailty that comes with added years and the finality of the event of death is a regular feature of their lives. While death is not everything, neither is life without death truly a life. And, what better life than one where the end (s) of life is made a topic for collective reflection? What of the solidarity that is jeopardized when the voice of those marked by their encounter with what has long been named "the great leveler" is silenced? I have not made room in my thesis to explicitly explore the implications of a world where death is denied recognition as a part of life but for those attuned I trust the implicit story can be heard. 


\section{Appendix 1 - CROP/CHSSN 2005, Social Capital Questions, English}

Q34A:

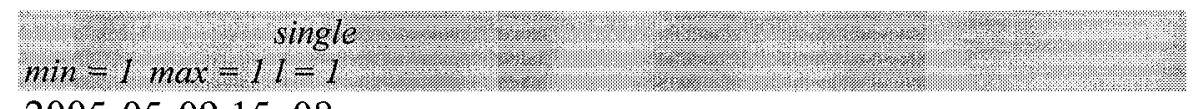

2005-05-09 15:08

In the past 12 months, were you a member or participant in a social club or organization?

\begin{tabular}{|c|c|}
\hline (1) & $\Rightarrow \mathrm{Q} 35 \mathrm{~A}$ \\
\hline 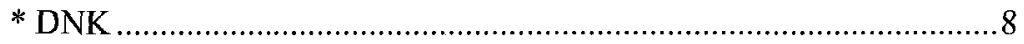 & Q35A \\
\hline 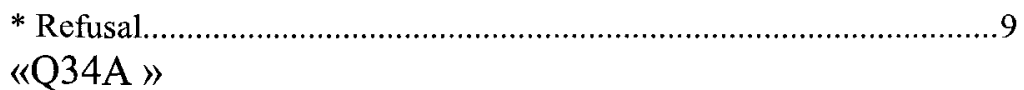 & $=>\mathrm{Q} 35 \mathrm{~A}$ \\
\hline
\end{tabular}

Q34B:

Single

$\min =1 \max =11=1$

2005-05-09 15:08

How important was the language of the social club or organization in your decision to join. Was it extremely important, very important, important, not important or not important at all?

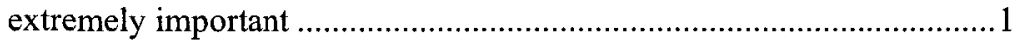

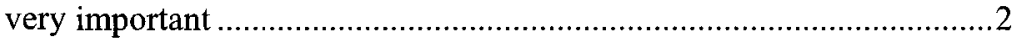

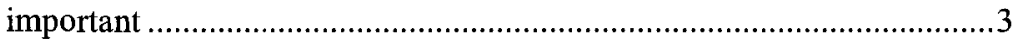

not important ........................................................................

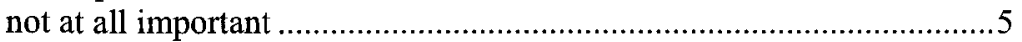

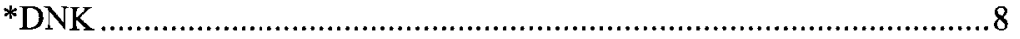

${ }^{*}$ Refusal.............................................................................. 9

«Q34B »

Q35A:

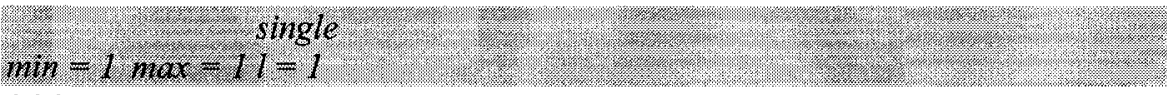

2005-05-09 15: 08

In the past 12 months, did you do any unpaid volunteer work?

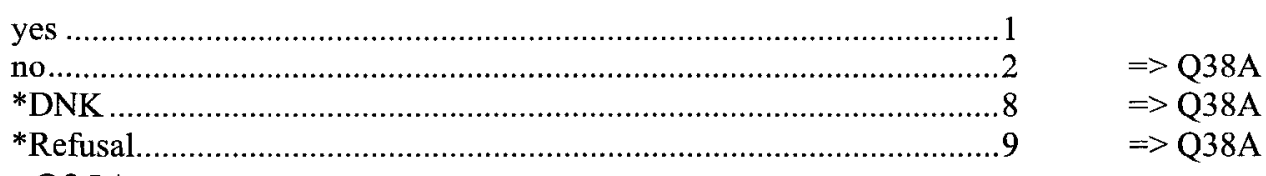

«Q35A » 
Q35B:

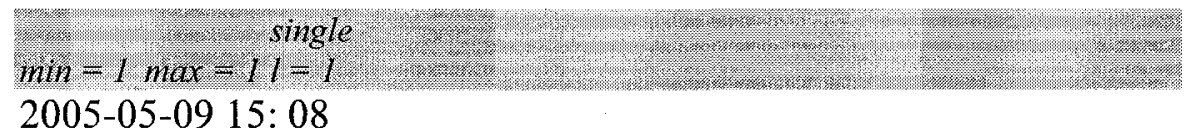

2005-05-09 15:08

What was the main language you used in your volunteering activity?

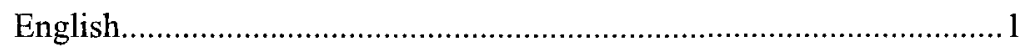

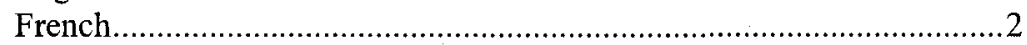

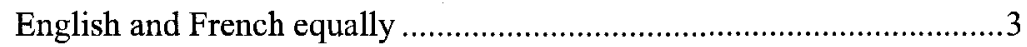

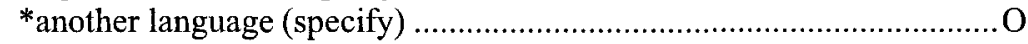

*DNK

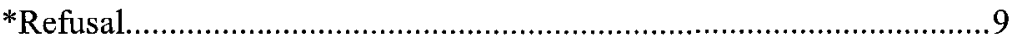

«Q35B »

Q35C:

$\min =1 \max -11-1$.

2005-05-09 15: 08

In average, about how many hours per month do you volunteer? DO NOT READ

over 30 hours per month..................................................................... 1

between 15 hours and 30 hours per month......................................... 2

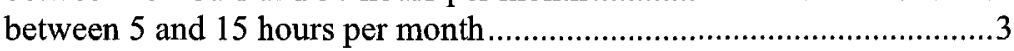

between 1 and 4 hours per month.................................................... 4

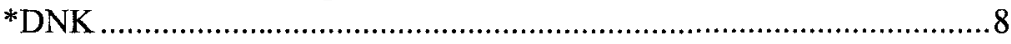

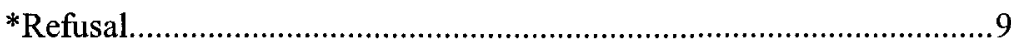

«Q35C »

Q35D:

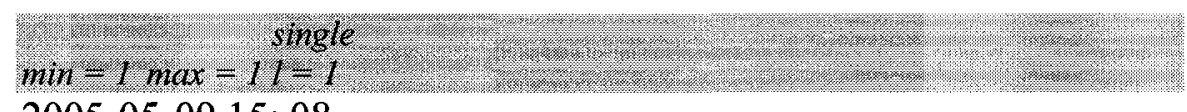

2005-05-09 15: 08

Was your volunteer work done as part of a group or organization?

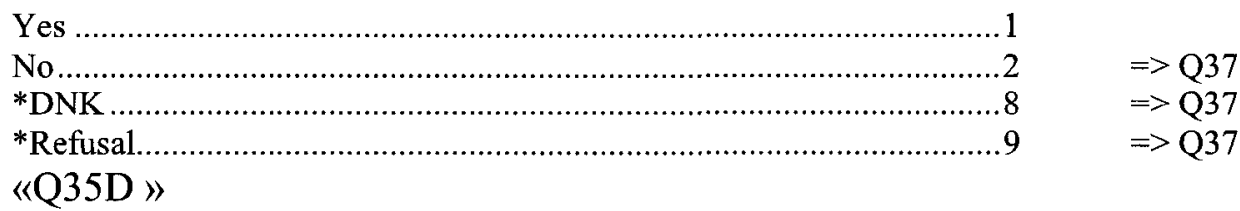




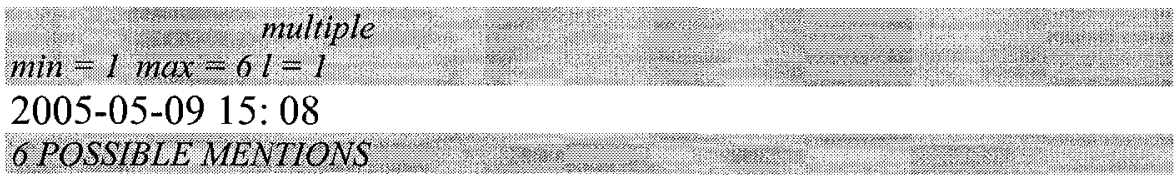

Which of the following types of organizations do you volunteer for? (List by order of most time spent in volunteer activity) READ

school 1

church, synagogue, mosque..............................................................

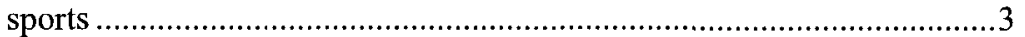

health or social services institution......................................................

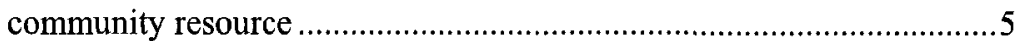

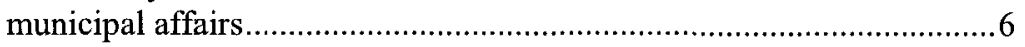

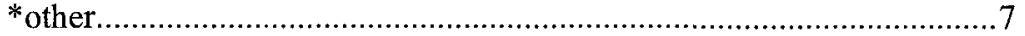

*DNK

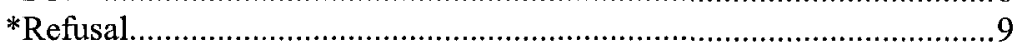

«Q36 $01 »$

«Q36_02 》

«36_03»

«Q36_04 »

«Q36 $05 »$

«Q36_06» »

Q37:

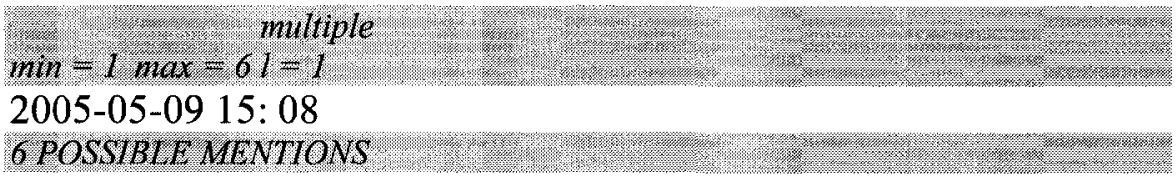

Please think about the type of unpaid help you gave others in the past 12 months. Which of the following ways did you volunteer help?

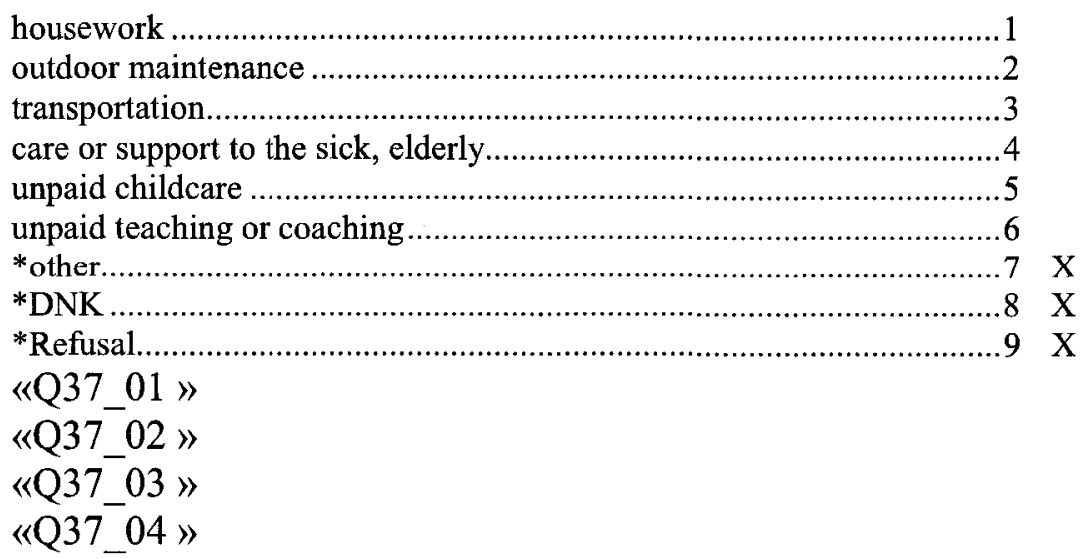


«Q37 $05 »$

«37_06»

Q38A:

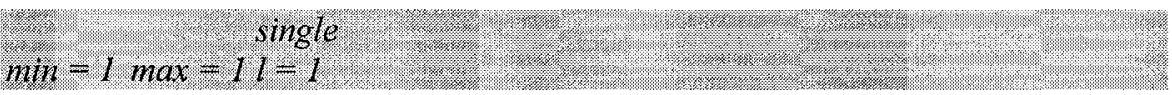

2005-05-09 15:08

Do you know about the activities of a community organization in your region promoting the interests of the English-speaking community in areas such as:

a) health and social services

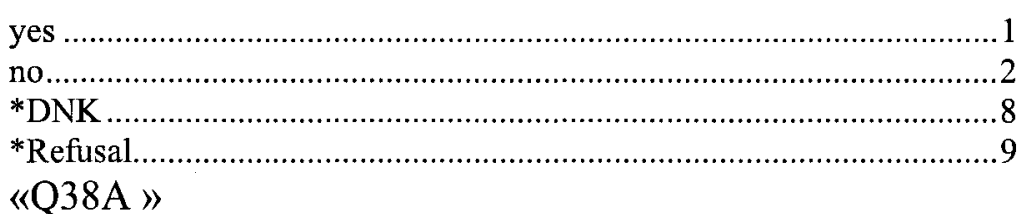

Q38B:

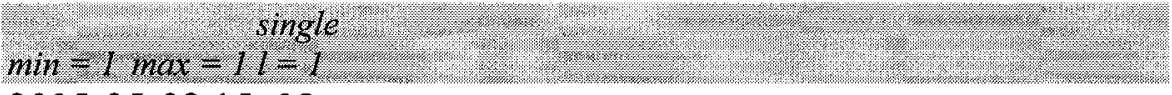

2005-05-09 15:08

Do you know about the activities of a community organization in your region promoting the interests of the English-speaking community in areas such as:

b) arts and culture

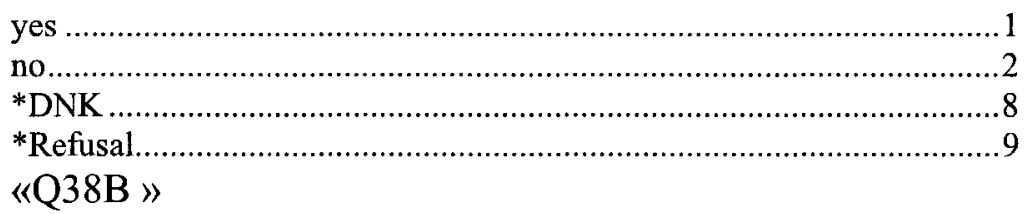

Q38C:

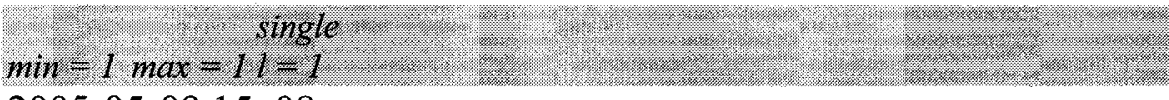

2005-05-09 15:08

Do you know about the activities of a community organization in your region promoting the interests of the English-speaking community in areas such as: 
c) economic development

yes

Q38D:

single

$\min =1 \max =11=1$

2005-05-09 15:08

Do you know about the activities of a community organization in your region promoting the interests of the English-speaking community in areas such as:

d) education

yes no

Q39:

angle

$\min =1 \max =11=1$

2005-05-09 15: 08

Do you feel that your language group through its leadership, its organizations and its institutions

influences factors that affect your daily life?

yes no

Q40:

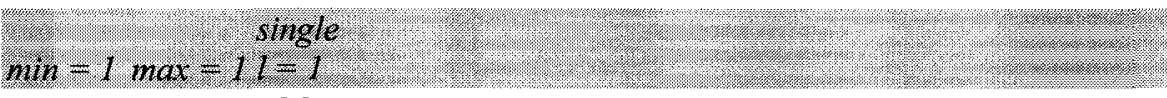

2005-05-09 15: 39

If you became ill, who other than your spouse would you likely turn to for support? 


$$
\begin{aligned}
& =>Q 45 \\
& \text { if } Q 4=\# 6
\end{aligned}
$$

relatives ...................................................................................... 1

friends ...................................................................................... 2

community resource, volunteer or religious organization ....................... 3

public social service institutions (hospitals , CLSC) ............................4

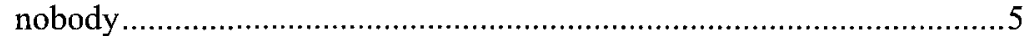

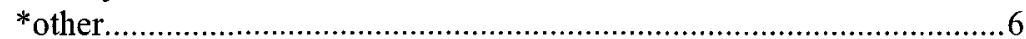

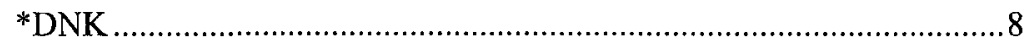

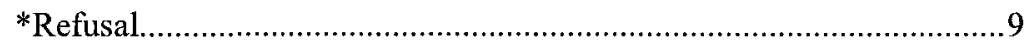

«Q40»

Q41:

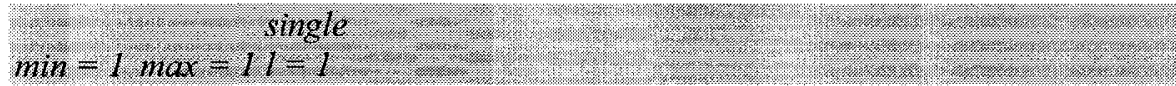

2005-05-09 15:08

Do you provide (unpaid) care for a person living outside your household?

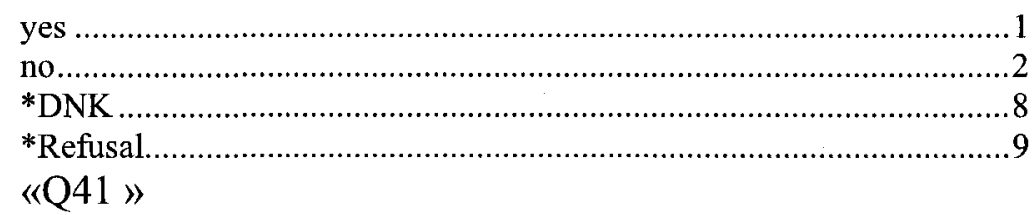

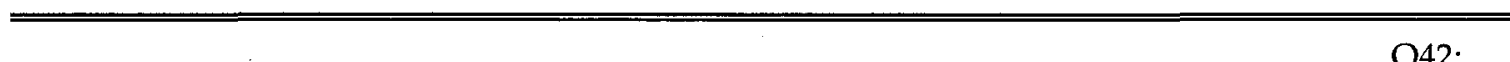

Q42:

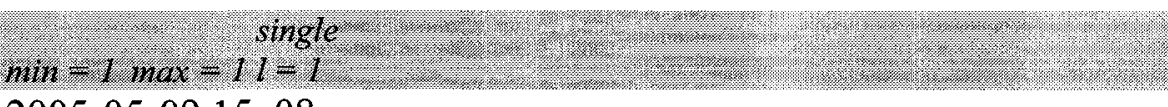

2005-05-09 15:08

Do you provide (unpaid) care for someone other than a relative?

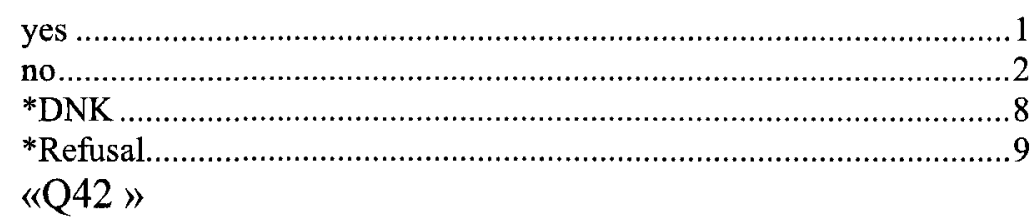

Q43:

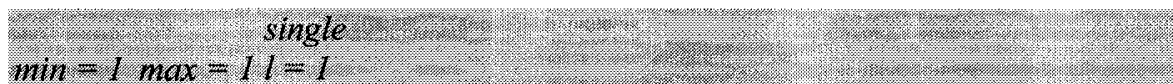

2005-05-09 15:08

Do your social contacts with friends generally take place... 


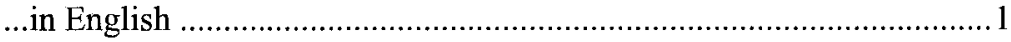

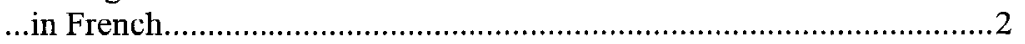

...Both English and French ..................................................................

...or in another language ..........................................................................

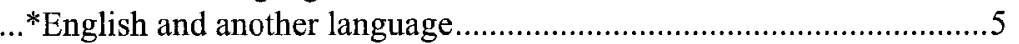

...*French and another language ................................................................. 6

...*Both English and French and in another language ............................. 7

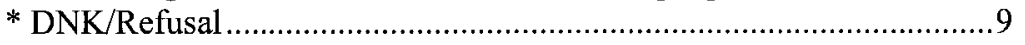

«Q43 » 


\section{Appendix 2 - CROP/CHSSN 2005, Social Capital Questions, French}

Q31:

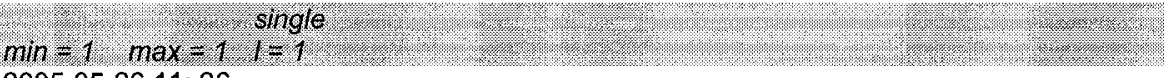
2005-05-26 11:26

31. Au cours des 12 derniers mois, avez-vous été membre ou participant d'un groupe ou organisation sociale?

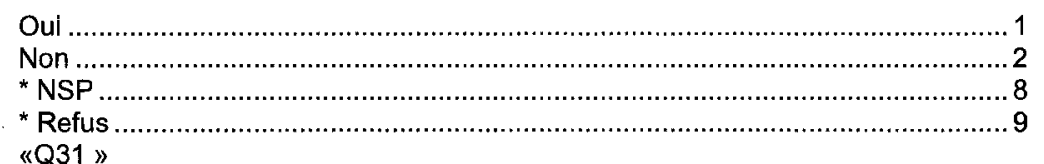

«Q31»

Q32:

$\min =1 \cdot \max -1: 1=1$ 2005-05-26 13: 40

32. Au cours des 12 derniers mois, avez-vous effectué du travail bénévole?

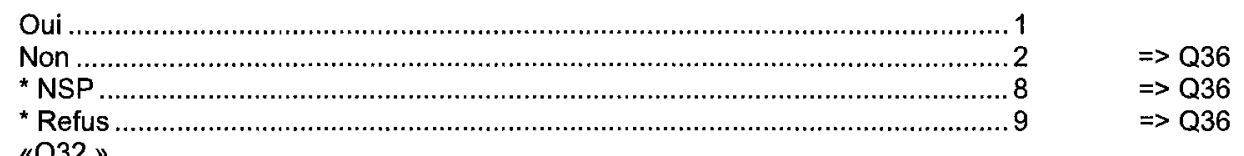

«Q32»

Q33:

- single $\min =1 . \max =1 . \quad 1=1$ 2005-05-25 17:09

33. En moyenne, environ combien d'heures avez-vous consacré par mois à faire du bénévolat? NE

PAS LIRE

plus de 30 heures par mois ...

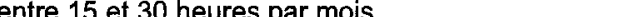

entre 5 et 15 heures par mois ......................................................................

entre 1 et 4 heures par mois .......................................................................

* NSP.....

* Refus

"Q33 " 


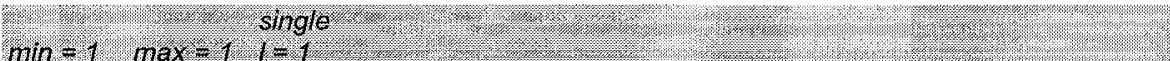

$\min =1$. $\max : 1: 1=1$. 2005-05-25 17:09

34. Votre travail bénévole était-il effectué au sein d'un groupe ou organisation?

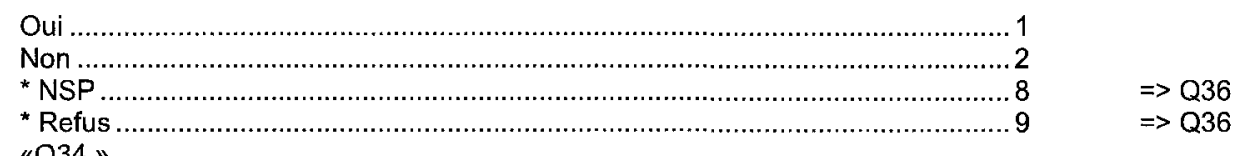

Q35A:

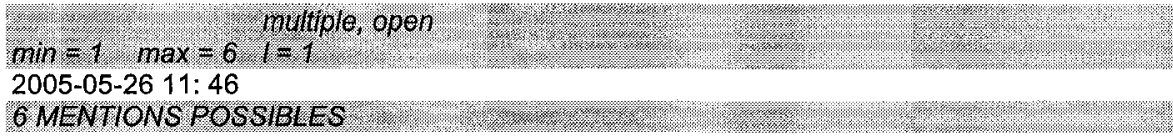

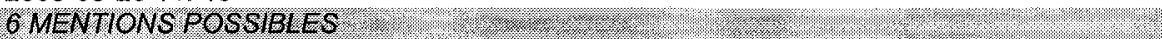

35a. Veuillez penser au type de bénévolat que vous avez effectué pour d'autres au cours des 12

derniers mois. Était-ce...

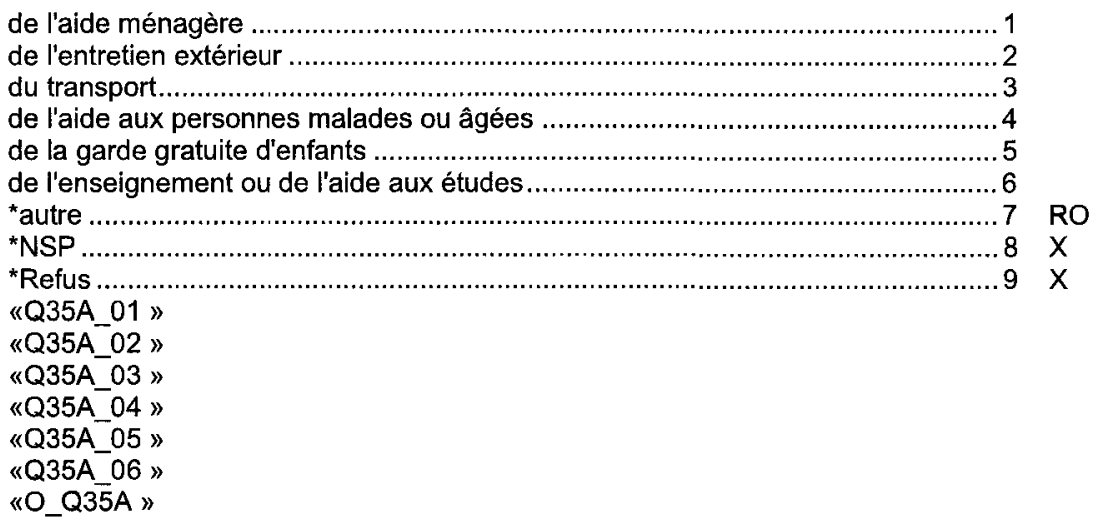

Q35B:

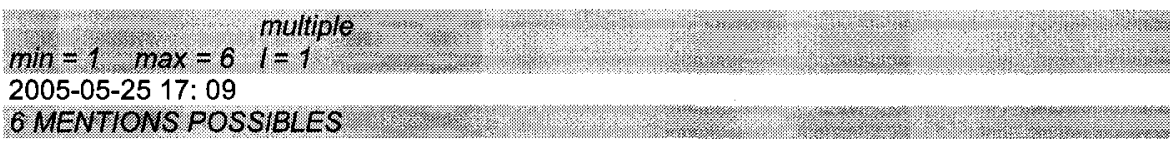

35b. Parmi les types d'organismes suivants pour lesquels faites-vous du bénévolat? (Classer par ordre de temps passé à faire l'activité de bénévolat en mettant en premier celle qui prend le plus de votre temps, etc.) LIRE 


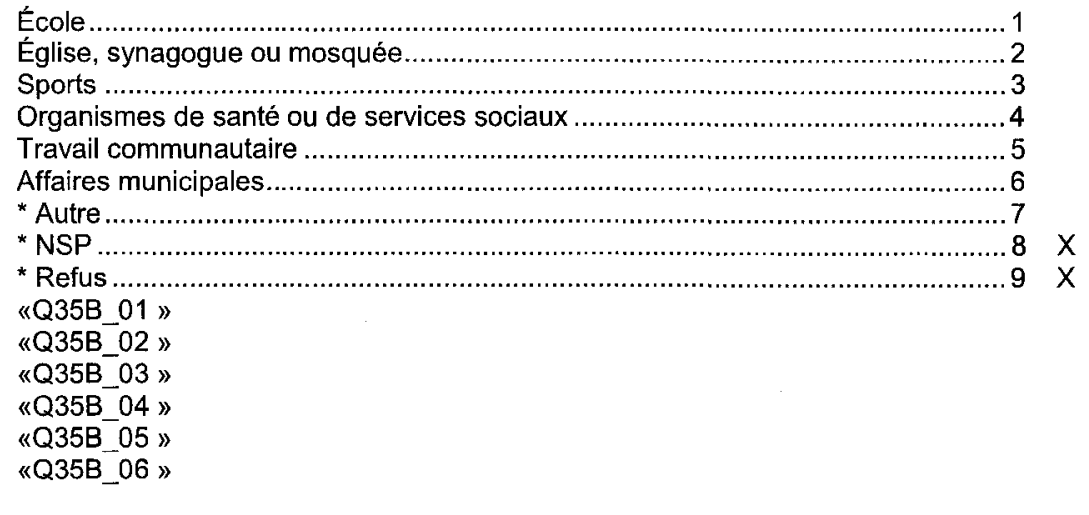

Q36:

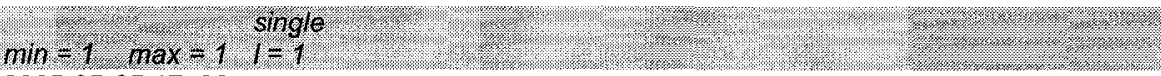

2005-05-25 17: 09

36. Êtes-vous au courant des activités d'un organisme communautaire de votre région faisant la promotion de services de santé ou de services sociaux?

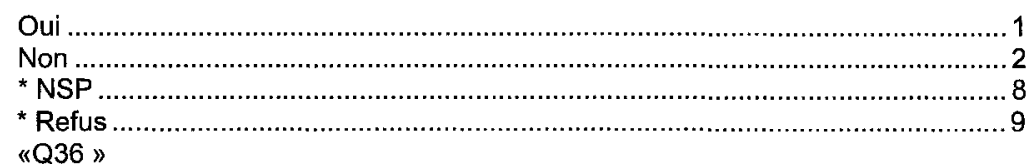

«Q36 »

Q37:

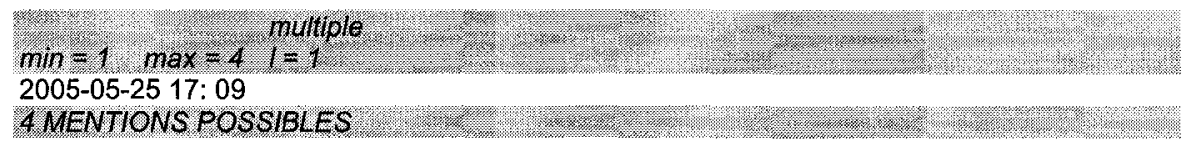

4 MENTIONS POSSIBLES.

37. Si vous tombiez malade, vers qui d'autre que votre conjoint (e) pourriez-vous compter pour avoir de l'aide? Serait-ce... LIRE

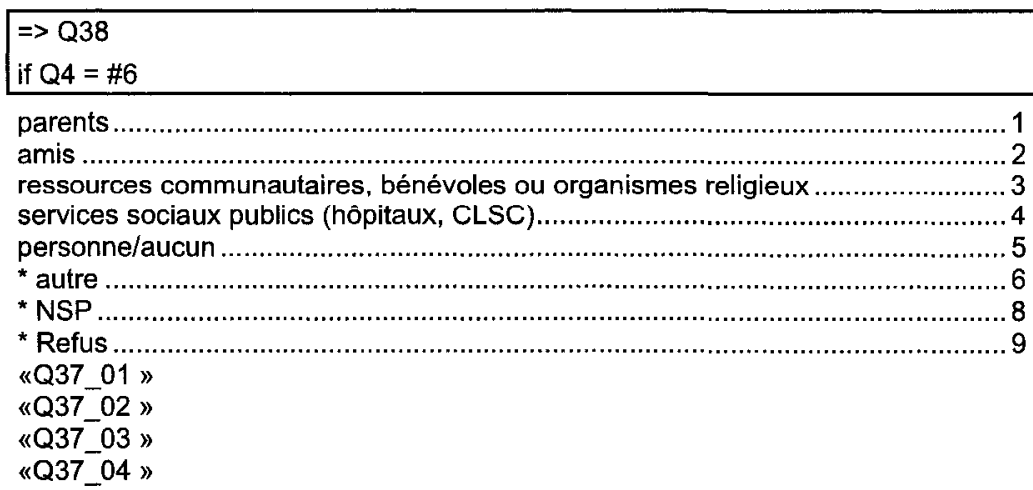


Q38:

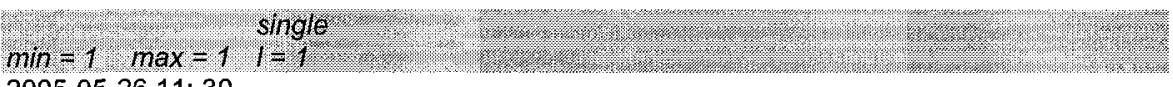

2005-05-26 11: 30

38. Procurez-vous du support (non-rémunéré) à une personne vivant en dehors de votre foyer?

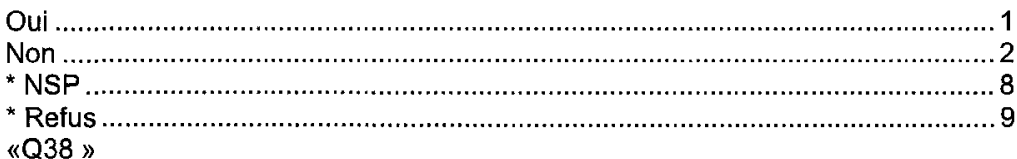

«Q38 »

Q39:

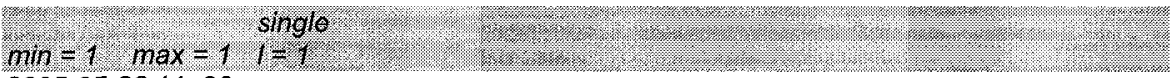

2005-05-26 11: 30

39. Procurez-vous du support (non-rémunéré) à une personne autre que dans votre famille?

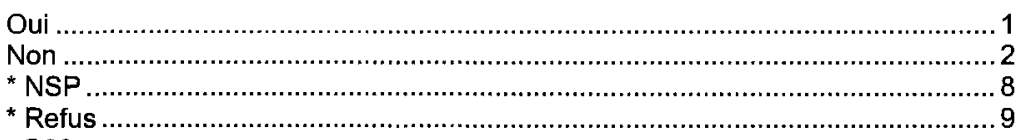

«Q39 »

Q40:

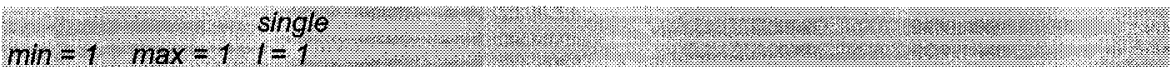

2005-05-26 09: 27

40. Vos rapports sociaux avec des amis se passent-ils généralement ...

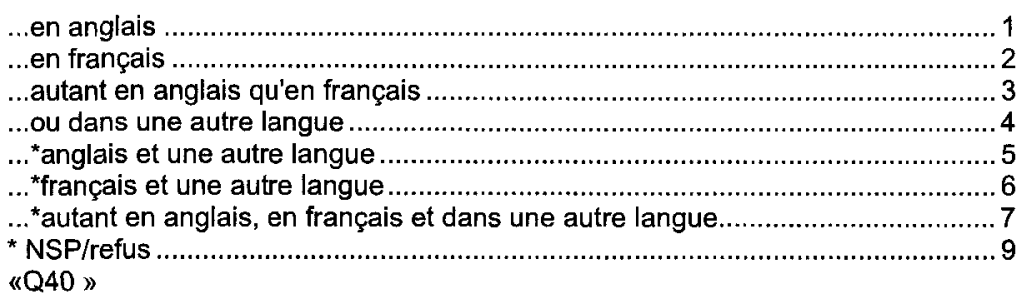




\section{References}

Anderson, J.M. (2000). "Gender, race, poverty, health and discussion of health reform in the context of globalization: A postcolonial feminist perspective in policy research", Nursing Inquiry, 7, pp. 220-229.

Anderson, T. (1999). "Taking a Bite out of the Sandwich Generation" USA Today, November, 1999, 128 No. 2654, 18-19.

Armstrong, P. \& H. Armstrong, \& D. Coburn, eds. (2001). Unhealthy Times: Political Economy Perspectives on Health and Care. Don Mills, Ont., Oxford University Press.

Armstrong, P. \& H. Armstrong. (1996). Wasting Away: the Undermining of Canadian Health Care. Toronto, Oxford University Press.

Armstrong, P. \& H. Armstrong. (2001). "Thinking it Through: Women, Work and Caring in the New Millenium", Healthy Balance Research Program, Canadian Institute for Health Research. (http: //www.healthyb.dal.ca/Thinking-It-Through-web.pdf)

Armstrong, P. (2004). "Health, Social Policy, Social Economies and the Voluntary Sector" in Dennis Raphael, Ed., Social Determinants of Health. Canadian Perspectives. Toronto: Canadian Scholars Press Inc. pp. 331-343. Armstrong, P. (2007). "Relocating Care: Home Care in Ontario" in Morrow, M, O. Hankivsky \& C. Varcoe, eds., Women's Health in Canada: Critical Perspectives on Theory and Policy. Toronto: University of Toronto Press, pp. 528-553.

Aronson, J. (1991). "Dutiful daughters and undemanding mothers: Constraining images of giving and receiving in middle and later life", in Women's Caring: Feminist Perspectives on Social Welfare, C. Baines, P. Evans \& S. Neysmith, (eds.). Toronto: McClelland \& Stewart, pp. 138-168..

Baines, C., P. M. Evans, et al. (1998). Women's Caring: Feminist Perspectives on Social Welfare. Toronto: New York, Oxford University Press.

Baum, F. (1999). "Social Capital: Is it Good for Your Health? Issues for a Public Health Agenda", Journal of Epidemiology and Community Health, 53: pp. 195196.

Berkman, L. et al. (2000). "From social integration to health: Durkheim in the new millennium", SocSciMed, 51 (6): pp. 843-857.

Bernier, J. \& Dallaire M. (2002). "What price have women paid for health care reform? The Situation in Quebec", in P. Armstrong et al. (eds.) Exposing privatization: Women and healthcare reform in Canada. Aurora ON: Garamond. 
Blank, S. \& G. Stanley. (1993). "Quebec and the Emerging Architecture of North America" Quebec Studies, 1993, Vol. 16, pp. 9-22.

Bolin, K., B. Lindgren, M. Lindstrom \& P. Nystedt. (2003). "Investments in social capital - implications of social interactions for the production of health", SocSciMed, 56 (2003), pp. 2379-2390.

Bourdon, S. \& F. Deschenaux. (2002). Portrait des conditions de travail dans les organismes communautaires québécois du secteur santé et services sociauxDonnées de l'enquête 2000. Université de Sherbrooke, Research group on occupations.

Bourhis, R. Y. Ed. (2008). The Vitality of the English-Speaking Communities of Quebec: From Community Decline to Revival. Montreal, Quebec: CEETUM, Université de Montréal.

Bourque, G. \& N. Laurin-Frenette. (1975). "Social Classes and National Ideologies in Quebec, 1760-1970" in Capitalism and the National Question in Canada, G. Teeple, Ed., Toronto: University of Toronto Press.

Bowen, S. (2001). Language Barriers in Access to Health Care. Ottawa: Health Canada.

Brannen, J. (1992). Mixing Methods: Qualitative and Quantitative Research. Aldershot: Brookfield, Avebury.

Brannen, J. (2003). “Towards a Typology of Intergenerational Relations: Continuities and Change in Families", Sociological Research Online, Vol. 8, No. 2 (www.socresonline.org.uk/8/2/brannen.html)

Breton, R. (1988). "From Ethnic to Civic Nationalism: English Canada and Quebec", Ethnic and Racial Studies. 11: 85-102.

Breton, R., H. Norbert, J. Leonards \& P. Reed. (2004). A Fragile Social Fabric? Fairness, Trust and Commitment in Canada. McGill-Queen's University Press.

Brodie, J. (1996). "Restructuring and the New Citizenship" in I. E. Baker, Ed., In Rethinking Restructuring: Gender Change in Canada. Toronto, University of Toronto Press: 126-140.

Caldwell, G. (1994). “English Quebec: Demographic and Cultural Reproduction", International Journal of the Sociology of Language. 105/106: 153179.

Canadian Council on Social Development. (1998). Most Seniors Live Independently. Ottawa, Division of Aging and Seniors, Health Canada.

Cannuscio, C., J. Block and I. Kawachi. (2003). "Social Capital and Successful Aging: The Role of Senior Housing", Annals of Internal Medicine, 139 (5, part 2), pp. 395-400. 
Carter, J. (2001). "Evaluation of Levels of Access to Entitled Services Identified in Access Programs of Health and Social Services in English." Montreal: Community Health and Social Services Network.

Carter, J. (2008). "What Future for English Language Health and Social Services in Quebec?" In R. Y. Bourhis, Ed., The Vitality of the English-Speaking Communities of Quebec: From Community Decline to Revival. Montreal, Quebec: CEETUM, Université de Montréal.

CCESMC. (2002). Report to the Federal Minister of Health. Consultative Committee for English-speaking Minority Communities, Health Canada, Ottawa.

CCESMC. (2007a). Building on the Foundations - Working Toward Better Health Outcomes and Improved Vitality of Quebec's English-speaking communities, Report to the Federal Minister of Health, Consultative Committee for English-speaking Minority Communities, Health Canada, Ottawa.

CCESMC. (2007b). Building on the Foundations - Working Toward Better Health Outcomes and Improved Vitality of Quebec's English-speaking communities. Compendium of Demographic and Health Determinants on Quebec's English-speaking communities, Consultative Committee for English-speaking Minority Communities, Health Canada, Ottawa.

Chantier de l'économie social. (2001). De nouveau, nous osons : Document de positionnement stratégique. Montreal: Chantier de l'économie sociale.

Checkland K., (2004). "National Service Frameworks and UK General Practitioners: Street-level Bureaucrats at Work." Sociology of Health and Illness (7): pp. 951-975.

CHSSN/CROP. (2005). Survey of Community Vitality.

CIHR, (2004). What's sex and gender got to do with it? Integrating sex and gender into Health Research, Final Report. (February 27 - March 12003 ).

Clugstun, M. (1986). "Going Flat Out", Canadian Business 58. (5).

Coleman, W. (1984). "The Class Bases of Language Policy in Quebec, 19491983" in A. Gagnon, Ed., Quebec: State and Society, pp. 388-409. Toronto: Methuen Publications.

Comeau, Y, L. Favreau, B. Lévesque \& M. Mendell. (2001). Emploi, économie sociale, développement local : les nouvelles filières. Sainte-Foy : Presse de l'université du Québec.

Comité sectoriel de main-d'œuvre / Économie Social Action Communautaire. (2006) "La relève : succession in Quebec's Community Sector". Emploi 
Québec : Comité sectoriel de main-d'œuvre / Économie Social Action Communautaire.

Creswell, J. W. (2003). Research Design: Qualitative, Quantitative, and Mixed Method Approaches. Sage Publications: Thousand Oaks, CA.

CROP and Missisquoi Institute. (2000). Survey on Attitudes, Experiences, and Issues for Quebec's Anglophone Communities. June 2000. Sara Saber-Freedman, lead consultant.

Cullen H., (1992). "Nation and its Shadow: Quebec's Non-French Speakers and the Courts", Revue Interdisciplinaire d'études juridiques, Law and Critique, Vol. III, no. 2, pp. 219-240

Dale, A. \& J. Onyx, eds. (2005). A dynamic balance: social capital and sustainable community development. Sustainability and the environment. Vancouver: UBC Press.

de Certeau, M. (1984). The Practice of Everyday Life. Berkeley, University of California Press. Dekker \& Uslaner, 2001.

Denzin, N. K. \& Y. S. Lincoln. (2003). Strategies of Qualitative Inquiry. Thousand Oaks, CA, Sage.

Desjarlais S. \& M. Moisan. (1999) "Ambulatory Care: The Hidden Price for Women". Quebec : Government of Quebec, Conseil du statut de la femme.

Doucet, A. (2001). "You See Need Perhaps More Clearly Than I Have." Journal of Family Issues 22 (3). : 328-348.

Duffy, A. \& N. Pupo. (1992). Part-time Paradox: Connecting Gender, Work \& Family Toronto: McClelland \& Stewart Inc, pp. 13-40.

Durkheim, E. (1964). The Rules of Sociological Method. Glencoe: Free Press.

Edmondson, R. (2003). "Social Capital: A Strategy for Enhancing Health?" SocSciMed, 57, pp. 1723-1733. (www.elsevier.com/locate/socscimed)

Fafard, P. (2008). “Evidence and Healthy Public Policy: Insights from Health and Political Sciences", National Collaborating Centre for Healthy Public Policy.

Finch, J. \& J. Mason. (1993). Negotiating Family Responsibilities. London, New York, Tavistock/Routledge.

Floch, W. (2004). Regional Profiles of Official-language Minority Communities, 1996-2001. Gatineau: Department of Canadian Heritage.

Floch, W. (2005). “Those Who Stayed and Those Who Left: Demographic Portrait of Quebec's English Mother Tongue Population, by Inter-provincial Mobility Status, 1971-2001", Journal of Eastern Townships Studies. (Summer 2005). 
Floch, W., \& J. Pocock. (2008). "Emerging Trends in the Socio-Economic Status of English Speaking Quebec: Those who Left and Those who Stayed", in R. Y. Bourhis, Ed. The Vitality of the English-Speaking Communities of Quebec: From Community Decline to Revival. Montreal, Quebec: CEETUM, Université de Montréal.

Flyvbjerg, B. (2006). "Five Misunderstandings about Case-Study Research", Qualitative Inquiry, Vol. 12, No. 2, pp. 219-245.

Fournier, M., M. Rosenberg, \& D. White, eds. (1997). Quebec Society - Critical Issues. Scarborough: Prentice Hall Canada Inc.

Fournier, P. (1984). "The New Parameters of the Quebec Bourgeoisie" in A. Gagnon Ed., Quebec: State and Society, Toronto: Methuen Publications, pp. 201-228.

Frank, J. (2003). "Making Social Capital Work for Public Policy". Horizons Policy Research Initiative, Vol. 6, No. 3. Government of Canada.

Fukuyama, F., (1995). Trust: The Social Virtues and the Creation of Prosperity. New York: The Free Press.

Fukuyama, F., (1999). The Great Disruption: Human Nature and the Reconstitution of Social Order. New York: The Free Press.

Geertz, C. (1995). After the Fact: Two Countries, Four Decades, One Anthropologist. Cambridge MA: Harvard University Press.

Gibbon, M., R. Labonte and G. Laverack. (2002) "Evaluating community capacity", Health and Social Care in the Community, 10: 6, 2002: 485-491.

Goffman, E., (1961). Asylums: Essays on the Social Situation of Mental Patients and other Inmates. Garden City NY: Anchor Books.

Gordon, A. (2001). Making Public Pasts. The Contested Terrain of Montreal's Public Memories 1891-1930. Montreal: McGill-Queen's University Press. Chapter 1, pp. 3-17 \& Chapter 7, pp. 116-144.

Graham, H. (1984). Women, Health, and the Family. Brighton, Sussex, Wheatsheaf Books: Distributed by Harvester Press.

Greater Montreal Community Development Initiative Steering Committee (GMCDI). (2007). Building upon Change and Diversity within the Englishspeaking Communities of the Greater Montreal Region: Pursuing Shared Development Goals and Strategies. Montreal: Report of the Greater Montreal Community Development Initiative Steering Committee. (www.qcgn.ca) Gubrium, J. F. \& A. Sankar. (1990). The Home Care Experience: Ethnography and Policy. Newbury Park, CA, Sage Publications. 
Gubrium, J. F. (1997). Living and Dying at Murray Manor. The University Press of Virginia.

Guindon, H. (1988). Quebec Society: Tradition, Modernity, and Nationhood. Toronto, University of Toronto Press.

Hamilton, R. (1998). "The Primacy of Primary Health Care", British Medical Journal 317 (19 Dec): pp. 1724-1725.

Health Canada, 1998. "Taking action on population health: a position paper for Health Promotion and Programs Branch staff", Health and Welfare Canada.

Hendricks, J., Ed. (1995). The Meaning of Reminiscence and Life Review. New York, Baywood Publishing Company.

Hudson, B., B. Hardy, M. Henwood \& G. Wistow. (1999). "In Pursuit of InterAgency Collaboration in the Public Sector: What is the contribution of theory and research", Public Management: An International Journal of Research and Theory, 1 (a): pp. 235-160.

Ignatieff, Michael. (1993). Blood and Belonging: Journeys into the New Nationalism. Toronto: Viking Press. See especially chapter 4 "Quebec", pp. 143-177.

Illich, I. (1975). Medical Nemesis. Toronto: McLelland \& Stewart.

Immen, W. (2004). "Caught in the Sandwich", The Globe \& Mail, March 17, 2004, C1-2.

Institut de la statistique du Québec (1998). Enquête sociale et de santé.

Jacobs, E., A. HM Chen, L. Karliner, N. Agger-Gupta \& S. Mutha. (2006). “The Need for More Research on Language Barriers in Health Care: A Proposed Research Agenda". The Milbank Quarterly, Vol. 84, No. 1, pp. 111-133.

Jedwab, J. (2008) "How shall we define thee? Determining who is an EnglishSpeaking Quebecer and Assessing its Demographic Vitality", in R. Y.

Bourhis, Ed. The Vitality of the English-Speaking Communities of Quebec: From Community Decline to Revival. Montreal, Quebec: CEETUM, Université de Montréal.

Jedwab, J. \& H. Maynard. (2008) "Politics of Community: The Evolving Challenge of Representing English-Speaking Quebecers", in R. Y. Bourhis, Ed. The Vitality of the English-Speaking Communities of Quebec: From Community Decline to Revival. Montreal, Quebec: CEETUM, Université de Montréal.

Jensen, J. (1997). "Who Cares? Gender and Welfare Regimes". Social Politics, summer: pp. 182-187. 
Jensen, J. (1998). Mapping social cohesion: The state of Canadian research. (CPRN Study No. F/03). Ottawa: Canadian Policy Research Networks. Jensen, J. (2002). "Against the Current: Child Care and Family Policy in Quebec" in Sonya Michel \& Rianne Mahon, eds., Child Care Policy at the Crossroads: Gender and Welfare State Restructuring. Routledge: New York, pp. 309-332.

Jensen, J. (2003). “Redesigning the 'Welfare Mix' for Families: Policy Challenges", Ottawa: Canadian Policy Research Networks.

Jensen, J., R. Mahon \& S.D. Phillips. (2003). "No Minor Matter: The Political Economy of Child Care in Canada" in Wallace Clement \& Leah Vasko (Eds.). Changing Canada: Political Economy as Transformation.

Jetté, C., B. Lévesque, Y. Vaillancourt. (2001). The social economy and the future of health and welfare in Quebec and Canada, Montreal: UQAM, Cahier du LAREPPS 01-04.

Justice Canada. (1998). Annotated Language Laws of Canada: Constitutional, Federal, Provincial and Territorial laws. Ottawa, Canadian Heritage.

Jutras, S. (1990). "Caring for the Elderly: The Partnership Issue", SocSciMed, Vol. 31, No. 7, pp. 763-771.

Kawachi, J., B.P. Kennedy, K. Lochner \& D. Prothrow-Stith. (1997). "Social Capital, Income Inequality and Mortality", American Journal of Public Health, 87 (9): pp. 1491-1498.

Keating, N., J. Fast, J. Frederick, K. Cranswick \& C. Perrier. (1999). Eldercare in Canada: Context, Content and Consequences. (Statistics Canada Catalogue 89-570-XPE) Ottawa: Statistics Canada.

Keating, N., P. Otfinowski, C. Wager, J. Fast, \& L. Derksen. (2003). "Understanding the caring capacity of informal networks of frail seniors: A case for care networks". Aging and Society, 23, pp. 115-127.

Keating, N., J. Swindle, \& D. Foster. (2004). "The Role of Social Capital in Aging Well", unpublished paper in a project by the Policy Research Initiative.

Kespichavawattana, J. \& S. Wivatani. (2005). "The Impacts of Migration on Physical Health and Psychological Well-being of the Elderly Parents Left Behind: A Study of Rural Thailand". Paper presented at the International workshop on the Impacts of Migration on the "left-behind" in Asia. Asia Research Institute, National University of Singapore, March 2005.

Kleiman, C. (2002). "Sandwich Generation Needs Support", The London Free Press, April 29, 2002, Business section. 
Knocks, S. \& Keefer, P. (1997). "Does social capital have an economic payoff? A cross-country investigation", Quarterly Journal of Economics, vol. 112, no. 4, pp. 1251-1288.

Lappé, F.M. (1977). Food First: Beyond the Myth of Scarcity. Houghton Mifflin.

Lustigman, M. \& M. Lustigman. (1995). "The Clash of Memories: Bibliographic Responses to the Canadian Quality of Nation". Lennoxville, QC: unpublished paper.

Luxton, M. (2004). "Social Reproduction and the Community". Paper presented at the Canadian Sociological and Anthropological Association Annual Meeting, Winnipeg MB.

Macinko, J. and B. Starfield. (2001). "The utility of social capital in studies on health determinants." Milbank Quarterly 79 (3): 387-428.

Mackian, S. (2002). "Complex Cultures: Rereading the Story about Health and Social Capital, Critical Social Policy, Vol. 22 (2) p 203-225.

Magnan, M. O. (2004). "To Stay or not to Stay" - Migration des jeunes angloquébécois: revue de la littérature. Montreal, QC: Institut national de la recherché scientifique: urbanisation, culture et société.

Marks, D.F. (2002). Perspectives on Evidence-Based Practice. HAD Contract no 02/042, Project 00477. London: Health Development Agency, Public Health Evidence Steering Group

Marks, N. (1998)."Does it hurt to care? Caregiving, work-family conflict and midlife well-being", Journal of Marriage and the Family, 60, No. 4 (November): pp. 951-966.

Marshall, B. L. (2000). Configuring Gender: Explorations in Theory and Politics. Peterborough ON, Broadview Press.

Marx, K. (1972). The Marx-Engels Reader. R. Tucker, Ed. New York: W. W. Norton \& Company.

McAndrew, M. (1986). “Études sur l'ethnocentrisme dans les manuels scolaires de langue française au Québec". Montréal, Université de Montréal, section d'éducation comparée fondements de l'éducation.

McDaniel, S. A. (1999). "Untangling Love and Domination: Challenges of Home Care for the Elderly in a Reconstructing Canada", Journal of Canadian Studies, vol. 34, no. 3, pp. 191-213.

McDaniel, S.A. (2001). “'Born at the Right Time': Gendered Generations and Webs of Entitlement and Responsibility," Canadian Journal of Sociology 26 (2): 193-214. 
McDaniel, S.A. (2002a). "Generational Consciousness Of and For Women," Pp.89-110 in June Edmunds and Bryan S. Turner (Eds.), Generational Consciousness, Narrative and Politics. Lanham, Maryland: Rowman Littlefield.

McDaniel, S.A. (2002b). "Women's Changing Relations to the State and Citizenship: Caring and Intergenerational Relations in Globalizing Western Democracies", CRSA/RCSA 39. (2): pp. 125-150.

McKeen, W. \& A. Porter. (2003). "Politics and Transformation: Welfare State Restructuring in Canada" in Wallace Clement \& Leah Vasko, eds. Changing Canada: Political Economy as Transformation.

McKnight, J. (1994) "Regenerating Community", Civic Practices Network, http: //www.cpn.org/topics/community/regenerating.html, pp. 1-7.

McRoberts, K. \& D. Posgate. (1980). Quebec: Social Change and Political Crisis. Toronto: McClelland \& Stewart.

Mendell, M. (2002). “The Social Economy in Quebec: Discourse and Strategies" in Abigail B. Bakan \& Eleanor MacDonald, Eds., Critical Political Studies: Debates and Dialogues from the Left, Montreal and Kingston: McGillQueen's University Press, pp. 319-49.

Mills, C. Wright. (1959). The Sociological Imagination. New York: Oxford University Press.

Milner, H. \& S. H. Milner. (1973). The Decolonization of Quebec: An Analysis of Left-wing Nationalism. Toronto: McClelland \& Stewart. See Chapter 2:

"Quebec: An Economic Satellite", pp. 31-51, Chapter 3: "Les Quebecois: An Oppressed Majority", pp. 52 -68 and Chapter 9: "The Struggle Intensifies", pp. 195-223.

Missisquoi Institute. (2000). Attitudes, Experiences and Issues of Quebec's Anglophone Communities. Montreal, Missisquoi Institute.

Montcalm, M. (1984). "Quebec Separatism in a Comparative Perspective" in A. Gagnon, Ed. Quebec: State and Society. Toronto: Methuen Publications, pp. 45-58.

Morrow, M, O. Hankivsky \& C. Varcoe. (2007). Women's Health in Canada: Critical Perspectives on Theory and Policy. Toronto: University of Toronto Press.

Morrow, Marina (2007) in Morrow, M, O. Hankivsky \& C. Varcoe, eds., Women's Health in Canada: Critical Perspectives on Theory and Policy. Toronto: University of Toronto Press. 
MSSS. (2006). "Frame of reference for the implementation of programs of access to health and social services in the English language for Englishspeaking persons", Quebec: Ministère de la santé et des services sociaux, 31. MSSS. (2008a). "Coordonnés des 95 CSSS dont 47 créés en vertu du projet de loi 25", Quebec: Ministère de la santé et des services sociaux.

MSSS. (2008b). "Institutions providing services in the English language", Quebec: Ministère de la santé et des services sociaux, Secrétariat à l'accès aux services en langue anglaise et aux communautés culturelles.

MSSS. (2008c). "Programme de soutien aux organismes communautaires", Quebec: Ministère de la santé et des services sociaux, 33.

Muntaner C, J. Lynch \& D. Smith, (2001). "Social Capital, Disorganized Communities, and the Third Way", International Journal of Health Services, Vol. 31, pp. 213-237.

Muntaner C., J. Lynch, M. Hillemeier, J.H. Lee, R. David, J. Benach \& C. Borrell, (2002). "Economic Inequality, Working-class Power, Social Capital, and Cause-specific Mortality in Wealthy Countries", International Journal of Health Services, Vol. 32, No. 4, pp. 629-656.

Myles, J. (1991). "Women, the welfare state and caregiving", Canadian Journal on Aging, Vol. 10, No. 2, pp. 82-85.

Narayan, D. (1999). "Bond and Bridges: Social Capital and Poverty." Washington, DC: World Bank.

Nehamas, A. (1985). Nietzche: Life as Literature. Cambridge MA: Harvard University Press.

Nocon, A. \& M. Pearson. (2000). “The Roles of Friends and Neighbours in Providing Support for Older People", Aging and Society, 20, pp. 341-367. Novak, M. W. (1997). Aging \& society: a Canadian perspective. Toronto: ITP Nelson.

O'Keefe, E. \& C. Hogg (1999). "Public Participation \& Marginalized Groups: the community development model", Health Expectations, 2: 245-254.

Pocock, J. (2003). "Marginalia: Family Documents in Qualitative Research". Paper presented at Qualitative Research Conference, Carleton University, Ottawa, Ontario.

Pocock, J. (2004a). “Baseline Data Report 2003-2004. Regional Profiles of Englishspeaking Communities", Community Health and Social Services Network. www.chssn.org.

Pocock, J. (2004b). “Not by Blood Alone: Language, Aging and the Canadian State". Paper presented at the Annual Meeting of the CSAA, Winnipeg, MB. 
Pocock, J. (2005). “Baseline Data Report 2004-2005. Profiles of English-speaking Communities in Selected CLSC Territories", Community Health and Social Services Network. www.chssn.org.

Pocock, J. (2006a). "Baseline Data Report 2005-2006. English-language Health and Social Services Access in Quebec", Community Health and Social Services Network. www.chssn.org.

Pocock, J. (2006b). “Social Support Networks in Quebec's English-speaking Communities: Building Community Vitality through Social Capital Strategies", Community Health and Social Services Network. www.chssn.org.

Pocock, J. (2007a). “Baseline Data Report 2006-2007. Community Network Building: Case studies on developing networks between English-speaking minority communities in Quebec and public partners to improve access to health and social services in English". Community Health and Social Services Network. www.chssn.org.

Pocock, J. (2007b). Dissertation interviews.

Pocock, J. (2008). “Baseline Data Report 2007-2008. Quebec's Social and Health Survey Information". Community Health and Social Services Network. www.chssn.org.

Pocock, J., \& Floch, W. (1999). "Aging and Rural Minority Communities: The Case of Hatley Township", Journal of Eastern Townships Studies No. 15, Fall: 17-42.

Portes, A. (1998). "Social Capital: Its Origin and Applications in Modern Sociology", Annual Reviews of Sociology, 24: pp. 1-24.

Putnam, R. D. (1993) “The prosperous community: social capital and public life" in the American Prospect, 4: 13

Putnam, R. D. (1995). "Tuning In, Tuning Out: The Strange Disappearance of Social Capital in America", Political Science and Politics, December: 664-683.

Putnam, R. D. (1996) "The Strange Disappearance of Civic America" in the American Prospect, 7: 24

Putnam, R. D. (2000a). "Bowling alone: America's declining social capital", Journal of Democracy, vol. 6, no. 1, pp. 65-78.

Putnam, R. D. (2000b). Bowling alone: the collapse and revival of American community. New York: Simon \& Schuster.

Quebec (2001). Le français, une langue pour tout le monde: Une nouvelle approche stratégique et citoyenne. Commission des États généraux sur la situation de la langue française au Québec. Québec: Gouvernement du Québec. 
Ragin, C. and H. Becker (Eds.) (1992). What is a Case? Exploring the Foundations of Social Inquiry. Cambridge UK: Cambridge University Press.

Reed, P. \& K. Selbee. (2000). "Patterns of Citizen Participation and the Civic Core in Canada". Presented at the 29th ARNOVA Annual Conference. New Orleans, Louisiana.

Reimer, (2003). “Understanding Social Capital: its Nature and Manifestations in Rural Canada", paper prepared for submission to Rural Sociology.

Renaud, M. (1984). "Quebec's New Middle Class in Search of Social Hegemony" in A. Gagnon Ed. Quebec: State and Society, pp. 150-185. Toronto: Methuen Publications.

Renaud, M. (1987). "Reform or Illusion? An Analysis of Quebec State Intervention in Health", in D. Coburn et al (eds.) Health and Canadian Society, $2^{\text {nd }}$ edition. Markham ON: Fitzhenry \& Whiteside.

Rendall M.S. \& R.A. Bahchieva. (1998) "An old -age security motive for fertility in the United States?" Population and Development Review, 24 (2): 293-307.

Revised Statutes of Canada. (2008). Canadian Charter of Rights and Freedoms. Revised Statutes of Canada. (2008). Official Languages Act.

Revised Statutes of Quebec. (2003). Charter of the French Language.

Revised Statutes of Quebec. (2008). An Act respecting Health services and social services which sets out the legislative framework for access to health and social services in English in Quebec

Roeher Institute, (1993).Social Well-being: A Paradigm for Reform. North York ON.

Rogers, W. (2004). "Evidence-based medicine and women. Do the principles and practice of EBM further women's health?" Bioethics, 18 (1), pp. 50-71.

Roos, N. P., Ed. (2001). Changes in health and health care use of Manitobans, 19851998. Winnipeg, Manitoba Centre for Health Policy and Evaluation.

Rosenthal, C. \& L. Stone. (1999). How much help is exchanged in families? Towards an understanding of discrepant research findings. SEDAP research paper no. 2. Program for Research on Social and Economic Dimensions of an Aging Population (SEDAP). Hamilton, Ont.: McMaster University

Rudin, Ronald. (1985). The Forgotten Quebecers. A History of English-speaking Quebec 1759-1980. Quebec: Institut québeçois de recherche sur la culture. Ryerson, Stanley. (1972). "Quebec: Concepts of Class and Nation" in Gary Teeple, Ed. Capitalism and the National Question in Canada. Toronto: University of Toronto Press. 
Saber-Freedman, S. (2001). "Building on our strengths: An action plan for improving access to health and social services in English in Quebec and enhancing the vitality of its English-speaking minority communities". (Prepared on behalf of Health Canada's Consultative Committee for the English-speaking Minority Communities.). Ottawa: Health Canada.

Salée, D. (1997). "Quebec Sovereignty and the Challenge of Linguistic and Ethnocultural Minorities: Identity, Difference, and the Politics of Ressentiment" Quebec Studies, fall 1997, Vol. 24, pp. 6-23.

Salée, D. (2003). "Transformative Politics, the State and the Politics of Social Change in Quebec" in W. Clement \& L. Vasko, eds. Changing Canada: Political Economy as Transformation. Kingston: McGill-Queen's University Press.

Secrétariat du Conseil du Trésor. (2003). Diversity in Québec Public Service : Action Plan. Quebec, QC: Government of Quebec, Secrétariat du Conseil du Trésor.

Shapiro, D.M. (1995). "Language and earnings in Quebec: trends over twenty years, 1970-1990". Montreal: Department of Economics, Concordia University, 19. (27).

Sherwin, S. (1992).No longer patient: feminist ethics and health care. Philadelphia: Temple University Press.

Shiell, A. \& P. Hawe, (1996). "Health promotion, community development and the tyranny of individualism", Health Economics, 5 (3): pp. 241.247.

Shragge, E. \& J.M. Fontan, (2000). Social Economy: International Debates and Perspectives. Montreal: Black Rose

Silver, R. (2000). "The Right to English Health and Social Services in Quebec: A Legal and Political Analysis", McGill Law Journal/Revue de droit de McGill, Vol. 45 pp. 681-755.

Simmel, G. (1950). The Stranger. The Sociology of Georg Simmel. K.H. Wolf, trans. and Ed. New York, The Free Press.

Smith and Kulynych (2002) "It May Be Social, but Why Is It Capital? The Social Construction of Social Capital and the Politics of Language". Politics E Society, vol.30 No.1, March 2002, p.149-186. Sage Publications

Statistics Canada. (1983). 1981 Census of Canada, Mobility Status, Ottawa.

Statistics Canada. (1998a). 1996 Census of Canada.

Statistics Canada. (1998b). Home Care in Canada. Ottawa.

Statistics Canada. (1998c). National Survey of Volunteering and Giving.

Ottawa. 
Statistics Canada. (2000). Information and Insights for the Nonprofit Sector.

Nonprofit Sector Knowledge Base Project. Catalogue no. 75F0033MIE Issue No. 2

Statistics Canada. (2002a). Ethnicity and Diversity Survey. Ottawa.

Statistics Canada. (2002b). General Social Survey Cycle 16: Social support and aging. Ottawa.

Statistics Canada. (2003a). General Social Survey Cycle 17. Ottawa.

Statistics Canada. (2003b). 2001 Census of Canada.

Statistics Canada. (2003c). "Canadian Community Health Survey". Statistics Canada, Ottawa.

Statistics Canada. (2005). "Canadian Community Health Survey". Statistics Canada, Ottawa.

Statistics Canada. (2007). 2006 Census of Canada.

Stelcner, M. (1993). An empirical analysis of earnings among ethnic groups in Canada. Montreal, Dept. of Economics, Concordia University.

Stobert, S. \& K. Cranswick, (2004). “Looking after seniors: Who Does What for Whom?" Canadian Social Trends, Autumn (74), pp. 2-6.

Truong, C.H. (2005). "At Home or Work? The Intensification of Family Relations of Migrant Households: An Ethnographic Case Study of a Commune in the Red River Delta". Paper presented at the International workshop on the Impacts of Migration on the "left-behind" in Asia. Asia Research Institute, National University of Singapore, March 2005.

Vaillancourt Rosenau, P. (2000). Public-Private Policy Partnerships. Cambridge MA: MIT Press.

Vaillancourt, F., D. Lemay, \& L. Vaillancourt. (2007). Laggards No More: The changed Socioeconomic Status of Francophones in Quebec. Toronto, Ontario: C.D. Howe Institute. No.103, August 2007. on-line: ISSN 1499-7991, www.cdhowe.org

Vaillancourt, Y., F. Aubry \& C. Jetté, eds. (2003). L'économie sociale dans les services à domicile. Québec: Presse de l'université du Québec.

Vaillancourt, Y., F. Aubry, M. d'Amours, C. Jetté, L. Thériault \& L. Tremblay. (2000). "The specificity of the Quebec model within the Canadian context", Canadian Review of Social Policy, 45/46, pp. 55-88.

Vaillancourt, Y., F. Aubry, M. Kearney, L. Theriault, \& L. Tremblay. (2004). "The Contribution of the Social Economy towards Healthy Social Policy Reforms in Canada: A Quebec Viewpoint", in Dennis Raphael, Ed. Social 
Determinants of Health. A Canadian Perspective. Toronto: Canadian Scholars' Press Inc, pp. 311-329

Walker, L. \& L. Gilson, (2004). "We are bitter but we are satisfied: nurses as street-level bureaucrats in South Africa". SocSciMed (59 (6): pp. 1251-1261.

Ward, R. \& G. Spitze. (1998) "Sandwiched marriages: The implications of child and parent relations for marital quality in midlife." Social Forces 77: 647-666.

Ward-Griffin, C. \& V.W. Marshall, (2003). "Reconceptualizing the relationship between private and public eldercare", Journal of Aging Studies, 17, 2, pp. 189-208.

Weber, M. (1947). The Theory of Social and Economic Organization. Talcott Parsons. ed., New York: Free Press.

Weber, M. (1978) "The Nature of Social Action" in W.G. Runciman, Ed. Max Weber: selections in translation. Cambridge, New York: Cambridge University Press, pp. 7-32.

Weisman, (1997). "Changing Definitions of Women's Health: Implications for Health Care and Policy", Maternal and Child Health Journal, Volume 01, Number 3, September 1997, pp. 179-189 (11)

Westmount Examiner, March 3, 2008.

White, D. (1997). "Quebec State and Society" in M. Fournier, M. Rosenberg \& D. White, eds. Quebec Society, Critical Issues, Scarborough: Prentice Hall Canada, pp. 17-44.

Williams C., (2004). "The Sandwich Generation", Perspectives, Vol. 5, No. 9, pp. 5-12. Statistics Canada Catalogue No. 75-001-XIE.

Winter, I. (2000). "Toward a theorized understanding of family life and social capital". Australian Institute of Family Studies, working paper no. 21, pp. 118.

Woolley, F. (2001). “The Voluntary Sector". Isuma, Vol. 2, No. 2, Summer 2001. Zunzunegui, M., A. Kone, M. Johri, F. Beland, C. Wolfson \& H. Bergman. (2004). "Social Networks and Self-rated Health in Two French-speaking Canadian Community Dwelling Populations Over 65", SocSciMed, 58, pp. 2069-2081. 